Portland State University

PDXScholar

3-11-2020

Peers' Academic Coping as a Resource for Academic Engagement and Motivational Resilience in the First Year of Middle School

Daniel Lee Grimes

Portland State University

Follow this and additional works at: https://pdxscholar.library.pdx.edu/open_access_etds

Part of the Educational Psychology Commons, and the Psychology Commons Let us know how access to this document benefits you.

Recommended Citation

Grimes, Daniel Lee, "Peers' Academic Coping as a Resource for Academic Engagement and Motivational Resilience in the First Year of Middle School" (2020). Dissertations and Theses. Paper 5500.

https://doi.org/10.15760/etd.7374

This Thesis is brought to you for free and open access. It has been accepted for inclusion in Dissertations and Theses by an authorized administrator of PDXScholar. Please contact us if we can make this document more accessible: pdxscholar@pdx.edu. 


\title{
Peers' Academic Coping as a Resource for Academic Engagement and Motivational Resilience in the First Year of Middle School
}

by

Daniel Lee Grimes

A thesis submitted in partial fulfillment of the requirements for the degree of

\author{
Master of Science \\ in \\ Psychology
}

Thesis Committee:

Thomas A. Kindermann, Chair

Ellen A. Skinner

Karlyn R. Adams-Wiggins

Portland State University

2020 
(C) 2020 Daniel Lee Grimes 


\title{
PEERS’ ACADEMIC COPING AND MOTIVATIONAL RESILIENCE
}

\begin{abstract}
Beginning middle school is a difficult transition for many young adolescents. Academic coping skills and the ability to exhibit motivational resilience in the face of potential academic adversity can contribute to the success with which students navigate this transition. Students' peer group affiliations are known to have the ability to contribute positively to students' academic engagement, motivation, and achievement at this time. The current study explores the potential of a student's peer group members' use of eleven ways of academic coping to affect the change in student academic engagement over the course of the first year of middle school. Data from the entire cohort of 366 sixth students in the only middle school in a small northeastern town were used to investigate several hypotheses. Models were tested using structural equation modeling. Peer group average levels of overall coping profile, combined total adaptive coping, and combined total maladaptive coping did not significantly predict engagement change over the first year of middle school. Peer group average levels of self-encouragement were found to negatively predict engagement change over the first year of middle school, and peer group average levels of rumination were found to positively predict engagement change over the year. These effects were in the opposite direction of what was expected. Possible explanations for the findings are discussed. Strengths and limitations, future research directions, and implications are described.
\end{abstract}




\section{PEERS’ ACADEMIC COPING AND MOTIVATIONAL RESILIENCE}

\section{Table of Contents}

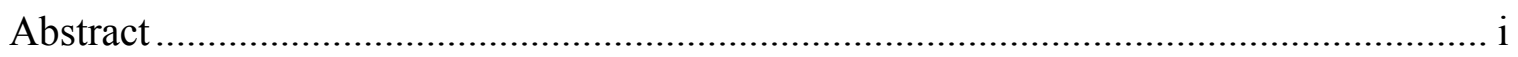

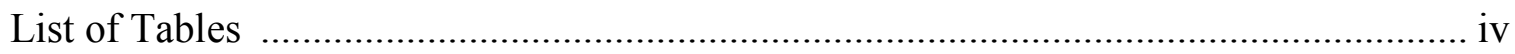

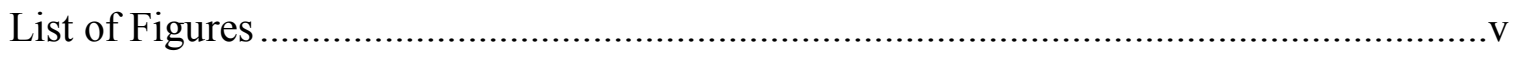

Chapter 1. Problem Statement ...............................................................................

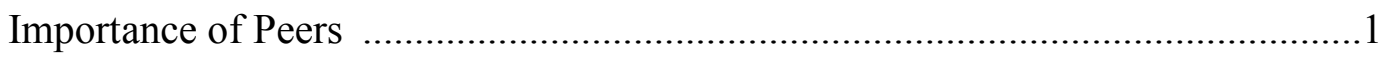

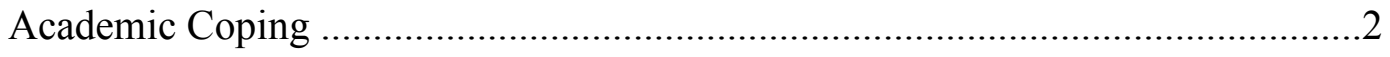

Transition to Middle School ................................................................................

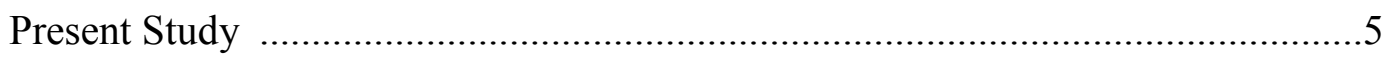

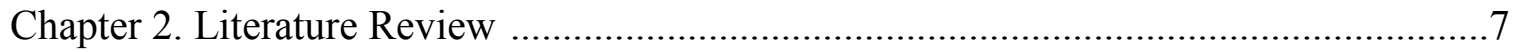

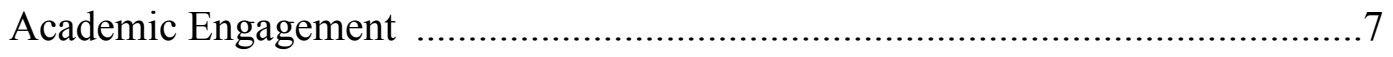

Transition to Middle School …..........................................................................

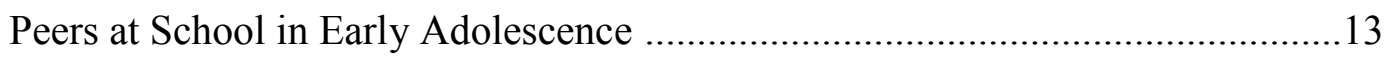

Chapter 3. Contributions of the Present Study .......................................................... 21

Academic Adversity, Coping, and Motivational Resilience ..............................21

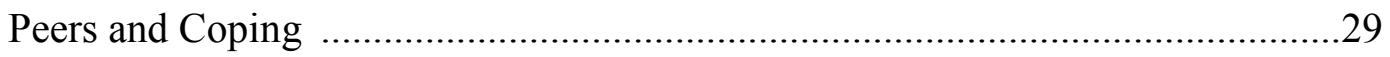

Challenges to the Study of Peer Relationships and Peer Influence ......................33

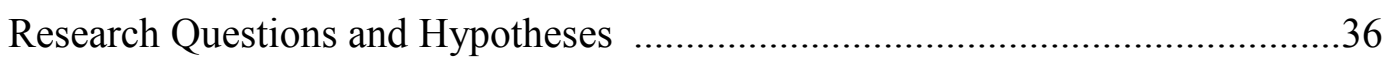

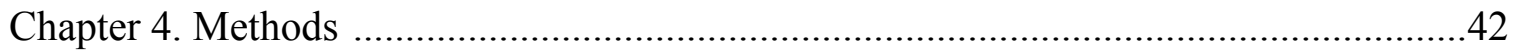

Measures ............................................................................................... 43

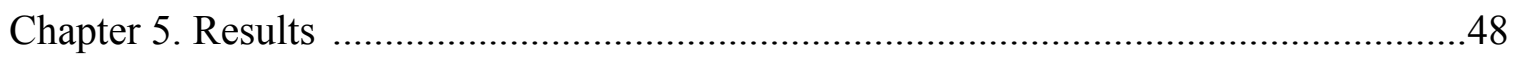

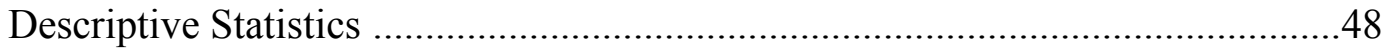




\section{PEERS’ ACADEMIC COPING AND MOTIVATIONAL RESILIENCE}

Structural Equation Models ..................................................................6

Research Question One. Effects of Peer Group Coping

on Student Engagement ...............................................................................6

Research Question Two. Effects of Peers' Adaptive Coping

and its Components on Student Engagement ...............................................64

Research Question Three. Effects of Peers' Maladaptive Coping

and its Components on Student Engagement ...............................................72

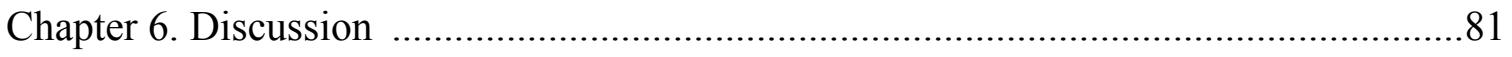

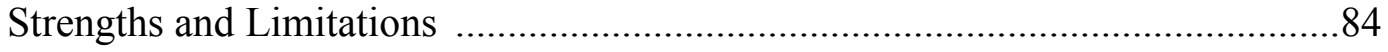

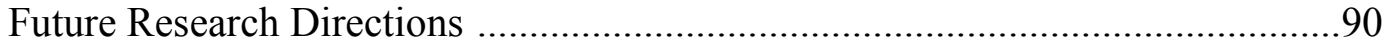

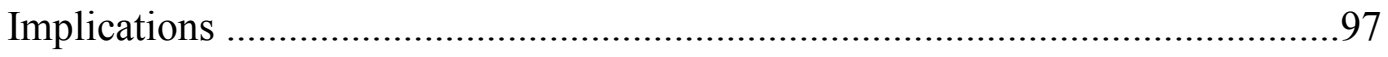

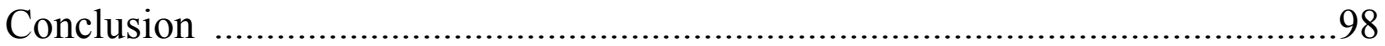

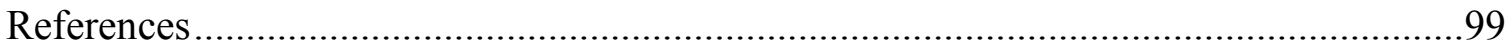

Appendix A. Raw Coping Score Results .........................................................115

Appendix B. Biological Sex and Academic Coping..................................................123

Appendix C. Group Averages and Diversity in the Peer Group ..................................126

Appendix D. Engagement, its Components, and Academic Coping ............................129

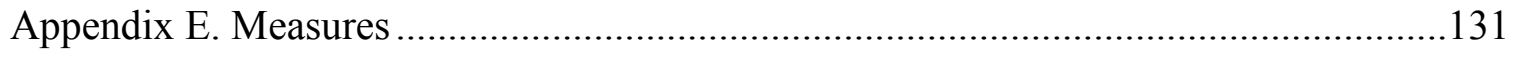




\section{PEERS' ACADEMIC COPING AND MOTIVATIONAL RESILIENCE}

\section{List of Tables}

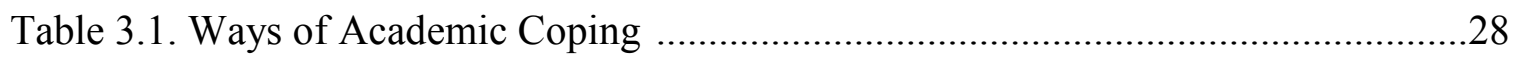

Table 4.1. Subset of a Co-occurrence Matrix of Girls in Sixth Grade ...........................47

Table 5.1. Summary of Descriptive Statistics - Engagement,

Control Variables, and Individual Coping ..................................................55

Table 5.2. Summary of Descriptive Statistics - Engagement,

Control Variables, and Peer Group Coping Averages ......................................56

Table 5.3. Intercorrelations Among Control Variables, Engagement, and Individual Coping Allocation Scores

Table 5.4. Intercorrelations Among Control Variables, Engagement, And Peer Group Coping Allocation Scores ….............................................58

Table 5.5. Intercorrelations Among Fall Individual Level Coping and Peer Group Averages

Table 5.6. Predictors of Spring Engagement when Controlling for Fall Engagement - Adaptive Coping - Peers

Table 5.7. Predictors of Spring Engagement when Controlling for

Fall Engagement - Adaptive Coping - Peers and Individual .70

Table 5.8. Model Fit Statistics 71

Table 5.9. Predictors of Spring Engagement when Controlling for

Fall Engagement - Maladaptive Coping - Peers

Table 5.10. Predictors of Spring Engagement when Controlling for

Fall Engagement - Maladaptive Coping - Peers and Individual. .80 


\section{PEERS' ACADEMIC COPING AND MOTIVATIONAL RESILIENCE}

\section{List of Figures}

Figure 4.1. Example of Application of Binomial Z-Test to Co-occurrence Matrix

Figure 5.1. Structural Model of Effect of Peer Group Average Coping Profile in Fall on Student Engagement in Spring, Controlling for Student Engagement in Fall.

Figure 5.2. Structural Model of Effect of Peer Group Average Adaptive Coping in Fall on Student Engagement in Spring, Controlling for Student Engagement in Fall

Figure 5.3. Structural Model of Peer Group Average Self-Encouragement Coping in Fall on Student Engagement in Spring, Controlling for Student Engagement in Fall

Figure 5.4. Structural Model of Effect of Peer Group Average Maladaptive Coping in Fall on Student Engagement in Spring, Controlling for

Student Engagement in Fall .76

Figure 5.5 Structural Model of Effect of Peer Group Average Rumination Coping in Fall on Student Engagement in Spring, Controlling for Student Engagement in Fall .77

Figure 5.6 Structural Model of Effect of Peer Group Average Projection Coping in Fall on Student Engagement in Spring, Controlling for Student Engagement in Fall and Controlling for Individual Projection Coping in Fall. 


\section{PEERS’ ACADEMIC COPING AND MOTIVATIONAL RESILIENCE}

\section{Chapter 1. Problem Statement}

Academic engagement, a robust predictor of students' school motivation and achievement (Fredricks, Blumenfeld \& Paris, 2004; Skinner, 2016; Skinner \& Pitzer, 2012), occurs within a context consisting of three key social partners: parents, teachers, and peers (Wentzel, 1998). These social partners may influence engagement and achievement by way of several processes, including increased relatedness or sense of belonging, coaching and mentoring, social and emotional support, and direct assistance. Decades of research have demonstrated that these contextual processes are important mechanisms by which students' interactions with peers, parents and teachers shape their own academic motivation and eventually, their achievement (Wentzel \& Ramani, 2016).

\section{Importance of Peers}

A students' peers are the other students that inhabit a school context together with each student. Especially important may be those others with whom a student forms affiliative bonds. In many respects, peers may be the unsung heroes of academic motivation (Juvonen, Espinoza \& Knifsend, 2012; Wentzel \& Muenks, 2016). Peer relationships exist in multiple forms, including close friendships, affiliated groups of children who spend time together, and crowds, which are larger social categories (Kindermann \& Gest, 2018). Peer groups, consisting of closely affiliated children who hang out together and share interests and activities, have been shown to be especially important in the academic context during early adolescence (Ryan, 2001).

Peers are understudied in the educational literature, partly because there are methodological challenges in investigating the complex structure of these networks of 


\section{PEERS’ ACADEMIC COPING AND MOTIVATIONAL RESILIENCE}

social relationships, and the processes of influence that occur within them. Groups of peers are self-organizing and dynamic, with changing compositions and variability in the characteristics of similarity that are usually portrayed as playing a key role for affinity between individuals.

Although peers have sometimes been shown to play a negative role in development (Dishion \& Tipscord, 2011), their normative effects on academic performance and functioning are largely positive (Kindermann \& Gest, 2018; Wentzel \& Muenks, 2016). Methods of capturing children's actual peer affiliations in school have made it possible for their effects to be studied on students' academic development, including the beneficial influence of peer groups on academic engagement (Kindermann, 1993). Several studies have revealed, for example, that students who belong to peer groups who are highly engaged show increases on their own engagement over the school year (Kindermann, 1993, 2007; Kindermann, McCollam \& Gibson, 1996). The full scope, however, of peers' positive role in academic engagement and motivation remains to be explored.

\section{Academic Coping}

Students' school motivation and academic engagement may depend in part on the strategies they use to cope with frustration and adversity in the academic context (Skinner, Pitzer, \& Steele, 2016). Academic coping refers to the variety of ways students deal with demands and stressors in their schoolwork, such as challenging tasks and setbacks. Multiple studies have examined how adaptive and maladaptive profiles of coping strategies affect student functioning and success (see Skinner \& Saxton, 2019, for 


\section{PEERS' ACADEMIC COPING AND MOTIVATIONAL RESILIENCE}

a review). Effective coping with the ordinary frustrations and challenges of schoolwork can contribute to students' everyday motivational resilience. Adaptive coping (such as problem-solving and help-seeking) seems to provide students a pathway back into engagement with challenging academic work, whereas maladaptive coping (such as escape or blaming others) seems to undermine students' persistence, contributing to avoidance and impaired performance. School-related motivational resilience, in turn, could be a resource contributing to subsequent engagement and other positive academic outcomes (Martin \& Marsh, 2008, 2009; Martin, 2013; Skinner, Pitzer, \& Steele, 2016). Like other processes involved in school motivation and academic success, academic coping is situated in a social context and may be affected by social partners. For example, multiple studies have examined the effects of parents and teachers on students' academic coping (Skinner \& Saxton, 2019). To date, however, few studies have considered the effects of peers, and those that have rely only on students' self-reports of their peers' support, and not on students' actual peer affiliations.

\section{Transition to Middle School}

The transition to middle school is a particularly interesting time to study the relationship between academic coping and academic motivation and engagement. This transition can be challenging, and often stressful, for early adolescents. Studies have found that academic achievement declines across adolescence and this decline is accompanied by losses in motivation and engagement (Anderman \& Mueller, 2010). Declines are sharpest during the first year of middle school. One prominent explanation for these declines is offered by theories of stage-environment fit, which emphasize the 


\section{PEERS' ACADEMIC COPING AND MOTIVATIONAL RESILIENCE}

ongoing and increasing mismatch between the middle school context and the developmental needs of early adolescents. Youth experience the middle school environment as less supportive than that of elementary school. Disciplinary concerns make the classroom more controlling, previously existing relationships are disrupted, and student perceptions of their academic ability decline (Eccles, Midgley, Wigfield, Buchanan, Reuman, Flanagan, \& MacIver, 1993).

As adolescents make the transition to middle school, their social relationships are also changing. The characteristics of their relationships with parents are changing, as young people move toward greater personal autonomy (Laursen \& Collins, 2009). The quality of relationships with teachers also seems to be declining in middle school. Students generally do not perceive these connections as being as warm and supportive as in elementary school (Barber \& Olsen, 2004). At the same time, youth spend more time with peers and less time with adults (Larson \& Richards, 1991). An increase in the number of same-age peers, compared to elementary school, is accompanied by changing groups of peers throughout the day, as adolescents move from class to class. Not surprisingly, large changes in the composition of the peer group often occur at the beginning of middle school. Old friendships may fade away and new connections form and reform during the middle school years, with this volatility especially pronounced immediately after the transition (Cantin \& Boivin, 2004).

The nature of peer relationships also changes. Increasing self-disclosure, intimacy, and warmth are part of the overall improvement in the quality of friendships during early adolescence (Berndt, 1996). In the peer context, social acceptance and 


\section{PEERS’ ACADEMIC COPING AND MOTIVATIONAL RESILIENCE}

rejection become more salient, introducing an additional source of challenge and potential stress for students, during what is already a challenging and stressful transition. But early adolescents also experience increases in instrumental, informational, and emotional support from peers (Cantin \& Boivin, 2004), suggesting that peers may have the potential to serve as a resource for motivation and coping. They offer a potential source of solutions for academic and social problems, and may have the capacity to exert a positive impact on an individual's functioning during this crucial transition. The academic outcomes for a student facing challenges and obstacles at school will depend, to some extent, on the peer group members with whom they affiliate, and the particular skills and abilities of those peers. Those skills and abilities could include the coping strategies they employ in challenging academic situations.

\section{Present Study}

The aim of the present study is to explore the role of peers in students' motivational resilience, examining whether peers are involved in the processes linking academic coping, engagement, and outcomes. Building on work showing the motivational benefits of affiliating with more engaged peers, this study uses strategies for capturing students' peer group affiliations to examine the effects of affiliating with peers who cope more (or less) adaptively. Building on studies showing that students own coping shapes their subsequent engagement, this study targets the effects of peers on changes in students' engagement across the first year of middle school. In processes of motivational resilience, peers' coping may serve as a social resource when students encounter academic challenges and stressors. Peers may bolster a student's interest and 


\section{PEERS' ACADEMIC COPING AND MOTIVATIONAL RESILIENCE}

involvement by affecting their motivational processes. In other words, if a student doesn't have the requisite adaptive coping strategies in his or her own individual repertoire, the student may still do well if these strategies are readily available within the larger repertoire of his or her peer group. If, for example, when students encounter problems or setbacks, their peers model or jump in with adaptive strategies (like problem-solving or self-encouragement), they can help a student overcome adversity. Receiving help from another student on challenging homework problems, for example, may relieve anxiety and increase a student's self-confidence. In contrast, if students' peers react to difficulties with maladaptive responses, such as providing distractions, or reinforcing a negative attitude, a student may have greater difficulty overcoming setbacks. In sum, using methods to capture students' actual peer affiliations, a study is planned that will examine whether peers' academic coping can act as a resource for students' motivational resilience, and thereby predict changes in student's own academic engagement over the first year of middle school. 


\section{PEERS' ACADEMIC COPING AND MOTIVATIONAL RESILIENCE}

\section{Chapter 2. Literature Review}

As background for the current study, this chapter reviews research on academic engagement and peer influences in middle school. I will begin with a look at engagement, and its link to motivational resilience. Then I will review the challenges students face in middle school and the role of peers. This will be followed by a brief consideration of academic adversity, the ways students cope, and how coping relates to academic engagement. Finally, I will discuss key studies involving the role of peers in academic coping and motivational resilience with a specific focus on the methodological difficulties for examination of peer influences in school.

\section{Academic Engagement}

Students' engagement, defined as their active, enthusiastic, participation with schoolwork in the classroom, is a multidimensional construct (Fredricks et al., 2004). Two primary components are behavioral engagement and emotional engagement. Behavioral engagement refers to active participation, whereas emotional engagement refers to positive affective involvement and enthusiasm. The opposite of engagement is not mere absence of engagement. It has been referred to variously as disengagement, disaffection, or alienation, and also includes behavioral and emotional components. Disaffection is more than the lack of engagement, but the two are closely related, and there is some core overlap (Skinner, Kindermann, \& Furrer, 2009).

Academic engagement is often conceptualized in motivational terms (Wigfield, Eccles, Fredricks, Simpkins, Roeser, \& Schiefele, 2015), but the relationship between engagement and motivation is complex and dynamic. Whereas motivation is the 


\section{PEERS' ACADEMIC COPING AND MOTIVATIONAL RESILIENCE}

direction, intensity and persistence of action, the wellspring from which activity arises, engagement is the quality or character of activity. It reflects motivation, but it also, in turn, influences motivation. Engagement is associated with a number of motivational variables, including goal pursuit and perseverance, mastery orientation, beliefs about ability and effort, self-efficacy, interest, and enjoyment. In fact, most theories of academic motivation include some aspect of active participation and enthusiastic involvement (Skinner, Kindermann, Connell, \& Wellborn, 2009; Skinner, 2016). Engagement is present when there is underlying motivation to be involved in schoolwork and to achieve.

Academic engagement, as the manifest sign of productive activity and emotions related to school, is good news for educators. It is an antecedent and a reliable predictor of positive school outcomes, including academic achievement, attainment, and general well-being (Fredricks et al., 2004; Upadyaya \& Salmela-Aro, 2013). Students who are more engaged work harder and get better grades. Engagement is a tangible and immediate manifestation of motivation and participation that can be observed and assessed by teachers. Because of its centrality to motivation and its link to positive outcomes, academic engagement is an important component of motivational resilience, the ability of students to bounce back from challenges and setbacks.

Moreover, engagement is malleable, and can be targeted for intervention in classroom structure and teaching practices. Although children may not be aware of the social dimension of academic engagement, schoolwork takes place within a complex social context. Engagement is a quality of academic activity by individual students, but 


\section{PEERS’ ACADEMIC COPING AND MOTIVATIONAL RESILIENCE}

other people are also participating in these activities. They are in the context, directing, encouraging, busily doing the same things, or being present and noninvolved, distracted or disinterested. In accordance with the social ecological theory of development (Bronfenbrenner \& Morris, 2006), and contextual views of academic motivation, (Wentzel, 2004), social partners are expected to play important roles in academic engagement, and empirical research demonstrates their importance (Wentzel, 1998).

Unfortunately, as children get older their academic engagement decreases. Their involvement and enthusiasm for school decline (Wigfield et al., 2015). These declines begin in late elementary school, with a sharp drop at the transition to middle school, and then a gradual decline across the remainder of middle school and secondary school (Fredricks et al., 2004). The decline in engagement is associated with declines in other processes that reflect motivation and achievement. These declines are different for boys and for girls, and subject to individual variation, but the overall trend is clear, and has been consistently documented in studies over several decades (Wigfield et al., 2015).

\section{Transition to Middle School}

The beginning of middle school holds promise and excitement for early adolescents. At this juncture, students make the tangible move from the school context that is typical of childhood to one that is associated with opportunities to behave in ways that are more grown-up. Their social world is expanding. The content of social activities is changing. The school day, schoolwork, and the school environment are also changing. From learning the basics, students move into subjects that are more complex and abstract. The school curriculum seems, from an adult perspective, to become more interesting, 


\section{PEERS’ ACADEMIC COPING AND MOTIVATIONAL RESILIENCE}

relevant and valuable. And yet, research shows that many students become less engaged in school and do less well than in elementary school. The transition to middle school is a tough time for a lot of kids. It is characterized by widespread stress (Goldstein, Boxer, \& Rudolph, 2015), arising from bewildering new contexts, unfamiliar experiences, and the weight of new responsibilities. This stressful transition is accompanied not only by losses in academic engagement and achievement, but also by declines in motivation. As children's cognitive functioning matures, perceptions of their academic ability become more realistic, and as a result, students' evaluations of their own ability and competence decline. There is also, on average, a decline in intrinsic motivation and in interest in and valuing of school (Gottfried, Fleming \& Gottfried, 2001).

Stage-Environment Fit Theory. The predominant explanation for this pattern of empirical findings has been articulated in Stage-Environment Fit Theory (Eccles \& Midgley, 1989; Eccles et al, 1993; Midgley, Middleton, Gheen, \& Kumar, 2002). From this perspective, the declines in academic achievement, engagement, and motivation that are typically seen in early adolescence are not an inevitable consequence of the many changes in early adolescent development following puberty. Rather, the premise of this theory is that there is a mismatch between the requirements and affordances of the middle school environment and the needs of youth at this age. Students need developmentally appropriate contexts and activities that provide adequate opportunities for the satisfaction of their psychological and developmental needs. These needs include not only basic human psychological needs, such as choice and relationships, but also the resources and opportunities that students require for growth. 


\section{PEERS’ ACADEMIC COPING AND MOTIVATIONAL RESILIENCE}

Developmental needs are age-specific, and are tied to expanding cognitive and social capabilities. Eccles and Midgley (1989) mention five such developmental changes that affect students' needs: 1) critical thinking, 2) more differentiated ability concept, 3) desire for more control, 4) greater self-consciousness and social comparison, and 5) relationships with peers and non-parental adults increase in importance. In a review of empirical research, Midgley and colleagues (2002) focused on the mismatch between the opportunities afforded in middle school and students' age-specific needs for complex and critical thinking, choice and control, and relatedness. They describe research showing that middle schools are poorly designed to meet these needs for children as they transition out of elementary school.

In middle school, entering students find themselves in a larger school, with more students, several classes throughout the day, and multiple teachers, instead of one teacher in one classroom throughout the day. Teachers are concerned with classroom management and potential discipline problems, so teaching practices are more controlling and provide fewer opportunities for choice and decision-making by students. The curriculum is geared to a greater extent toward test performance, and as a result, does not generally challenge the new cognitive capabilities that are developing for this age group. Although the subject matter may be more advanced, the focus on performance works against possibilities for more challenging mastery-oriented learning for individual students, and emphasizes instead rote-learning of material geared directly toward the contents of standardized tests. Pressure to perform on tests and increased competition 


\section{PEERS’ ACADEMIC COPING AND MOTIVATIONAL RESILIENCE}

with other students can threaten student perceptions of competence and contribute to doubts about their own academic ability.

In their work on stage-environment fit, Eccles, Midgley, and their colleagues (Eccles \& Midgley, 1989; Eccles et al., 1993; Midgley et al., 2002) have applied a motivational perspective, basing their empirical investigations on expectancy-value theory and goal theory. The mismatches, however, between salient stage-specific developmental needs and the middle school environment are not limited in their consequences to intrapsychic motivation, but have a similar pervasive negative effect on observable academic engagement. The fit or mismatch between the school environment and all of the needs described in stage-environment fit theory exert a significant downward pressure on adolescents' engagement.

Social relationships. At the same time that the school structure undergoes unfavorable changes, existing social relationships and supports may be disrupted. In this respect also, middle schools may not be providing the opportunities required for optimal growth and development. The relationships that students develop with their teachers are more impersonal than those in elementary school (Barber \& Olsen, 2004). And because there are more students and different students in different classes, old friendships from elementary school may dissolve while new friendships and connections with unfamiliar peers are forming. Increasing social demands and disruption of existing friendships, while new relationships may be temporary or uncertain, can interfere with students' need for connection or relatedness. (Baumeister \& Leary, 1995; Furrer \& Skinner, 2003). At the same time, the novelty of the middle school environment, in combination with 


\section{PEERS’ ACADEMIC COPING AND MOTIVATIONAL RESILIENCE}

unfamiliar activities, norms, and physical and social context, can threaten adolescents' sense of belonging, since students are unfamiliar with the world to which they are trying to connect (Hamm \& Faircloth, 2005).

The characteristics and consequences of the middle school transition for individual students depend to a great extent on the specific social contexts that surround them. For early adolescents, peer relationships play a key role in the unfolding of all developmental processes, especially at school. The domain in which adolescents encounter the most varied opportunities to explore their new capabilities, and arrive at effective solutions, is in experiences with others their own age. This is the world of peer relationships.

\section{Peers at School in Early Adolescence}

In order to better understand the effects of peers on students' academic engagement in middle school, it is useful to review what is known about the unique features of peer relationships in adolescence and how they influence the individual in the school context. In this section, I will summarize major developmental changes in peer relationships, and review foundational research on the positive influences of peers in middle school.

Developmental changes in peer relationships. Because the transition to middle school coincides approximately with the beginning of adolescence, students' new experiences include not only changes in the structure and organization of school, but also changing features of social relationships. These changes are associated with puberty and the developmental transition into adolescence. Peers are becoming more important in 


\section{PEERS’ ACADEMIC COPING AND MOTIVATIONAL RESILIENCE}

several ways, relative to parents, teachers, and other adults. Some of these changes may be involved in the effect of peers on student engagement in middle school. First, the amount of time spent with agemates outside the home increases, while the amount of time spent with the family decreases. (Larsons \& Richards, 1991; Larson, Richards, Moneta, Holmbeck, \& Duckett, 1996). This is consistent with adolescents' growing desire for greater independence and personal autonomy in the form of choice and control. Larson and colleagues (1996) found that the diminishing time spent with parents was not a function of family conflict, but instead reflected the increasing breadth and depth of relationships with peers and of activities outside the home.

Second, at this important developmental juncture, the activities that adolescents are involved in while away from adults and among themselves are also changing. Even though a variety of extracurricular activities are available in middle school, participation declines compared to elementary school (Juvonen, et al., 2012). Children are spending more time together, but they are doing it increasingly in their free time, and less frequently in structured and supervised activities. They are doing things with best friends and in small groups, playing sports, going places, conversing, joking, and hanging out. Undesirable activities that are rare in elementary school become more common, including smoking, substance abuse, and violence. Many parents are concerned about the influence of peers on their teens. Peers are sometimes seen as a hazard around which youth must navigate, a threat to their future as productive adults. But as peers become a bigger part of life in early adolescence, they also have the potential to play a positive role. 


\section{PEERS' ACADEMIC COPING AND MOTIVATIONAL RESILIENCE}

Some of the changes in peer relationships during adolescence reflect a move toward increasing social maturity. During this developmental period, peer relationships exhibit more intimacy and reciprocity, sharing, and mutual aid, compared to childhood. Informational, instrumental, and emotional support occur more frequently, and are not limited to close friendships (Cantin \& Boivin, 2004). Acceptance and rejection, the key processes involved in the elementary school social world, continue, but popularity takes on a new dimension in early adolescence with the development of complex cognitive capabilities. Social comparison becomes salient (Eccles \& Midgley, 1989), and selfcharacterization and self-categorization are now more determined by abstract categories and group membership (Brown and Larson, 2009).

Relatedness with particular others and belonging to groups and to the school community continue to fill a basic need, providing affiliation and fun, but they also take on deeper symbolic meaning and increasing importance in the lives of adolescents, as the age-specific social structure is transformed and new social dynamics appear (Farmer, et al., 2016; Hamm and Faircloth, 2005). Enmeshed in these new dynamics are developmental changes in the role of peer relationships: Early adolescents demonstrate a greater susceptibility to peer influences than at any other point in adolescence (Steinberg \& Monahan, 2007).

Positive influences of peers in middle school. Just as peers are playing a much larger overall role in the lives of young adolescents, they also have a growing role in students' school lives. The present study will focus on the positive impact of peers in school, specifically, on academic engagement. Because engagement is intimately 


\section{PEERS’ ACADEMIC COPING AND MOTIVATIONAL RESILIENCE}

connected to achievement and motivation, a basic understanding of the role of peers in school success provides a useful background for the current study. A considerable body of research has studied the association between peer characteristics and achievement, motivation, and engagement (for reviews see Wentzel \& Muenks, 2016; Ryan \& Shin, 2018). These three facets of academic functioning all decline across adolescence, most dramatically at the beginning of middle school, but all three have also been shown to be associated with positive influence from peers, at least for many students. The evidence suggests that positive peer relationships can serve as a resource that partially offsets these normative declines.

Peer effects on achievement. Compared to adolescents with poor peer relationships, those with good peer relationships generally perform better in school. A body of research shows there is an association between peer group member achievement and a student's own achievement (Altermatt \& Pomerantz, 2003, 2005; Burke \& Sass, 2013; Cook, Deng, \& Margano, 2007; Veronneau, Vitaro, Brendgen, Dishion, \& Tremblay, 2010; Wentzel \& Caldwell, 1997). A number of cross-sectional studies have sought to explain the positive relationship between peers and academic achievement by studying the qualities of peer relationships and the characteristics of individual peers and of the peer group that might account for the positive impact of peers on achievement in middle school. For example, Wentzel, McNamara Barry, and Caldwell (2004) found prosocial behavior by peers to be a significant factor, mediating the link between peer relationships and achievement. Other peer attributes found to be associated with achievement during middle school include perceived relationship quality (Liem \& 


\section{PEERS’ ACADEMIC COPING AND MOTIVATIONAL RESILIENCE}

Martin, 2011), emotional and academic support from peers (Azmitia \& Cooper, 2001;

Patrick, Ryan, \& Kaplan, 2007), peer emotional support and academic expectations of the student (Wentzel, Russell \& Baker, 2016), and sense of belonging (Roeser, Midgley, \& Urdan, 1996).

Peer effects on motivation. Research has also found an important relationship between positive peer relationships and several indicators of academic motivation (for reviews, see Ladd, Herald-Brown, \& Kochel, 2009; Wentzel, 2017). Kiuru and colleagues (Kiuru, Aunola, Vuori \& Nurmi, 2007), for example, in a study of Finnish $9^{\text {th }}$ graders, found both short-term academic expectations and long-term aspirations for schooling were strongly correlated among members of peer groups. There is more to peer effects, however, than just the rubbing off of desirable qualities. Other variables representing characteristics of the peer group may also affect adolescent academic motivation at the individual level. Nelson and DeBacker (2008) found that being valued and respected by classmates and having a best friend who valued academics were associated with adaptive achievement motivation (mastery, performance-approach, and responsibility goals). Several studies have also found that support from peers (peer acceptance, emotional support, or academic support) is a significant predictor of motivational outcomes, including students' liking of school (Boulton \& Boulton, 2011), achievement goals and self-efficacy (Patrick et al., 2007), interest in classroom activities (Wentzel, Battle, Russell, \& Looney, 2010), valuing and identification (Wang \& Eccles, 2012), and mastery orientation (Wentzel, Muenks, McNeish, \& Russell, 2017). 


\section{PEERS’ ACADEMIC COPING AND MOTIVATIONAL RESILIENCE}

The most persuasive evidence comes from three short-term longitudinal studies of peer groups and academic motivation. In a first study, Altermatt and Pomerantz (2003) found evidence of a positive impact of peers in a longitudinal investigation of fourth, fifth, and sixth graders, across the transition to middle school. The authors assessed competence-related beliefs (self-perceptions of competence, and ability attributions for success and failure) and motivational beliefs (level of personal standards for achievement, importance of meeting standards, and preference for challenge) at the individual and group levels, and analyzed change over the year. Peer group beliefs about ability attributions for success, and about the importance of meeting standards, positively predicted students' individual change in these variables from fall to spring.

In a second study, Ryan (2001), using multilevel modeling on a sample of seventh grade middle school students, found that peers' liking of school predicted students' own liking of school. Additionally, both peers' fall achievement and motivation (expectancy for success, intrinsic value for school, and utility value for school) were strong and significant predictors of changes in student achievement from fall to spring. In a third study, Shin and Ryan (2014) analyzed peer effects on achievement goals over the course of the school year, with a sample of sixth graders surveyed in the fall and spring. Peer group levels of mastery goals and performance approach goals were found to positively predict changes in individual mastery goals and performance approach goals across the academic year.

Peer effects on engagement. While the findings regarding peer effects on achievement and motivation are interesting and important, the most relevant work for the 


\section{PEERS’ ACADEMIC COPING AND MOTIVATIONAL RESILIENCE}

current study involves research that investigates the engaged participation of students in relation to the engagement and related characteristics of their peers (for reviews see Juvonen, Espinoza \& Knifsend, 2012; Wentzel, 2017; Ryan \& Shin, 2018). Research has found evidence of associations of academic engagement with a variety of variables assessed at the peer group level, including academic value (You \& Sharkey, 2009), peer culture (composed of relationship quality and academic oriented behaviors; Lynch, Lerner \& Leventhal, 2013), and academic support (Chen, 2005; Patrick, et al., 2007). Some studies have used generalized constructs of support from peers at school, while others have been more focused. One general measure of peer support, using four items focused on relationship quality, was positively associated with student engagement $(\mathrm{Li}$, Lynch, Kalvin, Liu, \& Lerner, 2011). A different, composite measure of peer support, including items assessing support for autonomy, relatedness, and competence, was also found to be positively associated with engagement. This relationship was found to be mediated by school fit (Zimmer-Gembeck, Chipuer, Hanisch, Creed, \& McGregor, 2006). Other authors have emphasized social support from peers (Wentzel, Donlan, \& Morrison, 2012). Peer social support, for example, has been found to predict school compliance, a component of behavioral engagement (Wang \& Eccles, 2012). Another specific form of support, emotional support from peers, has been found to be positively associated with academic engagement (Patrick et al., 2007).

Students with more positive peer relationships also show improvements in engagement in longitudinal studies (Kindermann, 1993; Kindermann, McCollam, \& Gibson, 1996). For example, in a study of a cohort of sixth graders, Kindermann (2007) 


\section{PEERS' ACADEMIC COPING AND MOTIVATIONAL RESILIENCE}

found that the average level of engagement of students' peer groups in the fall predicted students' own engagement in the spring, controlling for student engagement in the fall. Another recent study (Wang, Kiuru, Degol, and Salmela-Aro, 2018) also found that engagement levels in the peer group positively predicted student's engagement across the school year in a Finnish sample of secondary school students.

The literature reviewed demonstrates that peers can have positive effects for middle school students on several academic outcomes, including achievement, multiple facets of academic motivation, and engagement. Peers who are doing well, wanting to succeed, and actively participating in school can be beneficial for their classmates. Not only do achievement, motivation, and engagement found in the peer group affect students' own levels on those variables, additional characteristics of peers and peer relationships, as well as social, emotional, and instrumental support from peers, have been found to have positive relationships with desirable outcomes. A number of studies have been cross-sectional, showing associations of peer levels of motivation, engagement, and such other important predictors as grades, expectations, values, and relationship quality with student academic outcomes. But most importantly, longitudinal studies also support the existence of a strong positive, potentially causal, relationship between peer group level variables and student motivation and engagement. Peers can have a beneficial impact in adolescents' education. They may be a valuable resource for students making the transition to middle school. 


\section{PEERS' ACADEMIC COPING AND MOTIVATIONAL RESILIENCE}

\section{Chapter 3. Contributions of the Present Study}

Research has established that peers are an important part of the school context that can contribute in beneficial ways to students' education. Very little research, however, has investigated the connection between peers and academic coping. This chapter reviews the concepts of academic coping and motivational resilience. It considers the role of coping strategies used by peers as a characteristic of the peer context. The objectives of the current study are introduced in terms of how peers' coping might contribute to students' success at school.

\section{Academic Adversity, Coping, and Motivational Resilience}

The challenges that students face at the beginning of middle school, and the mismatch between the new school environment and the student's developmental stage, create stress for early adolescents making this transition. Their ability to cope with this stress will be a key determinant of their success in the years ahead. In fact, adaptive coping can be seen as a motivational resource. Those who possess positive and effective ways of academic coping, and put them into practice in the face of challenges at school, will have a greater chance of navigating the hazards of this transition and doing well in school. Students who use less productive and less effective ways of coping will have more difficulty overcoming obstacles, frustrations, and setbacks. Maladaptive copers are at greater risk of suffering declines in engagement and achievement across the middle school years, and these adverse consequences may carry forward into high school and later life. 


\section{PEERS’ ACADEMIC COPING AND MOTIVATIONAL RESILIENCE}

Adversity at school. Dealing with everyday academic adversity is a concern for all students. Everyday challenges include a variety of general hassles and stressors (Burnett \& Fanshawe, 1997). Some of these involve stressful or emotional experiences with contexts, and relationships, ranging from unfair treatment or not getting along with teachers, to crowded and noisy classrooms, feeling vulnerable or embarrassed, anxiety about performance, and school-related conflict in relationships with peers or parents. A central component of everyday hassles and stressors, however, involves academic work itself. This includes trouble completing schoolwork or homework, difficulty learning curriculum (in general or a particular subject), boredom and distraction during class, and difficulty answering a hard question or solving a problem in class. Stress from academic work can also involve exams, whether it be anxiety before and during exams, trouble with specific questions on an exam, or failing or doing poorly on an exam. Performance assessment, including grades on assignments, exams and report cards, may represent a threat of failure, and becomes a source of everyday school-related stress and anxiety for many students. Difficulties at schools may also include major adverse events, like suspension, failing a course, or being required to repeat a grade, but few students face such major setbacks. The present study looks at the everyday challenges, hassles, and setbacks faced by most students when dealing with their academic work.

Academic coping. In the school context, academic coping includes all the ways students deal with setbacks and adversity in their academic endeavors. A wide variety of ways of responding to the everyday hassles and academic demands of school have been identified. Some are more productive and adaptive than others. Adaptive strategies 


\section{PEERS’ ACADEMIC COPING AND MOTIVATIONAL RESILIENCE}

contribute to persistence, continuing engagement, or reengagement, and are associated with positive traits, including interest, self-efficacy, pro-social behavior, and optimism, as well as positive academic and personal outcomes, including adjustment to school transitions, use of deeper learning strategies, better academic performance, well-being, and life satisfaction. Maladaptive strategies typically lead to giving up, avoiding, or disengaging with academic tasks, and are associated with negative traits and outcomes, including feelings of ineffectiveness, use of surface learning strategies, poor academic performance, and school-related burnout (see Skinner \& Saxton, 2019, for a review). Skinner, Pitzer, and Steele (2013) identified 11 ways of coping that are common in academic settings, five adaptive ways, and six maladaptive ways. The following is a brief description of each way of coping and their importance in academic settings as reported by Skinner and colleagues (2013, for details, see Table 3.1)

The most common form of adaptive academic coping is strategizing, or problemsolving, a proactive approach to dealing with setbacks, that includes trying to understand the problem and take action to improve outcomes in the future. Strategizing is solutionfocused because it is the first step towards doing something about a problem: figuring out what to do and how to go about it so a plan can be put into action. Strategizing is strongly correlated with help-seeking, the second most common way of academic coping. Helpseeking involves reaching out to someone for information or assistance. Help-seeking and strategizing are strongly correlated with each other, and both are also strongly positively correlated with engagement and re-engagement or persistence. Re-engagement is the 


\section{PEERS' ACADEMIC COPING AND MOTIVATIONAL RESILIENCE}

ability to return to behaviorally and emotionally engaged learning after a frustration or setback (Pitzer \& Skinner, 2017).

Some studies have combined help-seeking and other ways of coping into a category labeled social support, but the current study uses a more fine-grained approach and distinguishes the functionally distinct forms of instrumental and informational support, which constitute help-seeking, on the one hand, from comfort-seeking, on the other hand. Comfort-seeking is an emotion- and relationship-based form of social support, which involves turning to others for comfort, reassurance, and encouragement, functioning primarily to regulate emotion. Comfort-seeking helps improve mood and replenish energetic resources, but is only moderately correlated with engagement. Two additional adaptive ways of coping also involve proactive approaches in the face of setbacks, functioning to up-regulate motivation. Self-encouragement includes reassuring oneself, increasing confidence and optimism. Commitment involves reminders of the personal importance of academic outcomes. It can include thoughts about why a task is important and worthwhile. Comfort-seeking, self-encouragement, and commitment are also positively correlated with both engagement and re-engagement.

Research has also identified a set of maladaptive ways of dealing with academic challenges and difficulties. Confusion is a nonproductive reaction to an obstacle or setback that takes the form of uncertainty, going blank, or getting stuck. Confusion is a common form of maladaptive coping, second only to rumination. Two additional common forms of maladaptive coping are self-pity and concealment. Self-pity consists of adopting an attitude of defeat and generalizing a bad experience into a pattern that often 


\section{PEERS’ ACADEMIC COPING AND MOTIVATIONAL RESILIENCE}

links to feeling sorry for oneself. Concealment involves trying to hide failures, mistakes, or setbacks from other people. Confusion, self-pity, and concealment have all been found to be negatively correlated with engagement and re-engagement.

Less common forms of maladaptive coping include escape, and projection. Escape is a form of mental avoidance or denial that includes devaluing or detaching oneself from the academic task or topic that led to the setback. Escape coping is closely related to disengagement. Projection involves blaming a setback or obstacle on someone else, or circumstances beyond one's own control. This could consist of blaming a teacher or characterizing a test as unfair. Projection is the least common way of coping, and is strongly negatively correlated with strategizing and help-seeking. Concealment and projection are negatively correlated with engagement and re-engagement. Finally, rumination, although it is the most common form of maladaptive coping, is somewhat of a unique breed. Rumination is worry or repetitive thoughts that take on an obsessional character. It is a passive process of focus on negative aspects of a situation. Rumination is not strongly correlated with other forms of maladaptive coping. It is the only maladaptive strategy that is not strongly negatively correlated with academic engagement and reengagement.

\section{Emotional reactivity, individual differences in stress, and ways of coping.}

Skinner and colleagues (2013) also investigated the connections between different ways of coping and emotional reactivity, defined as the extent, intensity, and duration of negative reactions to emotion-eliciting stimuli (Davidson, 1998; Nock, Wedig, Holmberg, \& Hooley, 2008). Emotional reactivity is seen as a characteristic of the initial 


\section{PEERS’ ACADEMIC COPING AND MOTIVATIONAL RESILIENCE}

reaction to a stressor. Students who show high levels of emotional reactivity tend to cope more maladaptively with academic adversity (Pitzer \& Skinner, 2017). This may be because students' emotional reactivity affects the quality of their emotional experiences at school and the appraisals they make about stressful situations. Students with high emotional reactivity may interpret things more negatively than others. A highly reactive student is likely to experience more disappointment and discouragement than a less emotionally reactive student. They may experience school as challenging and difficult with more frequency and greater intensity. Their overall level of stress is likely to be significantly higher than students with low reactivity, all other things being equal.

In addition to differences in emotional reactivity, other factors may be associated with differences in the frequency and intensity of stressful school experiences. Stressors (and resources) are unequally distributed among students, with some more likely to experience setbacks and difficulties in their academic work. Individuals are also differentially susceptible to conditions, in terms of whether they are experienced as stressful, and differentially susceptible to stress, when it is triggered by a situation (Ellis, Boyce, Belsky, Bakermans-Karanenburg, \& Van Ijzendoorn, 2011). Individual differences in the total amount of stress experienced and in susceptibility to potentially stressful situations will be a consideration in the present study.

\section{Methodological challenges in the measurement of coping: average versus}

allocation scores. The differences in the levels of stress and quantities of stressors between individuals present a challenge for the interpretation of survey data on coping strategies. The most common method for computing coping scores is to use average 


\section{PEERS’ ACADEMIC COPING AND MOTIVATIONAL RESILIENCE}

scores, a simple mean of participants' ratings on all items for a given subscale. However, researchers have found that average scores for all ways of coping, including both adaptive and maladaptive, are often positively correlated with each other (Connor-Smith, Compas, Wadsworth, Thomsen, \& Saltzman, 2000; Skinner \& Saxton, 2019). One explanation for this surprising finding is that participants who experience high levels of stress may use a large number of different ways of coping, both adaptive and maladaptive, and this leads to positive correlations among ways of coping. From this perspective, average scores are double-barreled: They reflect both a student's relative preferences for different ways of coping with stressful events and the frequency and intensity of overall stressful events encountered. One method researchers have developed to remove information about levels of stress from coping scores is to transform average scores into proportional scores, by dividing a student's average score by the total amount of coping reported by the student, both positive and negative (Vitaliano, Maiuro, Russo, \& Becker, 1987). The transformed scores are referred to as allocation scores, because they represent how much (i.e., what percentage) of an individual's total coping they have allocated to each of the possible ways of coping. This transformation is particularly important because the use of raw scores tends to overemphasize the importance of maladaptive coping. By using the allocation scores instead of the raw scores, the scores are adjusted to better reflect the relative importance of maladaptive and adaptive coping and, in a sense remove the distortion that results from the presence of high levels of stress. This method is used in the current study to adjust the measurement of coping for any differences in the levels of adversity and stress faced by students. 
PEERS' ACADEMIC COPING AND MOTIVATIONAL RESILIENCE

Table 3.1. Ways of Academic Coping

\begin{tabular}{lcc} 
& $\begin{array}{c}\text { ENG } \\
R\end{array}$ & $\begin{array}{c}\text { REENG } \\
r\end{array}$ \\
\hline Adaptive Ways of Coping, in order of prevalence & & .590 \\
\hline $\begin{array}{l}\text { Strategizing. Attempts to figure out what to do to solve } \\
\text { problems or prevent them in future encounters. }\end{array}$ & .621 \\
$\begin{array}{l}\text { Help-seeking. Going to teachers or other adults for } \\
\text { instrumental aid in understanding material or figuring out } \\
\text { how to learn more effectively. }\end{array}$ & .654 & .583 \\
$\begin{array}{l}\text { Comfort-seeking. Turning to others for emotional } \\
\text { reassurance, consolation, and cheer. }\end{array}$ & .533 & .443 \\
$\begin{array}{l}\text { Self-encouragement. Attempts to regulate one's flagging } \\
\text { emotions by bolstering confidence and optimism. }\end{array}$ & .582 & .506 \\
$\begin{array}{l}\text { Commitment. Attempts to remind oneself why challenging } \\
\text { academic work is personally important and worth the effort. }\end{array}$ & .578 & .511
\end{tabular}

Maladaptive Ways of Coping, in order of prevalence

Confusion. Stress reaction in which thoughts or next steps

$-.534$

$-.433$ become unclear or disorganized.

Escape. Attempts to mentally avoid or remove oneself from difficulties and poor outcomes.

$-.453-.561$

Concealment. Attempts to prevent others from finding out about the occurrence of negative events.

$-.485 \quad-.477$

Self-Pity. Feeling sorry for oneself and one's tribulations.

$-.627 \quad-.512$

Rumination. Preoccupation with the negative or anxious features of a stressful situation.

$-.171 \quad .014^{\mathrm{ns}}$

$\begin{array}{lll}\text { Projection. Blaming other people for the negative outcome. } & -.652 & -.692\end{array}$

Correlations ( $r$ ) are shown for each way of coping with engagement (ENG) as well as with Reengagement (REENG) in the fall for a sample of 1,020 students in grades 3 through 6 (Skinner, Pitzer, \& Steele, 2013). All correlations are significant at the $\mathrm{p}<.001$ level, except $\mathrm{ns}=$ nonsignificant. 


\section{PEERS' ACADEMIC COPING AND MOTIVATIONAL RESILIENCE}

Motivational resilience. All students face academic adversity, but they vary in the ways they respond. Some students exhibit a pattern of responding that is proactive and adaptive. They bounce back quickly and easily from difficulty or setbacks. Other students exhibit a pattern of responding passively or maladaptively. They may become mired in discouragement or helplessness. Most students are somewhere in between. The degree to which individuals are able to bounce back from challenges and threats and not lose their forward momentum can be considered a manifestation of motivational resilience (Skinner \& Pitzer, 2012). In the academic sphere, motivational resilience is the ability to maintain or regain persistent effort and participation in schoolwork following a setback, difficulty, or failure.

Motivational resilience is related to academic engagement. The ability to maintain engagement in the face of potentially demotivating circumstances, and to reengage after a setback, is a sign of motivational resilience (Pitzer \& Skinner, 2017). The current study investigates motivational resilience in a developmental way. The outcome of interest is changes in engagement from the beginning to the end of sixth grade, and the influence of peers. Maintaining or increasing academic engagement in the first year of middle school, a time of normative declines, is a manifestation of motivational resilience. The study seeks to determine whether, in the face of everyday challenges and setbacks, the academic coping of a students' peers contributes to motivational resilience.

\section{Peers and Coping}

The literature reviewed so far has revealed that peers can be a valuable resource for academic achievement, motivation, and engagement. In addition, academic coping 


\section{PEERS’ ACADEMIC COPING AND MOTIVATIONAL RESILIENCE}

has been shown to be a resource that contributes to students' motivational resilience. Knowing that peers are a resource, and that academic coping is a resource, suggests that peers' coping may also be a resource for the individual student. For some ways of coping, such as strategizing, self-encouragement, commitment, and help-seeking, having it present in your peer group may be similar to having it yourself. Peers good at strategizing, for example, might help a student with their schoolwork and show them how to do problem-solving. With other adaptive ways of coping, peers might serve as a role model. Seeing peers perform an adaptive coping strategy and maintain engagement could inspire other students, and help them become more energized and involved. On the other hand, maladaptive ways of coping, such as self-pity, escape, or blaming the teacher (projection), if present in the peer group, may be a liability for students. When peers are coping maladaptively with academic adversity, we can imagine that a student may be more susceptible to discouragement and have more trouble maintaining their academic engagement than when their peers are making use of adaptive ways of academic coping. Little research, however has directly investigated the effect of peers' coping on academic outcomes.

Research on peers and academic coping. In a recent review of academic coping (Skinner \& Saxton, 2019), only two studies looked at peers and coping. In the first study, Shih (2015) focused on academic burnout, which is sometimes considered as the opposite of engagement, and examined the roles of peer support, classroom structure, and two forms of adaptive academic coping as predictors of burnout in a sample of Taiwanese $8^{\text {th }}$ graders. Perceived peer support was assessed using the Student Social Support Scale 


\section{PEERS’ ACADEMIC COPING AND MOTIVATIONAL RESILIENCE}

(Belmont, Skinner, Wellborn, \& Connell, 1992; e.g., "My classmates say nice things to me when I have done something well"). Peer support was significantly negatively correlated with all three components of burnout: emotional exhaustion $(r=-.22, p<.05)$, cynicism $(r=-.15, p<.05)$, and lack of efficacy $(r=-.45, p<.01)$. In a structural equation model, the relationship between peer support and burnout was fully mediated by positive academic coping, with standardized path coefficients from peer support to “engagement coping" and from "engagement coping” to academic burnout of .30 and -.40 , respectively $(p<.05)$. In this sample, support from peers in the classroom was a moderately strong predictor of adaptive academic coping.

In the second study, Reschly, Huebner, Appleton, and Antaramian (2008) were interested in exploring the importance of positive affect as a predictor of academic outcomes in seventh to tenth graders. They found that adaptive academic coping was significantly related to several components of a multidimensional measure of engagement, and mediated the relationship between positive affect and engagement. A subscale of the Student Engagement Instrument, used in the study (Appleton, Christenson, Kim, \& Reschly, 2006), was Peer Support for Learning, which consists of six items related to peers at school (e.g., "Students at my school are there for me when I need them," "I have some friends at school"). The zero-order correlation of this measure with social support-seeking coping was .40 $(p<.01)$, and with problem-solving coping it was $.26(p<.01)$. In a multiple regression predicting peer support for learning from positive affect, with social support-seeking coping as another predictor, and controlling for sex and age, the standardized regression coefficient for support-seeking coping was 


\section{PEERS’ ACADEMIC COPING AND MOTIVATIONAL RESILIENCE}

$.23(p<.01)$. On the other hand, in a regression predicting peer support for learning from positive affect, with problem-solving coping as a predictor, and controlling for sex and age, problem-solving coping was not found to be a significant predictor. The correlations of peer support to two ways of adaptive coping, as well as the prediction of peer support for learning from support-seeking coping, provide evidence of a positive association between peer support, academic coping, and academic engagement.

Although both these studies documented links between peers (support from peers and positive affect associated with peers) and adaptive coping, they are also both limited in their measures and design. The links found suggest that peers are a resource in the school context, and that their ability to serve as a resource is, at least to some extent, related to academic coping processes. Although there is little research investigating directly the effect of peers' academic coping, either in terms of other students' academic coping or in terms of academic outcomes, the strong positive connection often found between peers and positive outcomes suggests that peers' academic coping may be an important but overlooked area. At the same time, like much of the work examining the effects of peers, both of these studies relied on students' reports of their impressions of peer characteristics rather than looking directly at peers themselves. Individual students' perceptions of their peers can be biased in response to their own interpretations of the nature and value of their relationships. Moreover, both studies used cross-sectional data collected at a single time point, making it impossible to discern the direction of effects. The current study utilized measures of actual peer groups and their characteristics in a short-term longitudinal design that allowed us to test whether the characteristics of 
PEERS’ ACADEMIC COPING AND MOTIVATIONAL RESILIENCE

students' actual peer groups can predict changes in their own engagement over the first year of middle school.

\section{Challenges to the Study of Peer Relationships and Peer Influence}

The research reviewed offers compelling evidence of multiple ways that desirable academic outcomes are connected to students' relationships with peers. Peers are seen to be a resource for students. The results of longitudinal models in some of this research provide empirical support for the proposition that peers often influence students in a positive direction in their schooling. But the study of peers is complex and methodologically challenging, for three reasons.

First, it can be difficult to identify peer groups. Natural peer groups consist of children who are affiliated and regularly interact. These groups are hard to define because they are created by the students, evolve dynamically, and sometimes overlap. There are different ways to obtain and analyze data about students' significant peer affiliations. Traditionally, studies simply ask students to provide lists of their affiliates (e.g., Altermatt \& Pomerantz, 2003). This provides information about each individual student's perceived peer group memberships. It has the disadvantage that participants may be biased in their perceptions of their relationships with others, for example, seeing themselves as friends with popular children, or omitting unpopular children (Kindermann, 1996). Some studies attempt to overcome this by including only ties that are reciprocally nominated by both parties. Another, more comprehensive approach is social-cognitive mapping (SCM, Cairns, Perrin, \& Cairns, 1985). Participants are asked to complete multiple lists of who "hangs out with whom." The lists obtained are then 


\section{PEERS’ ACADEMIC COPING AND MOTIVATIONAL RESILIENCE}

analyzed statistically to determine the significant peer group members for each student. This method has the advantage of providing information about students' actual affiliations from additional observers, the other students in their classes, as well as information about their own perceptions. The significance tests help guard against selfenhancement tendencies (Leung, 1996) because connections are only accepted when they reach reliability thresholds. SCM takes advantage of the use of both multiple observers and observers who are experts, in the respect that they have daily opportunities to see the structure and operation of groups close-up and first-hand. SCM also has an advantage in being less affected by participation rates, because reports from other participants include data about group affiliations of students who are absent or do not participate (Cairns \& Cairns, 1994). SCM will be used in the current study to determine each student's group of significantly affiliated peers.

Second, it is challenging to capture characteristics of the peer group. Children are biased in their perceptions of their affiliates, generally overestimating how similar they are (Ryan, 2000). Asking participants to describe the characteristics of their peer group yields a measure of their perception of the group, whereas asking group members for self-reports provides a more accurate assessment of actual characteristics at the individual level. The current study uses individual self-report data from each group member and then aggregates the data to generate a group average for the relevant variable. The use of an aggregate score for the entire group does not always reflect the composition of the group, depending on the extent of variability within the group. For example, if there may be some students within the group who are above the average and other students below 


\section{PEERS’ ACADEMIC COPING AND MOTIVATIONAL RESILIENCE}

the average. Overall, however, there is generally a high level of similarity within groups; homophily has consistently been found to be characteristic of peer groups (Laursen, 2017). Because of this, the group average provides a measure that is representative of the peer group and suitable for use in examining the effect of the group on the individual over time. In the current study, this averaging procedure is used to compute the peer group level variables for coping strategies.

The third issue in the study of peers is distinguishing selection from influence. Although it is well established that dyads and groups of affiliated individuals are generally similar to each other, exhibiting homophily (Hamm, 2005; Laursen, 2017), it is also known that this similarity results from a combination of two distinct processes. First, individuals select each other on the basis of similar characteristics at the beginning of a relationship. Second, group members become more similar over time as a result of processes of influence, or socialization (Kandel, 1978; Ryan, 2000). It is not easy to determine the extent to which similarity is attributable to the two separate sources. Two primary approaches to this problem are the use of autoregressive longitudinal models (Kindermann, 1996), and the use of stochastic actor-based network models (SIENA; Steglich, Snijders, \& Pearson, 2010; Shin \& Ryan, 2014). The current study uses an autoregressive longitudinal structural equation model in which peer attributes at time one predict student engagement at time two, controlling for student engagement at time one. The correlation of individual levels of academic engagement to their group levels of coping at the first time point is entered into the model. In addition, separate hypotheses are tested for each research question controlling for student's own coping at the 


\section{PEERS' ACADEMIC COPING AND MOTIVATIONAL RESILIENCE}

beginning of the year. Where the average similarity within the group on the coping variable does not change significantly over the course of the study, as is the case in the present study, this control for individual student coping at the first time points captures the selection effect and separates it from the influence of peers over time (Kindermann, 2007).

In spite of the challenges presented by the study of peer effects, the current study takes an approach that has proven useful for investigating the influence of peers in academic settings. As further discussed in Chapter 4 (Methods), peer group averages and SCM are used to examine the relationship between peers' coping and changes in students' academic engagement over the first year of middle school. Specifically, the following research questions are addressed.

\section{Research Questions and Hypotheses.}

The first research question addresses the effect of the overall coping profile of the peer group on student engagement over the course of the year. The question includes a second part, to determine whether the effect is different when controlling for student's own overall coping profile.

\section{Research Question 1: Effect of peer group coping on student's engagement}

over the year. Does the coping profile shown by a student's peer group in fall of sixth grade predict changes in that student's engagement over the school year?

1a. Do peers' overall profiles of adaptive and maladaptive coping predict changes in a student's engagement? 


\section{PEERS' ACADEMIC COPING AND MOTIVATIONAL RESILIENCE}

1b. Do peers' overall profiles of adaptive and maladaptive coping also predict changes in a student's engagement over and above that student's own profile of adaptive and maladaptive coping?

The hypotheses tested propose an effect for the peer group's coping profile on student engagement. Including student's own coping profile as a control in hypothesis $1 \mathrm{~b}$ will test the possibility that the effect of individual coping on change in engagement is confounded with the effect of the peer group, by separating the peer effect from the effect of students' own coping. Potential confounding would occur, for example, when there is individual similarity to the group, which would be the case if group membership were due to self-selection into the group on the basis of characteristics correlated with coping styles.

Hypothesis 1a. The combined adaptive and maladaptive coping profiles of students' peer groups predicts student engagement in the spring, controlling for student engagement in the fall.

Hypothesis 1b. The combined adaptive and maladaptive coping profiles of students' peer groups predicts student engagement in the spring, controlling for students' engagement in the fall and students' own combined adaptive and maladaptive coping profile.

The second research question addresses the effect of adaptive coping found in the peer group on student engagement over the course of the year. The combination of all adaptive academic coping strategies are investigated, as well as each of the five individual adaptive ways of coping. Each of these also includes a second part, to 


\section{PEERS' ACADEMIC COPING AND MOTIVATIONAL RESILIENCE}

determine whether the effect is different when controlling for student's own level on that coping measure.

\section{Research Question 2: Effects of adaptive coping and its components on}

student engagement. Does the adaptive coping shown by a student's peer group predict increases in that student's own engagement?

2a. Do peers' profiles of adaptive coping predict increases in a student's engagement?

2b. Do peers' profiles of adaptive coping also predict increases in a student's engagement over and above that student's own profile of adaptive coping?

2c. Do peers' individual ways of adaptive coping (strategizing, help-seeking, comfort-seeking, self-encouragement, commitment) predict increases in a student's own engagement?

2d. Do peers' individual ways of adaptive coping (strategizing, help-seeking, comfort-seeking, self-encouragement, commitment) also predict increases in a student's own engagement over and above that students' own individual ways of adaptive coping?

The hypotheses tested are that an effect exists for the peer group's adaptive coping on student engagement. Student's own coping is again included as a control in separate hypotheses to separate out the effect of students' own coping, and to address the possibility that there is similarity in coping due to self-selection into the group. 


\section{PEERS’ ACADEMIC COPING AND MOTIVATIONAL RESILIENCE}

Hypothesis 2a. The adaptive coping profiles of students' peer groups predict increases in student engagement in the spring, controlling for student engagement in the fall.

Hypothesis $2 \boldsymbol{b}$. The adaptive coping profiles of students' peer groups predict increases in student engagement in the spring, controlling for student engagement in the fall, and students' own adaptive coping profile.

Hypothesis 2c. The individual ways of adaptive coping (strategizing, helpseeking, comfort-seeking, self-encouragement, commitment) of students' peer groups predict increases in student engagement in the spring controlling for student engagement in the fall.

Hypothesis $2 \boldsymbol{d}$. The individual ways of adaptive coping (strategizing, helpseeking, comfort-seeking, self-encouragement, commitment) of students' peer groups predict increases in student engagement, controlling for student engagement in the fall, and students' own individual ways of adaptive coping.

The third research question addresses the effect of maladaptive coping found in the peer group on student engagement over the course of the year. The combination of all maladaptive academic coping strategies are investigated, as well as each of the six individual maladaptive ways of coping. Each of these also includes a second part, to determine whether the effect is different when controlling for student's own level on that coping measure. 


\section{PEERS’ ACADEMIC COPING AND MOTIVATIONAL RESILIENCE}

\section{Research Question 3: Effects of maladaptive coping and its components on}

student engagement. Does the maladaptive coping shown by a student's peer group predict decreases in that student's own engagement?

3a. Do peers' profiles of maladaptive coping predict decreases in a student's engagement?

3b. Do peers' profiles of maladaptive coping also predict decreases in a student's engagement over and above that student's own profile of maladaptive coping?

3c. Do peers' individual ways of maladaptive coping (escape, confusion, isolation, self-pity, rumination, projection) predict decreases in a student's engagement?

3d. Do peers' individual ways of maladaptive coping (escape, confusion, isolation, self-pity, rumination, projection) also predict decreases in a student's engagement over and above that student's own individual ways of maladaptive coping?

The hypotheses tested for question three are that an effect exists for the peer group's maladaptive coping on student engagement. Maladaptive coping in the peer group could be a liability for student's own academic engagement, and is hypothesized to have a negative effect. Student's own coping is again included as a control in separate hypotheses to separate out the effect of students' own coping, and to address the possibility that there is similarity in coping due to self-selection into the group. 


\section{PEERS’ ACADEMIC COPING AND MOTIVATIONAL RESILIENCE}

Hypothesis 3a. The maladaptive coping profiles of students' peer groups negatively predict student engagement in the spring, controlling for student engagement in the fall.

Hypothesis $3 \boldsymbol{b}$. The maladaptive coping profiles of students' peer groups negatively predict student engagement in the spring, controlling for student engagement in the fall, and students' own maladaptive coping profiles.

Hypothesis 3c. The individual ways of maladaptive coping (escape, confusion, isolation, self-pity, rumination, projection) of students' peer groups negatively predict student engagement in the spring controlling for student engagement in the fall.

Hypothesis 3d. The individual ways of adaptive coping (escape, confusion, isolation, self-pity, rumination, projection) of students' peer group negatively predict student engagement in the spring, controlling for student engagement in the fall, and students' own individual ways of maladaptive coping. 


\section{PEERS' ACADEMIC COPING AND MOTIVATIONAL RESILIENCE}

\section{Chapter 4. Methods}

The data for this study come from an existing dataset of a longitudinal study of an entire cohort of sixth graders in the only public middle school in a town in the northeastern United States. Data collection was during the 1990-1991 academic year. At the time of the study, approvals were in place from the school Principal and teachers, as well as the University of Rochester. The current study was conducted upon reapproval by the Human Subjects Review Board of Portland State University.

The sample consisted of 366 sixth graders enrolled at the school; 340 (93\%) students participated whose parents consented. Ethnicity and socioeconomic status data were not collected. The town, however, was predominately (over 90\%) European American by descent, and largely lower middle to middle class. $87 \%$ of the adult population had at least a high school degree. The sample was $48 \%$ female.

The data collection was organized around the students' homerooms. Each student had one homeroom teacher and had a class in their homeroom once a day. Homeroom teachers had primary responsibility for their homeroom students and indicated that they were familiar with each of them. All 13 sixth grade homeroom teachers participated in the study, and they indicated that they knew their students very well. Data collection took place at two time points, October and May, of sixth grade, the students' first year in middle school. This allows for the use of a longitudinal model of the relationship between study variables. 


\section{PEERS’ ACADEMIC COPING AND MOTIVATIONAL RESILIENCE}

\section{Measures}

At each of the two time points, students and teachers completed questionnaires. Measures used in the current study included self-report (ways of coping), teacher-report (student engagement), and peer report (peer groups). In addition, peer engagement profiles were computed for each student's peer group. The surveys for ways of coping and student engagement used 4-point Likert scales. The data collected for peer groups consisted of lists completed by students. Trained research assistants monitored and assisted in the data collection.

Academic engagement was assessed using a 14-item scale measuring teacher perception of student academic engagement (Wellborn, 1992), including a six item subscale for behavioral engagement (e.g., "This student works as hard as he/she can”), and an eight item subscale for emotional engagement (e.g., "In my class this student appears happy"). Previous research has found the two components to be significantly intercorrelated ( $r=.72, n=1018$, Skinner, Kindermann, \& Furrer, 2009), and to be internally consistent ( $\alpha=.90$, Skinner et al., 2009). Cronbach's alphas in the current study were .87 for fall engagement and .89 for spring engagement. Teacher reports of academic engagement were obtained for 318 students in fall and for 322 students in spring. 300 students were assessed at both time points.

Academic coping was assessed using student responses to items measuring their coping with everyday problems with academic work. Subscales consisting of five items each assessed 11 ways of coping. All scales have been found to have good internal consistency reliabilities (Cronbach's $\alpha=.59$ to .81 ) and stability across time (Skinner et 


\section{PEERS’ ACADEMIC COPING AND MOTIVATIONAL RESILIENCE}

al., 2013). Each subscale asks students about their response to stressful events in school, with items using one of four different stems ("When something bad happens to me in school ...," "When I have trouble with a subject in school ...," "When I run into a problem on an important test ...," "When I have difficulty learning something ...”). Five of the subscales assessed adaptive ways of coping, including strategizing (e.g., "...I try to see what I did wrong), help-seeking (e.g., “...I ask for some help with understanding the material”), comfort-seeking (e.g., "...I talk about it with someone who will make me feel better”), self-encouragement (e.g., “...I tell myself it'll be okay”), and commitment (e.g., "I think about all the reasons it's important to me"). Six of the subscales assessed maladaptive ways of coping, including confusion (e.g., "I'm not sure what to do next"), escape (e.g., “...I tell myself it's not such a big deal”), concealment (e.g., “...I don't tell anyone about it"), self-pity (e.g., "...I say "this always happens to me"”), rumination (e.g., “...I think about it all the time"), and projection (e.g., "...I say it was the teacher's fault"). A measure for each subscale was computed by taking the mean of the five items for that subscale.

In addition, these raw scores were then converted to allocation scores by dividing the average across the items for each subscale by the total of all the subscale scores of that student for all 11 subscales. The idea is to have an assessment of the extent to which students distribute their coping resources. Thus two students with the same raw coping score will have different allocation scores if one of them uses a specific coping strategy exclusively $(100 \%)$ whereas the other uses all alternatives. Composites were computed 


\section{PEERS’ ACADEMIC COPING AND MOTIVATIONAL RESILIENCE}

for the combined allocation scores for adaptive ways of coping and for maladaptive coping.

Additionally, coping profile scores were computed by averaging the adaptive and maladaptive subscale allocation scores, with maladaptive scores reverse coded. These overall coping profile scores indicate for each student the relative balance overall of adaptive and maladaptive coping allocations.

Peer groups were assessed using SCM (Social Cognitive Mapping; Cairns et al., 1985). Student participants were asked to complete a form with room for up to twenty groups that they observed interacting frequently, each group having spaces for up to twenty members. None of the students exhausted the space provided on the form. Students were asked to provide lists of students whom they regularly observe to "hang out together," regardless of whether the group included the reporters themselves or not. They were encouraged to list as many groups as they could think of, including dyads. This method allows students to be placed into more than one group. At the fall time point, 280 participants completed the peer group questionnaire. At the spring time point, 219 students provided the information.

From the student-completed peer group questionnaires, lists of each student's significantly affiliated peer group members were identified using a multiple step procedure (Kindermann, 1993, 1996). First, the frequency of co-nominations for each pair of students was entered into a co-occurrence matrix. Next, binomial $z$-tests were used to determine whether an individual was more likely to be co-nominated as a group member with another individual than would be expected by chance. (For an illustration of 


\section{PEERS' ACADEMIC COPING AND MOTIVATIONAL RESILIENCE}

this step, see the subset of a co-occurrence matrix in Table 2 and the example included there.) In a final step, to avoid problems associated with low expected cell frequencies in the co-occurrence matrix for many participants, Fisher's exact test (Sterling's approximation, von Eye, 1990) was used in conjunction with the binomial $z$-test. Network connections that are significant at the $p=.01$ level using both tests were entered into each student's list of significantly affiliated peers (Kindermann, 2007).

Peer group size, which will be used as a control variable, will be assessed as the count of the number of members in each student's group of significantly affiliated peers, not counting the individual student.

Peer group coping scores were computed by taking the arithmetic mean of the coping allocation scores for all the affiliates of a student, excluding the respective student. For example, if student A has a peer group of significantly affiliated peers including student B, C, D, and E, with allocation scores for strategizing of 10, 9, 11, and 10 , respectively, then student A's peer group strategizing profile allocation score would be 10.0. The peer group averages were computed using allocation scores for each of the 11 separate ways of coping, and for the composite average of the five adaptive and of the six maladaptive ways of coping, as well as for the overall coping profile, which is obtained from all 11 scores, with the maladaptive scores reversed. 
PEERS’ ACADEMIC COPING AND MOTIVATIONAL RESILIENCE

Table 4.1. Subset of a Co-occurrence Matrix of Girls in Sixth Grade (Kindermann, 2007)

\begin{tabular}{|c|c|c|c|c|c|c|c|c|c|c|c|c|c|}
\hline & KER & RYB & DAL & COD & SUO & ROM & STQ & CHR & KAA & KAW & ELT & JEP & Nom's. \\
\hline KER & - & 28 & 23 & 12 & 10 & 3 & 3 & 0 & 0 & 0 & 0 & 0 & 36 \\
\hline RYB & 28 & - & 20 & 11 & 12 & 3 & 4 & 0 & 0 & 0 & 0 & 0 & 32 \\
\hline DAL & 23 & 20 & - & 10 & 9 & 4 & 2 & 0 & 0 & 0 & 0 & 0 & 28 \\
\hline COD & 12 & 11 & 10 & - & 19 & 8 & 13 & 0 & 0 & 0 & 0 & 0 & 29 \\
\hline SUO & 10 & 12 & 9 & 19 & - & 9 & 10 & 0 & 0 & 0 & 0 & 0 & 29 \\
\hline ROM & 3 & 3 & 4 & 8 & 9 & - & 4 & 0 & 0 & 0 & 0 & 0 & 11 \\
\hline STQ & 3 & 4 & 2 & 13 & 10 & 4 & - & 0 & 0 & 0 & 0 & 0 & 17 \\
\hline CHR & 0 & 0 & 0 & 0 & 0 & 0 & 0 & - & 10 & 10 & 9 & 10 & 14 \\
\hline KAA & 0 & 0 & 0 & 0 & 0 & 0 & 0 & 10 & - & 13 & 13 & 12 & 16 \\
\hline KAW & 0 & 0 & 0 & 0 & 0 & 0 & 0 & 10 & 13 & - & 13 & 10 & 17 \\
\hline ELT & 0 & 0 & 0 & 0 & 0 & 0 & 0 & 9 & 13 & 13 & - & 10 & 18 \\
\hline JEP & 0 & 0 & 0 & 0 & 0 & 0 & 0 & 10 & 1 & 10 & 10 & - & 13 \\
\hline LIP & 0 & 0 & 0 & 0 & 0 & 0 & 0 & 0 & 0 & 0 & 0 & 0 & 24 \\
\hline $\begin{array}{l}\text { No. of } \\
\text { Inf. }\end{array}$ & & & & & & & & & & & & & 260 \\
\hline Total & & & & & & & & & & & & & 3,047 \\
\hline Nom. & & & & & & & & & & & & & \\
\hline Groups & & & & & & & & & & & & & 694 \\
\hline Genrtd. & & & & & & & & & & & & & \\
\hline
\end{tabular}

\section{Figure 4.1 Example of Application of the Binomial Z-test to the Co-occurrence Matrix}

Consider the two students KER and RYB. KER was reported to be observed as belonging to a group a total of 36 times, and RYB was reported to be observed as belonging to the same group 28 times. RYB was reported to be observed as belonging to a group a total of 32 times. There was a grand total of 694 groups listed by all informants.

The conditional probability of observing RYB as a member of a group, given that KER was a member of one of those groups, is computed $(28 / 36=.78)$ and compared to the unconditional probability that RYB belonged to any group $(32 / 694=.05)$ using a binomial z-test. The significant $\mathrm{z}$-score resulting from this comparison $(z=21.47, p$ $<.01$ ), indicates that the two are significantly affiliated. RYB is a member of KER's peer group. 


\section{PEERS’ ACADEMIC COPING AND MOTIVATIONAL RESILIENCE}

\section{Chapter 5. Results}

The analyses consisted of two phases. First, descriptive statistics and measurement properties of all measures were computed. Means, standard deviations, and other descriptive statistics were used get an overall picture of the data, and to verify statistical assumptions underlying the main analyses. Second, all hypotheses associated with the research questions were tested using structural equation modeling (SEM) in Amos version 25 (Arbuckle, 2017). Missing values were handled by the use of full information maximum likelihood estimation (FIML; Enders \& Bandalos, 2001).

\section{Descriptive Statistics}

Mean levels, standard deviations, minimums, maximums, skewness, and kurtosis for all individual level variables are shown in Table 5.1 and for group level averages in Table 5.2. Mean levels of student engagement were comparable between fall $(m=3.08$, $\mathrm{SD}=.62)$ and spring $(m=3.07, \mathrm{SD}=.68)$ with good reliability $(\alpha=.87$ in fall, $\alpha=.89$ in spring), and moderate stability across time $(r=.74, p<.001)$. Mean levels and standard deviations for engagement and individual coping allocation scores were consistent with previous research (Vollet, Kindermann \& Skinner, 2017, Skinner, Pitzer \& Steele, 2013), and minimum and maximum ranges did not suggest the presence of outliers. Cronbach's alphas for the raw coping scores on which the allocation scores are based are shown in Appendix A, Table A.1. The results of these internal consistency reliability alphas in the current study were similar to previous research (Skinner et al., 2013). The mean levels of allocation scores for adaptive ways of coping and total adaptive coping were higher, ranging from 10.69 to 11.16 , than maladaptive ways and total maladaptive coping, which 


\section{PEERS’ ACADEMIC COPING AND MOTIVATIONAL RESILIENCE}

ranged from 6.63 to 9.33 . Mean levels of the group averages for specific ways of coping and coping composite measures (Table 5.2), showed a similar pattern, with means for adaptive coping generally higher than means for maladaptive coping.

Skewness was less than 2.0 for all variables, within the generally accepted range for the assumption of normality in multiple regression and structural equation analyses. Kurtosis was within acceptable levels, under 3.0, for fall and spring student engagement, both control variables (sex and group size), and for student individual coping allocation scores for combined adaptive, combined maladaptive, overall coping profile, and each of the eleven separate specific ways of academic coping. For the peer group averages of coping allocation scores, however, kurtosis statistics for commitment, rumination, and projection exceeded 3.0. These flattened distributions are inconsistent with the assumption of normality, and might potentially affect the significance levels in the analyses. This potential effect is noted as a limitation of the study.

Correlations between individual level variables are shown in Table 5.3 and for group averages in Table 5.4. Biological sex was significantly positively correlated with individual total adaptive coping, as well as with strategizing, help-seeking, and comfortseeking, and was significantly negatively correlated with individual total maladaptive coping, as well as with escape, concealment, and projection. Thus, mean levels of total adaptive coping and of those strategies with significant positive correlations with sex were higher for girls than for boys, while mean levels of total maladaptive coping and of strategies with significant negative correlations with sex were higher for boys than for girls. Group size was not correlated with individual coping allocation levels. Allocation 


\section{PEERS’ ACADEMIC COPING AND MOTIVATIONAL RESILIENCE}

scores for all of the adaptive ways, as well as total adaptive coping, were positively and significantly correlated with fall engagement. Conversely, all of the maladaptive ways except rumination, as well as total maladaptive coping, were negatively and significantly correlated with fall engagement. Similar but generally weaker relationships were found between fall coping allocation scores and spring engagement.

At the individual level, intercorrelations for coping allocation scores showed a simple pattern. Consistent with prior research (Skinner, Pitzer, and Steele, 2013), adaptive ways of coping were generally positively correlated with each other $(r=.36$ to $.58, p<.01)$ and negatively correlated with maladaptive ways of coping other than rumination $(r=-.37$ to $-.67, p<.01)$, while maladaptive ways of coping other than rumination were generally positively correlated with each other $(r=.31$ to $.66, p<.01)$ and, negatively correlated with adaptive ways of coping. Comfort-seeking showed a weaker version of the general pattern than other adaptive ways of coping, with the smallest correlations with other adaptive ways $(r=.36$ to.38, $p<.01)$. A notable exception to the overall pattern was rumination, which was only weakly or nonsignificantly correlated with most other specific ways of coping. Among adaptive ways, rumination was negatively correlated only with self-encouragement, and was uncorrelated with specific maladaptive ways, except that it had significant negative correlations with escape and projection. Among maladaptive ways of coping, escape and self-pity had an unusually small positive intercorrelation $(r=.31, p<.01)$, compared to other pairs of maladaptive ways of coping. 


\section{PEERS’ ACADEMIC COPING AND MOTIVATIONAL RESILIENCE}

Overall, group averages of allocation scores for separate ways of coping and combined adaptive, maladaptive, and profile scores were less strongly related to biological sex, to engagement, and to each other than were the individual coping allocation scores. The pattern of correlations for sex with group coping averages was similar to that found for individuals, with positive correlations (higher levels for girls) on strategizing, help-seeking, comfort-seeking, and total adaptive coping, and negative correlations (lower levels for girls) on escape, concealment, projection, and total maladaptive coping. Correlations were smaller at the group level, however, and selfencouragement at the group level, unlike at the individual level, was not significantly correlated with sex.

The associations between peer group level coping and student academic engagement are especially interesting, since they relate directly to the thesis that peers' coping is a resource for student engagement. Total adaptive coping and coping profile group averages were positively and significantly correlated with individual student engagement in the fall $(r=.14, r=.15$, respectively, $p<.05)$, and total adaptive coping but not the coping profile group average was positively and significantly correlated with individual spring engagement $(r=.14, p<.05)$. Total maladaptive coping was negatively and significantly correlated with individual student engagement $(r=-.14, p<.05)$ in the fall, but not in the spring. Strategizing, help-seeking, and comfort-seeking group averages were significantly positively correlated with fall engagement $(r=.16, p<.01$ for strategizing, $r=.15, p<.05$ for help-seeking and comfort-seeking) and significantly positively correlated with spring engagement $(r=.16, p<.05$ for strategizing, $r=.16, p<$ 


\section{PEERS’ ACADEMIC COPING AND MOTIVATIONAL RESILIENCE}

.05 for help-seeking, $r=.14, p<.05$ for comfort-seeking). Self-encouragement at the group level, unlike at the individual level, was not significantly correlated with fall or spring engagement. Among specific maladaptive ways of coping, only confusion and projection at the group level were significantly negatively correlated with fall engagement ( $r=-.14, p<.05$ and $r=-.20, p<.01$, respectively), and group average projection was also significantly negatively correlated with spring engagement $(r=-.25$, $p<.01)$. Concealment and self-pity at the group level, unlike at the individual level, were not significantly negatively correlated with engagement. Escape was negatively correlated with engagement in spring $(r=-.14, p<.05)$ but not in fall. Rumination was not significantly correlated with student engagement in fall, but was significantly positively correlated with spring engagement $(r=.25, p<.01)$.

Specific ways of coping at the group level showed the same pattern of correlations with each other as that seen at the individual level, with some modest variation in the strengths of relationships. The small negative correlation between rumination and comfort-seeking and small positive correlation between rumination and self-pity, which were not significant at the individual level, were found to be significant at the group level $(r=.18$ and $.12, p<.05)$.

Correlations between individual levels and group average levels of coping are shown in Table 5.5. In contrast to correlations at the individual level and correlations between group averages for different ways of coping, which were often quite strong, correlations between the individual allocation scores and average levels of their peer groups were generally small or nonsignificant. Individual levels of total adaptive, total 


\section{PEERS' ACADEMIC COPING AND MOTIVATIONAL RESILIENCE}

maladaptive, and coping profile allocation scores in fall were weakly but positively and significantly correlated with peer group averages on those variables $(r=.13, p<.05, r=$ $.14, p<.05$, and $r=.20, p<.01$, respectively). Individual levels of coping allocation scores and peer group averages for specific ways of coping were mostly uncorrelated, although a few small significant correlations were found. Individual levels were also significantly positively correlated with group levels for strategizing $(r=.20, p<.01)$, escape $(r=.13, p<.05)$, self-pity $(r=.17, p<.01)$, rumination $(r=.13, p<.05)$, and projection $(r=.16, p<.05)$. Individual levels of total adaptive coping were generally not correlated with group levels of specific ways of coping, except for being significantly positively correlated with strategizing $(r=.18, p<.01)$, and significantly negatively correlated with projection $(r=-.15, p<.05)$. Group levels of total adaptive coping were significantly positively correlated with strategizing $(r=.18, p<.05)$, and comfortseeking $(r=.14, p<.05)$, and significantly negatively correlated with projection $(r$ $=-.18, p<.01)$. Individual levels of total maladaptive coping were significantly negatively correlated with group levels for strategizing $(r=-.18, p<.01)$, and significantly negatively correlated with self-pity $(r=.13, p<.05)$, and projection $(r=.14$, $p<.05$ ), while group levels of total maladaptive coping were significantly negatively correlated with individual levels for strategizing $(r=-.18, p<.01)$, and comfort-seeking $(r=-.14, p<.05)$, and significantly positively correlated with individual levels of projection $(r=.14, p<.05)$. Group level coping profile generally showed the same pattern of correlations as total adaptive coping, but unlike total adaptive coping, coping profile at the individual level was significantly negatively correlated with group average 


\section{PEERS’ ACADEMIC COPING AND MOTIVATIONAL RESILIENCE}

self-pity, and the group average for coping profile was not significantly correlated with individual levels of comfort-seeking, and was significantly negatively correlated with individual levels of self-pity.

Positive correlations between the individual and the group in fall generally indicate homophily, possibly resulting from selection effects. Selection effects can, but do not necessarily, imply that individuals sought out the members of their groups directly according to coping preferences. Other explanations are possible. For example, students may have formed affiliations based on shared interests (e.g., sports or academics) and individuals' similarity in coping may just be a byproduct of the underlying selection tendencies. In addition to the correlations between the individual and their group average on certain measures, there were also significant correlations between individual levels on some specific ways of coping and group levels on other specific ways. These effects are complicated, representing an interplay between correlations within individuals and possible selection effects at the group level. In general, the overall difference in the pattern of correlations at individual and group levels and the pattern seen in the correlations between individuals and their peer group averages suggests some diversity in coping repertoires among members of peer groups. 


\section{PEERS’ ACADEMIC COPING AND MOTIVATIONAL RESILIENCE}

Table 5.1. Summary of Descriptive Statistics -

Engagement, Control Variables, and Individual Coping

\begin{tabular}{lcccrrr}
\hline & $n$ & $M($ S.D.) & \multicolumn{1}{l}{ Min } & \multicolumn{1}{c}{ Max } & \multicolumn{1}{c}{ Skew } & Kurtosis \\
\hline Student Eng. Fall & 304 & $3.08(.62)$ & 1.46 & 4.00 & -.23 & -.82 \\
Student Eng. Spring & 288 & $3.07(.68)$ & 1.35 & 4.00 & -.31 & -.85 \\
Sex & 366 & $1.47(.50)$ & 1.00 & 2.00 & .11 & -2.00 \\
Peer Group Size & 366 & $5.59(4.81)$ & 0.00 & 20.00 & .73 & -.30 \\
Adaptive Coping & & & & & & \\
Allocations: & & & & & & \\
\hline$\quad$ Strategizing & 313 & $11.14(1.97)$ & 4.20 & 16.32 & .01 & .22 \\
Help-seeking & 315 & $11.16(2.33)$ & 4.99 & 17.91 & -.05 & .14 \\
Comfort-seeking & 310 & $10.69(2.01))$ & 3.81 & 16.24 & -.10 & .32 \\
Self-Encourgment & 326 & $10.75(1.90)$ & 4.10 & 15.65 & -.17 & .64 \\
Commitment & 321 & $10.63(1.95)$ & 5.44 & 15.44 & .04 & -.02 \\
\hline All Adaptive & 329 & $10.86(1.53)$ & 5.38 & 14.66 & .07 & -.05 \\
Maladaptive Coping & & & & & & \\
Allocations: & & & & & & \\
\hline Confusion & 315 & $7.69(1.45)$ & 4.03 & 14.29 & .01 & .84 \\
Escape & 315 & $6.98(2.04)$ & 3.28 & 15.66 & .42 & .34 \\
Concealment & 323 & $7.42(2.05)$ & 3.42 & 14.88 & .19 & .02 \\
Self-pity & 323 & $7.48(2.20)$ & 3.47 & 12.92 & -.01 & -.93 \\
Rumination & 316 & $9.33(1.74)$ & 4.43 & 14.82 & .03 & -.04 \\
$\quad$ Projection & 325 & $6.63(2.17)$ & 2.93 & 13.52 & .64 & .03 \\
\hline All Maladaptive & 329 & $7.57(1.29)$ & 3.94 & 12.19 & -.16 & -.15 \\
Coping Profile & 329 & $9.77(.94)$ & 7.38 & 11.83 & -.02 & -.49 \\
\hline
\end{tabular}

Note: Missing values for descriptive statistics were handled with pair-wise deletion. 


\section{PEERS' ACADEMIC COPING AND MOTIVATIONAL RESILIENCE}

Table 5.2. Summary of Descriptive Statistics - Peer Group Coping Averages

\begin{tabular}{lcccccr}
\hline & $n$ & $M($ S.D. $)$ & Min & Max & Skew & Kurtosis \\
\hline $\begin{array}{l}\text { Adaptive Coping } \\
\text { Allocations: }\end{array}$ & & & & & & \\
\hline Strategizing & 286 & $11.15(1.13)$ & 7.22 & 16.23 & .26 & 1.94 \\
Help-seeking & 285 & $11.20(1.32)$ & 5.80 & 15.75 & -.32 & 2.47 \\
Comfort-seeking & 284 & $10.85(1.05)$ & 8.01 & 14.60 & .43 & .84 \\
Self-Encourgment & 287 & $10.78(.99)$ & 7.75 & 15.45 & .36 & 1.89 \\
Commitment & 286 & $10.71(1.01)$ & 6.34 & 15.33 & -.24 & 3.43 \\
\hline All Adaptive & 287 & $10.92(.85)$ & 7.81 & 13.79 & .13 & .87 \\
Maladaptive Coping & & & & & & \\
Allocations: & & & & & & \\
\hline Confusion & 285 & $7.66(.76)$ & 4.81 & 10.12 & .35 & 1.27 \\
Escape & 285 & $6.95(1.12)$ & 3.71 & 10.67 & .44 & 1.12 \\
Concealment & 286 & $7.35(1.06)$ & 3.69 & 11.34 & .00 & 1.25 \\
Self-pity & 286 & $7.38(1.17)$ & 4.00 & 10.96 & -.20 & .25 \\
Rumination & 286 & $9.29(.97)$ & 4.43 & 12.71 & -.75 & 3.08 \\
Projection & 287 & $6.60(1.26)$ & 3.45 & 13.52 & 1.04 & 4.11 \\
\hline All Maladaptive & 287 & $7.53(.72)$ & 5.17 & 9.84 & -.18 & .50 \\
Coping Profile & 287 & $9.81(.54)$ & 7.46 & 11.51 & -.30 & 2.29 \\
\hline
\end{tabular}

Note: Missing values for descriptive statistics were handled with pair-wise deletion. 
Table 5.3. Intercorrelations Among Control Variables, Engagement, and Individual Coping Allocation Scores

\begin{tabular}{|c|c|c|c|c|c|c|c|c|c|c|c|c|c|c|c|c|c|c|}
\hline & 1 & 2 & 3 & 4 & 5 & 6 & 7 & 8 & 9 & 10 & 11 & 12 & 13 & 14 & 15 & 16 & 17 & 18 \\
\hline \multicolumn{19}{|l|}{ 1. Sex } \\
\hline 2. Group Size & $.26 * *$ & & & & & & & & & & & & & & & & & \\
\hline 3. Fall & $.15^{*}$ & $.19 * *$ & & & & & & & & & & & & & & & & \\
\hline \multicolumn{19}{|l|}{ Engagement } \\
\hline 4. Spring Eng. & $.21 * *$ & .08 & $.74 * *$ & & & & & & & & & & & & & & & \\
\hline 5. Strategizing & $.17 * *$ & .00 & $.26 * *$ & $.27 * *$ & & & & & & & & & & & & & & \\
\hline 6. Help-seeking & $.21 * *$ & .07 & $.27 * *$ & $.27 * *$ & $.58 * *$ & & & & & & & & & & & & & \\
\hline 8 Self-encourgmt. & .09 & -.02 & $.23 * *$ & $.21 * *$ & $.50 * *$ & $.53 * *$ & $.38 * *$ & & & & & & & & & & & \\
\hline 9 Commitment & .09 & .10 & $.12 *$ & .08 & $.49 * *$ & $.48 * *$ & $.38 * *$ & $.43 * *$ & & & & & & & & & & \\
\hline 10 Total Adaptive & $.21 * *$ & .08 & $.29 * *$ & $.26 * *$ & $.78 * *$ & $.81 * *$ & $.66 * *$ & $.75 * *$ & $.74 * *$ & & & & & & & & & \\
\hline 11 Confusion & -.10 & -.08 & $-.26 * *$ & $-.25 * *$ & $-.64 * *$ & $-.63 * *$ & $-.54 * *$ & $-.67 * *$ & $-.58 * *$ & $-.81 * *$ & & & & & & & & \\
\hline .12 Escape & $-.18 * *$ & -.02 & $-.13 *$ & $-.14 *$ & $-.53 * *$ & $-.52 * *$ & $-.47 * *$ & $-.37 * *$ & $-.59 * *$ & $-.66^{* *}$ & $.44 * *$ & & & & & & & \\
\hline 13 Concealment & $-.11 *$ & -.03 & $-.16^{* *}$ & -.11 & $-.61 * *$ & $-.64 * *$ & $-.52 * *$ & $-.50 * *$ & $-.56 * *$ & $-.75 * *$ & $.60 * *$ & $.48 * *$ & & & & & & \\
\hline 14 Self-Pity & -.08 & -.04 & $-.34 * *$ & $-.31 * *$ & $-.66 * *$ & $-.64 * *$ & $-.46 * *$ & $-.61 * *$ & $-.53 * *$ & $-.73 * *$ & $.66 * *$ & $.31 * *$ & $.52 * *$ & & & & & \\
\hline 15 Rumination & .04 & .04 & .02 & .11 & .02 & -.02 & -.11 & $-.25 * *$ & -.07 & -.11 & .08 & $-.25 * *$ & -.09 & .10 & & & & \\
\hline 17 Total Maladptv. & $-.18 * *$ & -.05 & $-.31 * *$ & $-.27 * *$ & $-.79 * *$ & $-.80 * *$ & $-.66 * *$ & $-.71 * *$ & $-.72 * *$ & $-.94 * *$ & $.82 * *$ & $.66 * *$ & $.76^{* *}$ & $.78 * *$ & $.13 *$ & $.72 * *$ & & \\
\hline 18 Coping Profile & .10 & .04 & $.31 * *$ & $.23 * *$ & $.68 * *$ & $.73 * *$ & $.54 * *$ & $=.65 * *$ & $.63 * *$ & $.85 * *$ & $-72 * *$ & $-.48 * *$ & $-.63 * *$ & $-.77 * *$ & $-.21 * *$ & $-.60 * *$ & $-.88 * *$ & \\
\hline \multicolumn{19}{|c|}{ Correlation coefficients, $r$, are shown below the diagonal. $* p<.05 . * * p<01$} \\
\hline
\end{tabular}


Table 5.4. Intercorrelations Among Control Variables, Engagement, and Peer Group Coping Allocation Scores

\begin{tabular}{|c|c|c|c|c|c|c|c|c|c|c|c|c|c|c|c|c|c|c|}
\hline & 1 & 2 & 3 & 4 & 5 & 6 & 7 & 8 & 9 & 10 & 11 & 12 & 13 & 14 & 15 & 16 & 17 & 18 \\
\hline \multicolumn{19}{|l|}{ 1. Sex } \\
\hline 2. Group Size & $.18 * *$ & & & & & & & & & & & & & & & & & \\
\hline 3. Fall & $.15^{*}$ & $.19 * *$ & & & & & & & & & & & & & & & & \\
\hline \multicolumn{19}{|l|}{ Engagement } \\
\hline 4. Spring Eng. & $.21 * *$ & .08 & $.74 * *$ & & & & & & & & & & & & & & & \\
\hline 5. Strategizing & $.26 * *$ & .04 & $.16^{* *}$ & $.16^{*}$ & & & & & & & & & & & & & & \\
\hline 6. Help-seeking & $.31 * *$ & $.15^{*}$ & $.15^{*}$ & $.16^{*}$ & $.69 * *$ & & & & & & & & & & & & & \\
\hline 7 Comfort-seeking & $.25 * *$ & .01 & $.15^{*}$ & $.14^{*}$ & $.53 * *$ & $.41 * *$ & & & & & & & & & & & & \\
\hline 8 Self-encouragmt. & $.16^{* *}$ & -.09 & .04 & -.01 & $.53 * *$ & $.40 * *$ & & & & & & & & & & & & \\
\hline 9 Commitment & .11 & .11 & .00 & .02 & $.46 * *$ & $.44 * *$ & $.32 * *$ & $.44 * *$ & & & & & & & & & & \\
\hline 10 Total Adaptive & $.30 * *$ & .08 & $.14^{*}$ & $.14^{*}$ & $.85 * *$ & $.81 * *$ & $.68 * *$ & $.73 * *$ & $.70 * *$ & & & & & & & & & \\
\hline 11 Confusion & -.11 & $-.15 *$ & $-.14 *$ & -.09 & $-.61 * *$ & $-.69 * *$ & $-.52 * *$ & $-.61 * *$ & $-.60 * *$ & $-.78 * *$ & & & & & & & & \\
\hline 12 Escape & $-.23 * *$ & -.00 & -.10 & $-.14 *$ & $-.57 * *$ & $-.51 * *$ & $-.51 * *$ & $-.47 * *$ & $-.57 * *$ & $-.68 * *$ & $.45^{* *}$ & & & & & & & \\
\hline 13 Concealment & $-.17 * *$ & .03 & -.03 & -.03 & $-.67 * *$ & $-.66 * *$ & $-.55 * *$ & $-.51 * *$ & $-.50 * *$ & $-.77 * *$ & $.55^{* *}$ & $.48 * *$ & & & & & & \\
\hline 14 Self-pity & -.06 & -.01 & -.12 & -.08 & $-.78 * *$ & $-.73 * *$ & $-.44 * *$ & $-.64 * *$ & $-.44 * *$ & $-.80 * *$ & $.71 * *$ & $.38 * *$ & $.60 * *$ & & & & & \\
\hline 15 Rumination & -.02 & .10 & .08 & $.19 * *$ & .03 & .03 & $-.18 * *$ & $-.29 * *$ & .08 & -.06 & -.00 & $-.29 * *$ & .06 & $.12 *$ & & & & \\
\hline 16 Projection & $-.39 * *$ & $-.16^{* *}$ & $-.20 * *$ & $-.25 * *$ & $-.71 * *$ & $-.66^{* *}$ & $-.55 * *$ & $-.47 * *$ & $-.53 * *$ & $-.78 * *$ & $.53 * *$ & $.57 * *$ & $.47 * *$ & $.54 * *$ & $-.23 * *$ & & & \\
\hline 17 Total Maladptv. & $-.25 * *$ & -.05 & $-.14 *$ & -.11 & $-.84 * *$ & $-.81 * *$ & $-.68 * *$ & $-.74 * *$ & $-.64 * *$ & $-.97 * *$ & $.78 * *$ & $.67 * *$ & $.79 * *$ & $.84 * *$ & $.12 *$ & $.76^{* *}$ & & \\
\hline 18 Coping Profile & $.14^{*}$ & .02 & $.15^{*}$ & .10 & $.79 * *$ & $.76^{* *}$ & $.56^{* *}$ & $.70 * *$ & $.54 * *$ & * $.89 * *$ & $-.73 * *$ & $-.49 * *$ & $-.67 * *$ & $-.85 * *$ & $-.19 * *$ & $-.65 * *$ & $-.90 * *$ & \\
\hline
\end{tabular}

Correlation coefficients, $r$, are shown below the diagonal. $* p<.05$. $* * p<01$. 
Table 5.5. Intercorrelations among Fall Individual Level Coping and Peer Group Averages

\begin{tabular}{|c|c|c|c|c|c|c|c|c|c|c|c|c|c|c|}
\hline \multirow[b]{2}{*}{ Individual Variable } & \multicolumn{14}{|c|}{ Peer Group Average Variable } \\
\hline & $\mathrm{ST}$ & HS & $\mathrm{CS}$ & $\mathrm{SE}$ & $\mathrm{CM}$ & ADAP & $\mathrm{CF}$ & $\mathrm{ES}$ & $\mathrm{CL}$ & SP & $\mathrm{RM}$ & PJ & MAL & PRFL \\
\hline Strategizing & $.20 * *$ & $.13^{*}$ & $.16^{*}$ & .12 & .06 & $.18^{*}$ & -.12 & -.07 & $-.12 *$ & $-.22 * *$ & .02 & $-.18 * *$ & $-.18 * *$ & $-.19 * *$ \\
\hline Help-Seeking & .11 & .07 & .11 & -.02 & .03 & .09 & -.06 & -.05 & -.07 & -.09 & .07 & -.11 & -.09 & .08 \\
\hline Comfort-Seeking & $.22 * *$ & $.13 *$ & .09 & .04 & .06 & $.14^{*}$ & -.10 & $-.13 *$ & -.07 & -.08 & .03 & $-.17 * *$ & $-.14 * *$ & $.13^{*}$ \\
\hline Self-Encouragement & .10 & .01 & .03 & .08 & .01 & .06 & -.07 & -.03 & -.02 & -.09 & -.09 & .01 & -.07 & .09 \\
\hline Commitment & .05 & .05 & .03 & .00 & .04 & .05 & -.00 & -.09 & -.07 & .00 & .11 & -.09 & -.05 & .04 \\
\hline Total Adaptive & $.17 * *$ & .11 & .11 & .05 & .06 & $.13 *$ & -.09 & -.08 & -.10 & -.11 & .03 & $-.15^{*}$ & $-.13 *$ & $.14^{*}$ \\
\hline Confusion & -.11 & -.07 & -.06 & -.04 & -.01 & -08 & .01 & .05 & .05 & .09 & -.06 & .09 & .08 & -.07 \\
\hline Escape & -.08 & -.09 & -.08 & -.03 & $-.13 *$ & -.10 & -.08 & $.13 *$ & .12 & .03 & -.10 & .10 & .10 & -.05 \\
\hline Concealment & $-.14 *$ &,- 06 & -.09 & -.03 & -.09 & -.11 & .06 & .10 & .10 & .07 & -.02 & $.13 *$ & .12 & -.10 \\
\hline Self-Pity & $-.22 * *$ & -.10 & -.05 & -.08 & .04 & -.10 & .07 & .05 & .02 & $.17 * *$ & -.03 & $.15^{*}$ & .12 & $-.15^{*}$ \\
\hline Rumination & .05 & .10 & .02 & -.03 & $.17 *$ & .08 & -.09 & -.12 & -.07 & -.04 & $.13 *$ & -.09 & -.07 & .05 \\
\hline Projection & $-.19 * *$ & $-.16^{* *}$ & $-.15^{*}$ & -.02 & $-.13^{*}$ & $-.18 * *$ & $.13^{*}$ & .10 & $.15^{*}$ & $.17 * *$ & -.06 & $.16^{*}$ & $.17 * *$ & $-.19 * *$ \\
\hline Total Maladaptive & $-.18 * *$ & -.11 & -.11 & -.06 & -.05 & $-.13 *$ & .07 & $/ 08$ & .10 & $.13 *$ & -.02 & $.15^{*}$ & $.14^{*}$ & $-.14^{*}$ \\
\hline Coping Profile & $.21 * *$ & .11 & .11 & .11 & .05 & $.15^{*}$ & -.10 & -.06 & -.08 & $-.18 * *$ & -.00 & $-.17 * *$ & $-.16^{* *}$ & $.20 * *$ \\
\hline
\end{tabular}

$* p<.05 . * * p<01$. 


\section{PEERS' ACADEMIC COPING AND MOTIVATIONAL RESILIENCE}

\section{Structural Equation Models}

Structural equation modeling (SEM) was used to examine the hypothesized relationships among peer group coping scores in fall of sixth grade and students' academic engagement in the spring of sixth grade, controlling for academic engagement in the fall, for each research question. Models were estimated using AMOS 25 (Arbuckle, 2017). Missing data were handled using full information maximum likelihood (FIML, Enders \& Bandalos, 2001). Figure 5.1 presents an example of a path model for the analysis using the peer group coping allocation score for the coping profile as the predictor at the fall time point. In all models, both individual engagement in the fall and individual engagement in the spring were treated as latent variables. All models specified a direct path from fall engagement to spring engagement, and from peers' coping to spring engagement, such that peers' coping was tested as a predictor of spring engagement controlling for fall engagement. Peer group size and biological sex were entered as controls because, based on the correlations with other variables and on previous research on peers at school, they were expected to remove shared variance and contribute to more useful results.

\section{Research Question One: Effect of peer group coping on student engagement.}

The first research question was: Does the coping profile shown by a student's peer group in fall of sixth grade predict changes in that student's engagement over the school year? This question was investigated by testing two hypotheses. First, it was hypothesized that peers' coping profiles would positively predict change in a student's engagement over the school year, controlling for peer group size and sex. Second, it was 


\section{PEERS’ ACADEMIC COPING AND MOTIVATIONAL RESILIENCE}

hypothesized that peers' coping profiles would positively predict change in student engagement, controlling for students' individual coping profiles, and controlling for peer group size and sex. Structural equation models were tested for each hypothesis. The hypotheses were not supported. 


\section{PEERS’ ACADEMIC COPING AND MOTIVATIONAL RESILIENCE}

Figure 5.1. Structural Model of Effect of Peer Group Average Coping Profile in Fall on Student Engagement in Spring, Controlling for Student Engagement in Fall.

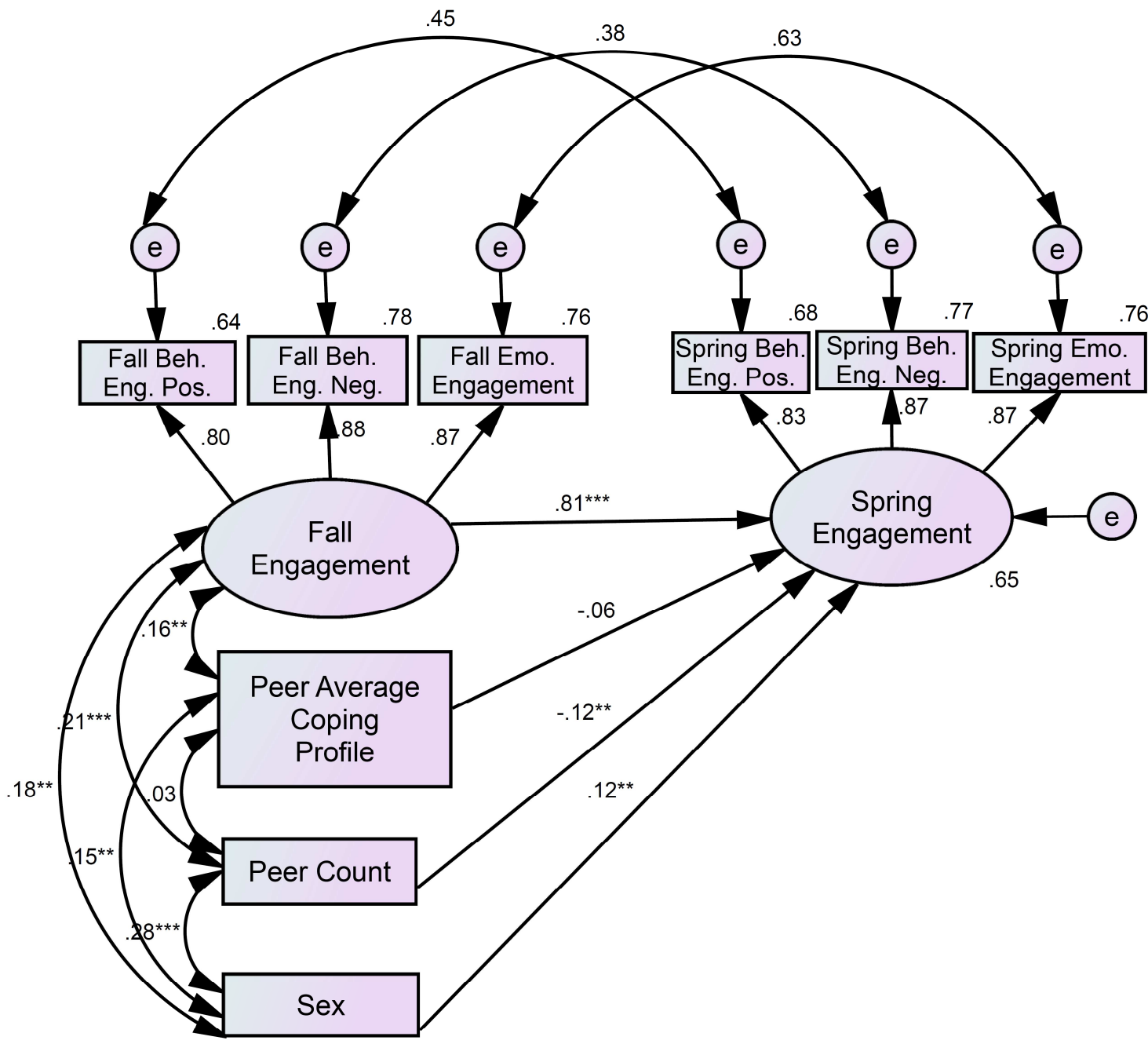

Coefficients are standardized.

Model fit: $\chi_{2}(17)=23.304, p=.140, \mathrm{CFI}=.996$, RMSEA(C.I. $)=.032(.006-.061)$. 


\section{PEERS' ACADEMIC COPING AND MOTIVATIONAL RESILIENCE}

Results for coping profile are included in Table 5.6 and Table 5.7, with model fit statistics included in Table 5.8. Model fit was good for the overall coping profile model, $\chi^{2}(17)=23.304, p=.140, \mathrm{CFI}=.996, \operatorname{RMSEA}(90 \% \mathrm{CI})=.032(.000-.061)$. As shown in Figure 5.1, results indicated that peers' coping profile did not significantly predict student spring engagement controlling for fall engagement, $b=-.077, \mathrm{SE}=.052, \beta=-.065$ (standardized), ns. Model fit was also good for the model with peers' coping profile controlling for individual coping profile, $\chi^{2}(21)=29.934, p=.093, \mathrm{CFI}=.994$, $\operatorname{RMSEA}(90 \% \mathrm{CI})=.034(.000-.060)$. Results indicated that peers' coping profile controlling for individual coping profile did not significantly predict spring engagement controlling for fall engagement, $b=-.073, \mathrm{SE}=.052, \beta=-.062$ (standardized), ns. In addition, individual coping profile controlling for peers' coping profile did not significantly predict individual student spring engagement controlling for fall engagement, $b=-.006, \mathrm{SE}=.030, \beta=-.009$ (standardized), ns. Peer group size significantly negatively predicted spring engagement controlling for fall engagement in the model with peers' coping profile as a predictor $(b=-.016, \mathrm{SE}=.006, \beta=-.117$ (standardized), $p<.01$ ), as well as in the model with peers' coping profile as a predictor and also controlling for individual's own coping profile $(b=-.016, \mathrm{SE}=.006, \beta=-.118$ (standardized), $p<.01$ ). Biological sex significantly positively predicted spring engagement controlling for fall engagement in the model with peers' coping profile as a predictor $(b=.160, \mathrm{SE}=.054, \beta=.123$ (standardized), $p<.01)$, as well as in the model with peers' coping profile as a predictor and also controlling for individual's own coping profile $(b=.161, \mathrm{SE}=.055, \beta=.124($ standardized $), p<.01)$. 


\section{PEERS’ ACADEMIC COPING AND MOTIVATIONAL RESILIENCE}

\section{Research Question Two: Effects of peers' adaptive coping and its components on student engagement.}

The second research question was: Does the adaptive coping shown by a student's peer group members predict increases in that student's own engagement? This question was investigated using four hypotheses. First, it was hypothesized that peers' combined adaptive coping would positively predict change in a student's engagement over the school year. Second, it was hypothesized that peers' combined adaptive coping would positively predict change in a student's engagement over the school year, controlling for the student's own level of combined adaptive coping. Third, it was hypothesized that each of five separate ways of adaptive coping would positively predict change in a student's engagement over the school year. Fourth, it was hypothesized that each of five separate ways of adaptive coping would positively predict change in a student's engagement over the school year, controlling for the student's own level of those specific ways of coping. Models with peers combined adaptive coping and five specific ways of adaptive coping were tested separately, as well as models that also included individual students' own combined adaptive and specific ways of adaptive coping as controls. Results for adaptive coping are shown in Table 5.6 and Table 5.7, with model fit statistics included in Table 5.8.

Hypotheses $2 a$ and $2 b$. The analyses did not support the hypotheses concerning the positive effect on engagement of peers' combined adaptive coping. Model fit was good for the combined adaptive coping model, $\chi^{2}(17)=23.626, p=.130, \mathrm{CFI}=.996$, $\operatorname{RMSEA}(90 \% \mathrm{CI})=.033(.000-.062)$. As seen in Figure 5.2, results indicated that peers' 


\section{PEERS' ACADEMIC COPING AND MOTIVATIONAL RESILIENCE}

combined adaptive coping did not significantly predict spring engagement controlling for fall engagement, $b=-.032, \mathrm{SE}=.034, \beta=-.042$ (standardized), ns. Model fit was also good for the model with peers' combined adaptive coping controlling for individual combined adaptive coping, $\chi^{2}(21)=28.223, p=.134, \mathrm{CFI}=.995, \operatorname{RMSEA}(90 \% \mathrm{CI})=$ $.031(.000-.057)$. Again, results indicated that peers' combined adaptive coping controlling for individual combined adaptive coping did not significantly predict spring engagement controlling for fall engagement, $b=-.032, \mathrm{SE}=.034, \beta=-.043$

(standardized), ns. In addition, individual combined adaptive coping controlling for peers' combined adaptive coping did not significantly predict spring engagement controlling for fall engagement, $b=.011, \mathrm{SE}=.018, \beta=.027$ (standardized), ns.

Hypotheses $2 c$ and $2 d$. Peers use of five specific ways of adaptive coping were tested separately: strategizing, help-seeking, comfort-seeking, self-encouragement, and commitment. As shown in Figure 5.3, a significant effect on engagement was found for peers' self-encouragement coping, but not for other specific ways of adaptive coping. The effect was negative, contrary to the hypothesis that peers' adaptive coping would have a positive effect on engagement change. Model fit was good for all models. See table 5.7 for model fit statistics, and table 5.5 and 5.6 for estimated coefficients and related statistics. Peers' self-encouragement significantly negatively predicted spring engagement controlling for fall engagement, $b=-.075, \mathrm{SE}=.028, \beta=-.114$ (standardized), $p<01$. None of the other specific ways of peers' adaptive coping significantly predicted spring engagement controlling for fall engagement. 


\section{PEERS' ACADEMIC COPING AND MOTIVATIONAL RESILIENCE}

Peers' self-encouragement coping controlling for individual self-encouragement coping did not significantly predict spring engagement controlling for fall engagement. None of the other separate ways of peers' adaptive coping significantly predicted spring engagement controlling for fall engagement and controlling for individual students' own use of the separate way of coping. In addition, individuals' own use of separate ways of adaptive coping did not significantly predict spring engagement controlling for fall engagement and controlling for peers' use of that way of adaptive coping. 


\section{PEERS’ ACADEMIC COPING AND MOTIVATIONAL RESILIENCE}

Figure 5.2. Structural Model of Effect of Peer Group Average Adaptive Coping in Fall on Student Engagement in Spring, Controlling for Student Engagement in Fall.

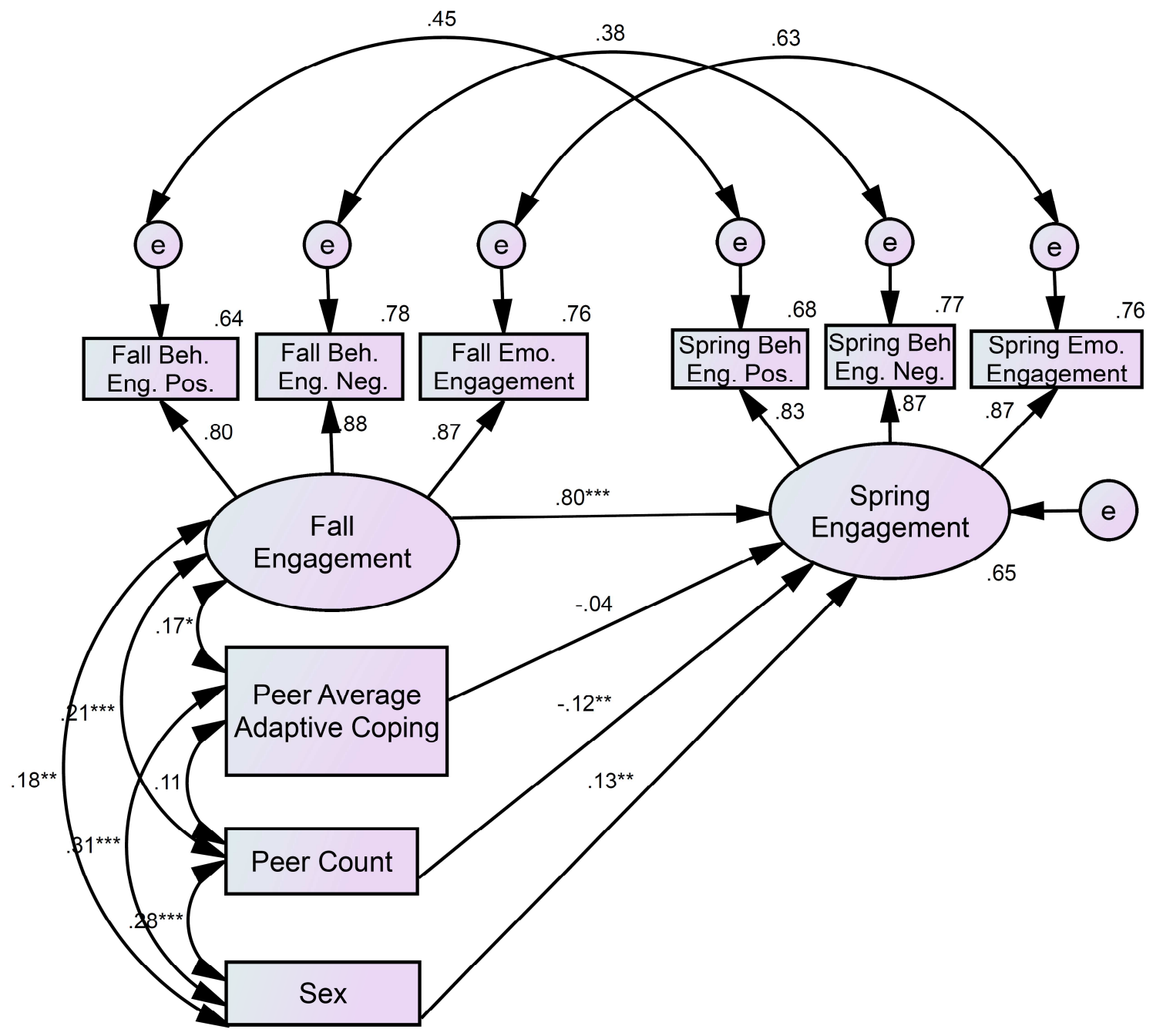

Coefficients are standardized.

Model fit: $\chi_{2}(17)=23.626, p=.130, \mathrm{CFI}=.996$, RMSEA(C.I. $)=.033(.000-.062)$. 


\section{PEERS’ ACADEMIC COPING AND MOTIVATIONAL RESILIENCE}

Figure 5.3. Structural Model of Peer Group Average Self-Encouragement Coping in Fall on Student Engagement in Spring, Controlling for Student Engagement in Fall

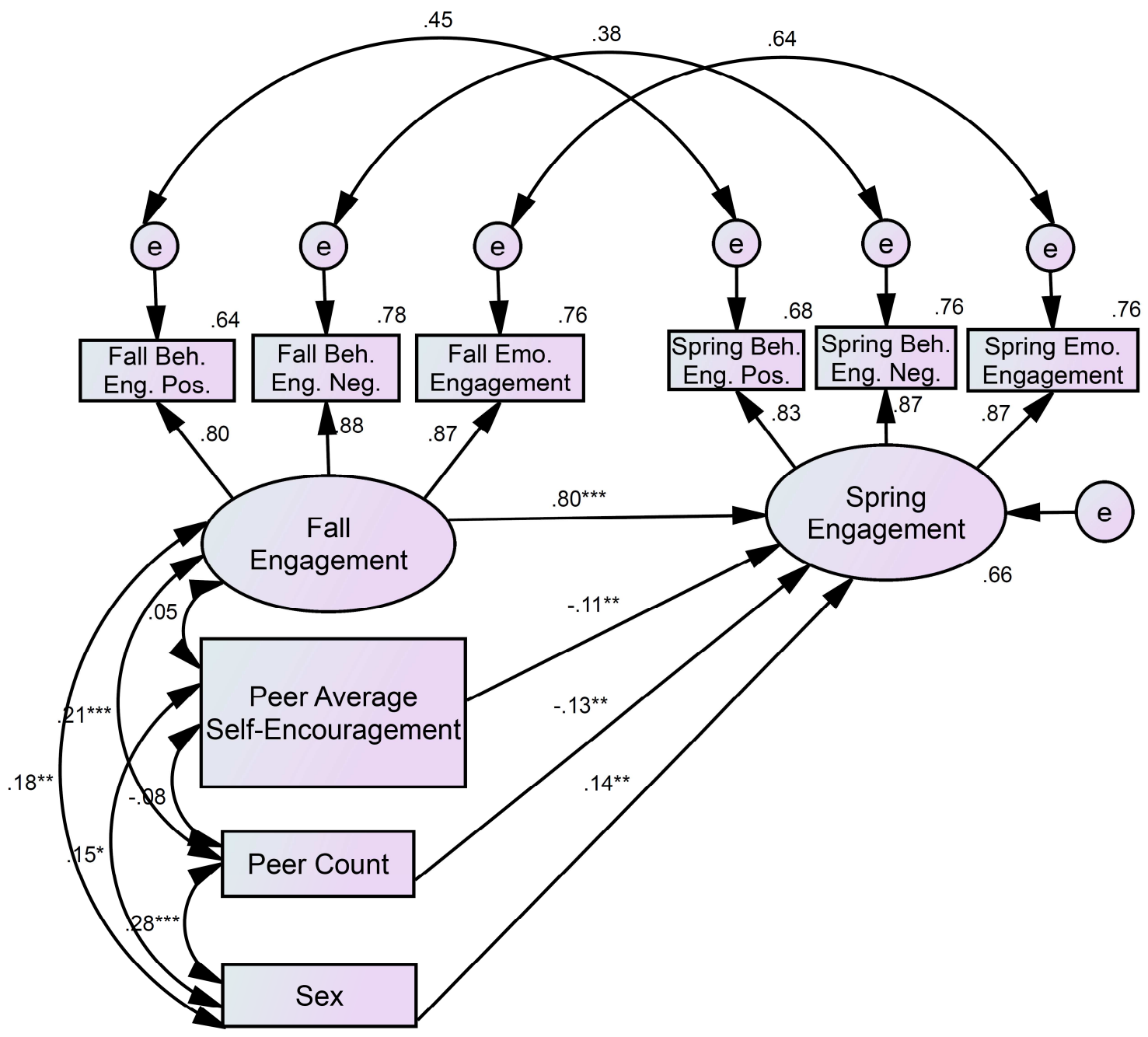

Coefficients are standardized.

Model fit: $\chi_{2}(17)=23.787, p=.125, \mathrm{CFI}=.995$, RMSEA(C.I. $)=.033(.000-.062)$. 
Table 5.6. Predictors of Spring Engagement when Controlling for Fall Engagement - Adaptive Coping - Peers 
Table 5.7. Predictors of Spring Engagement when controlling for Fall Engagement Adaptive Coping; Peers and Individual

\begin{tabular}{|c|c|c|c|c|c|c|c|c|c|c|c|c|}
\hline \multirow[b]{2}{*}{ Predictor } & \multicolumn{4}{|c|}{ Strategizing } & \multicolumn{4}{|c|}{ Help-Seeking } & \multicolumn{4}{|c|}{ Comfort-Seeking } \\
\hline & $\beta$ & $b$ & S.E. & $p$ & $\beta$ & $b$ & S.E. & $p$ & $\beta$ & $b$ & S.E. & $p$ \\
\hline Peers' Coping Avg. & -.036 & -.021 & .026 & .426 & -.020 & -.010 & .022 & .656 & .011 & .007 & .028 & .806 \\
\hline Individual Coping & .057 & .019 & .014 & .188 & .054 & .015 & .012 & .210 & -.022 & -.007 & .014 & .607 \\
\hline Total Eng. Fall & $.786 * *$ & .841 & .061 & .000 & $.785^{* *}$ & .840 & .096 & .000 & $.799 * *$ & .854 & .061 & .000 \\
\hline Peer Count & $-.110^{* *}$ & -.015 & .006 & .009 & $-.111 * *$ & -.015 & .006 & .008 & $-.115^{* *}$ & -.016 & .006 & .006 \\
\hline \multirow[t]{2}{*}{ Sex } & $.116^{* *}$ & .150 & .056 & .007 & $.113 *$ & .146 & .057 & .010 & $.116^{* *}$ & .150 & .056 & .008 \\
\hline & \multicolumn{4}{|c|}{ Self-Encouragement } & \multicolumn{4}{|c|}{ Commitment } & \multicolumn{4}{|c|}{ Total Adaptive } \\
\hline Predictor & $\beta$ & $b$ & S.E. & $p$ & $\beta$ & $b$ & S.E. & $p$ & $\beta$ & $b$ & S.E. & $p$ \\
\hline Peers' Coping Avg. & $-.114 *$ & -.075 & .028 & .008 & -.016 & -.011 & .028 & .707 & -.043 & -.032 & .034 & .347 \\
\hline Individual Coping & .049 & .017 & .014 & .235 & -.010 & -.003 & .014 & .804 & .027 & .011 & .018 & .534 \\
\hline Total Eng. Fall & $.790 * *$ & .847 & .060 & .000 & $.797 * *$ & .856 & .060 & .000 & $.794 * *$ & .849 & .061 & .000 \\
\hline Peer Count & $-.126^{* *}$ & -.017 & .006 & .003 & $-.114 * *$ & -.015 & .006 & .007 & $-.114 * *$ & -.015 & .006 & .007 \\
\hline \multirow[t]{2}{*}{ Sex } & $.135 * *$ & .175 & .054 & .001 & $.117 * *$ & .152 & .054 & .005 & $.123 * *$ & .160 & .057 & .005 \\
\hline & \multicolumn{4}{|c|}{ Coping Profile } & & & & & & & & \\
\hline Predictor & $\beta$ & $b$ & S.E. & $p$ & & & & & & & & \\
\hline Peers' Coping Avg. & -.062 & -.073 & .052 & .161 & & & & & & & & \\
\hline Individual Coping & -.009 & -.006 & .030 & .837 & & & & & & & & \\
\hline Total Eng. Fall & $.809 * *$ & .865 & .062 & .000 & & & & & & & & \\
\hline Peer Count & $-.118^{* *}$ & -.016 & .006 & .005 & & & & & & & & \\
\hline Sex & $.124 * *$ & .161 & .055 & .003 & & & & & & & & \\
\hline
\end{tabular}


PEERS' ACADEMIC COPING AND MOTIVATIONAL RESILIENCE

Table 5.8. Model Fit Statistics

\begin{tabular}{|c|c|c|c|}
\hline Research Question / Model & $\chi^{2}(\mathrm{df}) p$ & CFI & RMSEA(C.I.) \\
\hline 1a. Group Coping Profile & $23.304(17) .140$ & .996 & $.032(.006-.061)$ \\
\hline $\begin{array}{l}\text { 1b. Group Coping Profile with } \\
\text { Individual Coping Profile }\end{array}$ & $29.934(21) .093$ & .994 & $.034(.000-.060)$ \\
\hline 2a. Total Adaptive & $23.626(17) .130$ & .996 & $.033(.000-.062)$ \\
\hline 2b. Total Adaptive with & & & \\
\hline Individual Adaptive & $28.223(21) .134$ & .995 & $.031(.000-.057)$ \\
\hline 2c. Strategizing & 24.013(17).119 & .995 & $.034(.000-.062)$ \\
\hline Help-seeking & $23.715(17) .127$ & .996 & $.033(.000-.062)$ \\
\hline Comfort-seeking & $23.053(17) 148$ & .996 & $.031(.000-.061)$ \\
\hline Self-Encouragement & $23.787(17) .125$ & .995 & $.033(.000-.062)$ \\
\hline Commitment & 27.081(17).057 & .993 & $.040(.000-.068)$ \\
\hline 2d. Strategizing w/Individual & $28.181(21) .135$ & .995 & $.031(.000-.057)$ \\
\hline Help-seeking w/Individual & $30.473(21) .083$ & .994 & $.035(.000-.061)$ \\
\hline Comfort-Seeking w/Individual & $29.310(21) .107$ & .994 & $.033(.000-.059)$ \\
\hline Self-Encouragement w/Ind. & $30.604(21) .081$ & .994 & $.035(.000-.061)$ \\
\hline Commitment w/Individual & $27.905(21) .143$ & .995 & $.030(.000-.057)$ \\
\hline 3a. Total Maladaptive & $22.816(17) .155$ & .996 & $.031(.000-.060)$ \\
\hline $\begin{array}{l}\text { 3b Total Maladaptive with } \\
\text { Individual Maladaptive }\end{array}$ & $27.795(21) .146$ & .996 & $.030(.000-.057)$ \\
\hline 3c. Confusion & $28.230(17) .042$ & .992 & $.043(.008-.069)$ \\
\hline Escape & $26.431(17) .067$ & .994 & $.039(.000-.067)$ \\
\hline Concealment & 25.514(17).084 & .994 & 037(.000-.065) \\
\hline Self-Pity & $23.451(17) .135$ & .996 & $.032(.000-.061)$ \\
\hline Rumination & $24.324(17) .111$ & .995 & $.034(.000-.063)$ \\
\hline Projection & 25.778(17).079 & .994 & $.031(.000-.060)$ \\
\hline 3d. Confusion w/Individual & $32.801(21) .048$ & .992 & $.039(.003-.064)$ \\
\hline Escape w/Individual & $28.969(21) .115$ & .995 & $.032(.000-.059)$ \\
\hline Concealment w/Individual & $27.665(21) .150$ & .995 & $.029(.000-.056)$ \\
\hline Self-Pity w/Individual & $27.459(21) .156$ & .996 & $.029(.000-.056)$ \\
\hline Rumination w/Individual & $30.352(21) .085$ & .994 & $.035(.000-.061)$ \\
\hline Projection w/Individual & $27.243(21) .163$ & .996 & $.030(.000-.057)$ \\
\hline
\end{tabular}


PEERS’ ACADEMIC COPING AND MOTIVATIONAL RESILIENCE

Research Question Three: Effects of peers' maladaptive coping and its components on student engagement.

The third research question was: Does the maladaptive coping shown by a student's peer group predict decreases in that student's own engagement? This question was investigated using four hypotheses. First, it was hypothesized that peers' combined maladaptive coping would negatively predict change in a student's engagement over the school year. Second, it was hypothesized that peers' combined maladaptive coping would negatively predict change in a student's engagement over the school year, controlling for the student's own level of combined maladaptive coping. Third, it was hypothesized that each of six separate ways of maladaptive coping would negatively predict change in a student's engagement over the school year. Fourth, it was hypothesized that each of six separate ways of maladaptive coping would negatively predict change in a student's engagement over the school year, controlling for the student's own level of those specific ways of coping. Models with peers combined maladaptive coping and six specific ways of maladaptive coping were tested separately, as well as models that also included individual students' own combined maladaptive and specific ways of maladaptive coping as controls. Results for maladaptive coping are shown in Table 5.9 and Table 5.10, with model fit statistics included in Table 5.8.

Hypotheses $3 a$ and $3 b$. The analyses did not support the hypotheses concerning the negative effect on engagement of peers' combined maladaptive coping. Model fit was good for the combined maladaptive coping model, $\chi^{2}(17)=22.816, p=.155, \mathrm{CFI}=.996$, $\operatorname{RMSEA}(90 \% \mathrm{CI})=.031(.000-.060)$. As shown in Figure 5.4, results indicated that 


\section{PEERS' ACADEMIC COPING AND MOTIVATIONAL RESILIENCE}

peers' combined maladaptive coping did not significantly predict spring engagement controlling for fall engagement, $b=.059, \mathrm{SE}=.040, \beta=.066$ (standardized), ns. Model fit was also good for the model with peers' combined maladaptive coping controlling for individual combined maladaptive coping, $\chi^{2}(21)=27.795, \mathrm{p}=.146, \mathrm{CFI}=.996$, $\operatorname{RMSEA}(90 \% \mathrm{CI})=.030(.000-.057)$. Results indicated that peers' combined maladaptive coping controlling for individual combined maladaptive coping did not significantly predict spring engagement controlling for fall engagement, $b=.059, \mathrm{SE}=$ $.040, \beta=.066$ (standardized), ns. In addition, individual combined maladaptive coping controlling for peers' combined maladaptive coping did not significantly predict spring engagement controlling for fall engagement, $b=-.014, \mathrm{SE}=.022, \beta=-.028$ (standardized), ns.

Hypotheses $3 c$ and $3 d$. Peers use of six specific ways of maladaptive coping were tested separately: confusion, escape, concealment, self-pity, rumination, and projection. A significant effect on engagement was found for peers' rumination coping, but not for other specific ways of maladaptive coping. The effect was positive, contrary to the hypothesis that peers' maladaptive coping would have a negative effect. The model fit was good for all models. See table 5.7 for model fit statistics, and table 5.8 and 5.9 for estimated coefficients and related statistics. As shown in Figure 5.5, results showed that peers' rumination coping positively predicted spring engagement controlling for fall engagement, $b=.088, \mathrm{SE}=.028, \beta=.133$ (standardized), $p<01$. This relationship was in the opposite direction of what was expected, since rumination is classified here as a maladaptive way of coping. Peers' rumination coping when controlling for individual 


\section{PEERS' ACADEMIC COPING AND MOTIVATIONAL RESILIENCE}

rumination also significantly and positively predicted spring engagement controlling for fall engagement, $b=.083, \mathrm{SE}=.029, \beta=.124$ (standardized), $p<.01$. None of the other specific maladaptive ways of peers coping significantly predicted spring engagement controlling for fall engagement.

Individual's own rumination coping controlling for peers' rumination did not significantly predict spring engagement controlling for fall engagement, $b=.031, \mathrm{SE}=$ $.015, \beta=.082$ (standardized), ns. Of the other ways of maladaptive coping, individual projection coping controlling for peers' projection was the only one that significantly predicted spring engagement controlling for fall engagement, and controlling for peers' average level of projection, $b=-.026 \mathrm{SE}=.013, \beta=-.087$ (standardized), $p<.05$ (see Figure 5.6). This negative relationship between individual maladaptive projection coping and engagement change was in the expected direction.

The two predictors which were entered into the analyses as control variables, biological sex and peer group size, both showed significant and consistent effects across all analyses. The standardized regression coefficients for peer group size were negative in all cases, including both the analyses with peer group coping levels only, and also those including individual coping as a control $(\beta=-.10$ to $-.13, p<.01)$. For a one standard deviation increase in peer group size (4.8), spring engagement controlling for fall engagement was found to be lower by .10 to .13 standard deviation (.07 to .09 points). A possible interpretation of this negative effect of group size on engagement is as an adverse effect on academic involvement of higher levels of social involvement, on average. It can't be determined from these analyses, however, what processes are actually 


\section{PEERS' ACADEMIC COPING AND MOTIVATIONAL RESILIENCE}

responsible for the effect. It may be due to the presence of greater levels of certain attributes in larger peer groups, differences in the allocation of time, or some other causal factor. If nothing more, the results underscore the importance of peers as a component of the social context of schooling. When the models are run without peer group size as a control, however, there was no change in which coping variables had significant relationships with spring engagement controlling for fall engagement.

Results suggest an important role for biological sex in understanding academic coping, and effects on motivational resilience. Standardized regression coefficients for sex were positive in all cases, including both the analyses with peer group coping levels only, and those with individual coping as a control $(\beta=.10$ to $.14, p<.05)$. Since the standard deviation for sex was .50, the effect of being a girl versus a boy on spring engagement controlling for fall engagement is twice the standardized coefficient, or .21 to .27 standard deviations (.14 to .18 points). Noticeable differences across sex for different ways of coping were also found. By controlling for sex, the regression coefficients for peer group coping are at the average level, and remove the potential distortion in the interpretation of the findings that might otherwise result as consequence of the high proportion of peers of the same sex in students' individual peer groups. When the models are run without sex as a control, however, there was no change in which coping variables had significant relationships with spring engagement controlling for fall engagement. These results and their implications are discussed further under future research directions and in Appendix B. 


\section{PEERS’ ACADEMIC COPING AND MOTIVATIONAL RESILIENCE}

Figure 5.4. Structural Model of Effect of Peer Group Average Maladaptive Coping in Fall on Student Engagement in Spring, Controlling for Student Engagement in Fall.

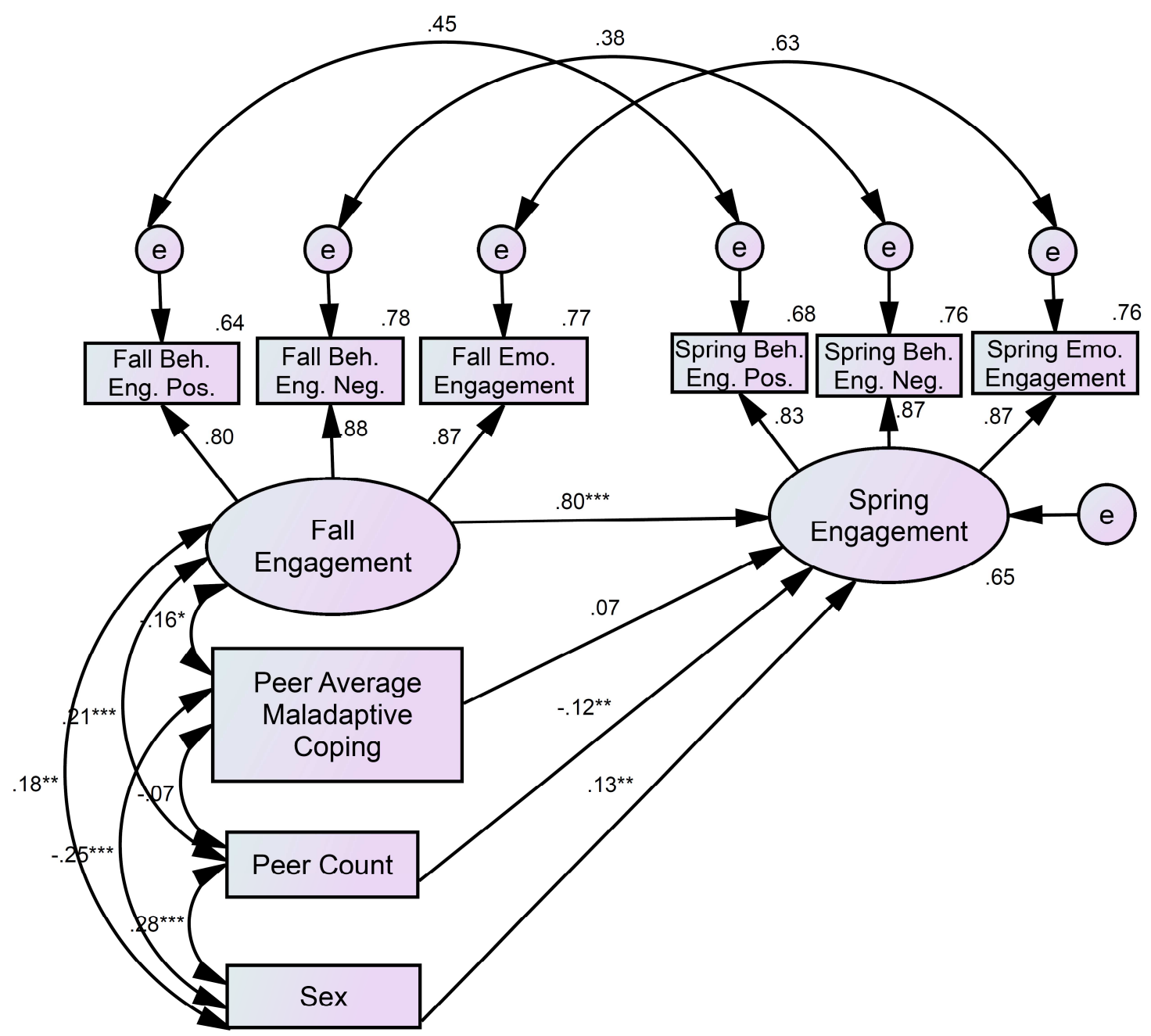

Coefficients are standardized.

Model fit: $\chi_{2}(17)=22.816, p=.155, \mathrm{CFI}=.996$, RMSEA(C.I. $)=.031(.000-.060)$. 


\section{PEERS’ ACADEMIC COPING AND MOTIVATIONAL RESILIENCE}

Figure 5.5. Structural Model of Effect of Peer Group Average Rumination Coping in Fall on Student Engagement in Spring, Controlling for Student Engagement in Fall.

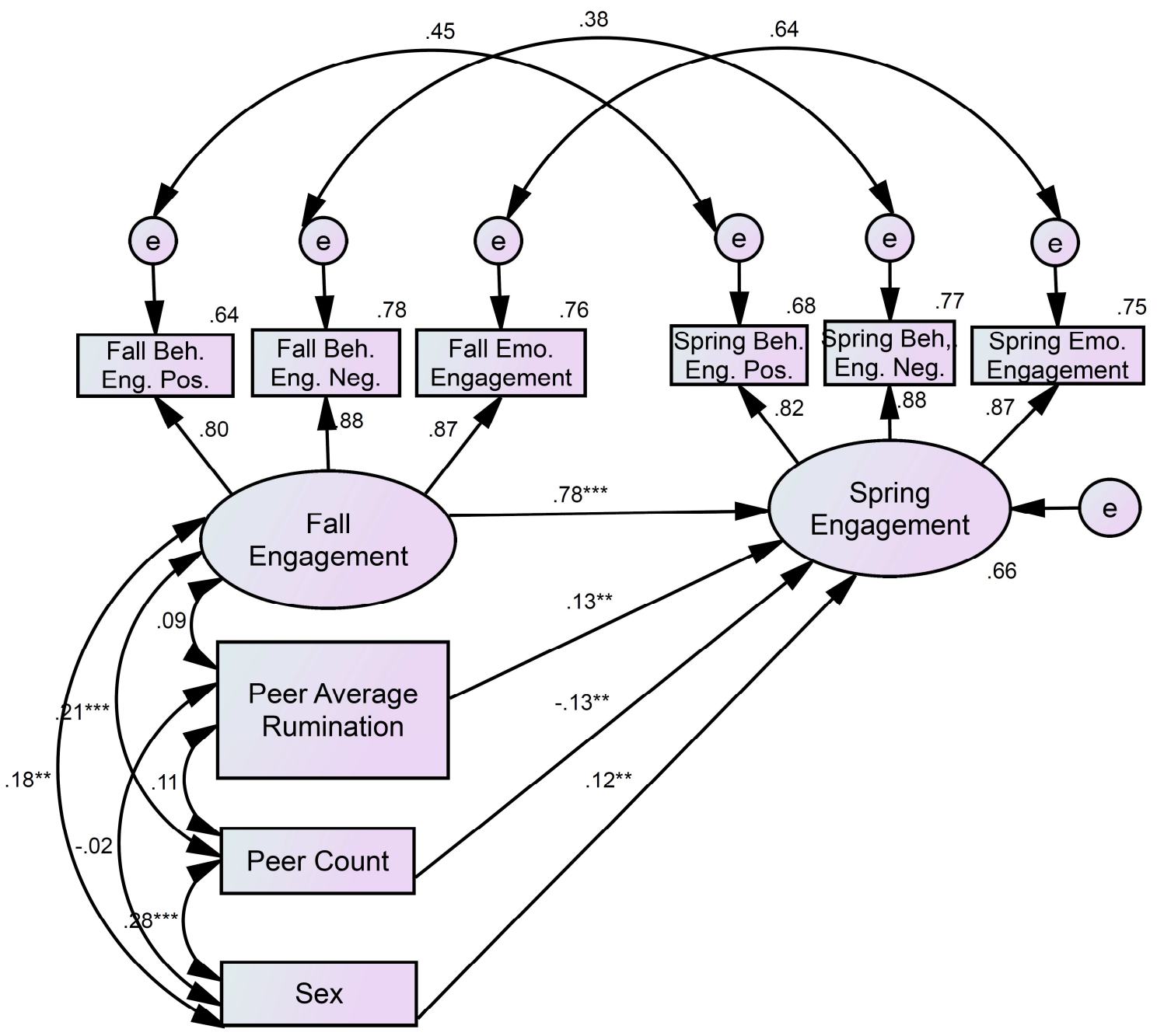

Coefficients are standardized.

Model fit: $\chi_{2}(17)=24.324, p=.111, \mathrm{CFI}=.995$, RMSEA(C.I. $)=.034(.000-.063)$. 


\section{PEERS’ ACADEMIC COPING AND MOTIVATIONAL RESILIENCE}

Figure 5.6. Structural Model of Effect of Peer Group Average Projection Coping in Fall on Student Engagement in Spring, Controlling for Student Engagement in Fall and Controlling for Individual Projection Coping in Fall.

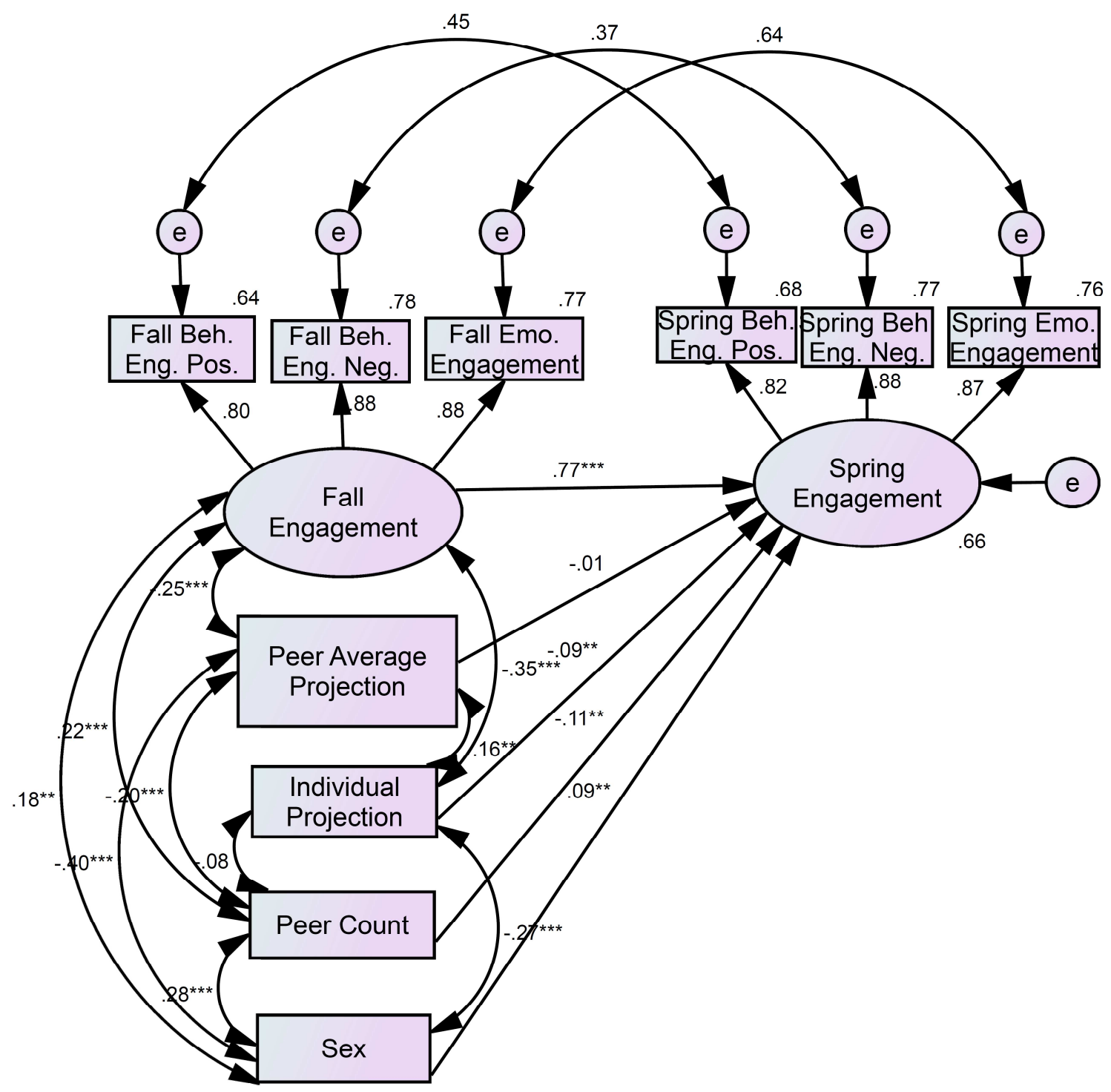

Coefficients are standardized.

Model fit: $\chi_{2}(21)=27.243, p=.163, \mathrm{CFI}=.996$, RMSEA(C.I. $)=.030(.000-.057)$. 
Table 5.9. Predictors of Spring Engagement when Controlling for Fall Engagement - Maladaptive Coping - Peers

\begin{tabular}{|c|c|c|c|c|c|c|c|c|c|c|c|c|}
\hline \multirow[b]{2}{*}{ Predictor } & \multicolumn{4}{|c|}{ Confusion } & \multicolumn{4}{|c|}{ Escape } & \multicolumn{4}{|c|}{ Concealment } \\
\hline & $\beta$ & $b$ & S.E. & $p$ & $\beta$ & $b$ & S.E. & $p$ & $\beta$ & $b$ & S.E. & $p$ \\
\hline Peers' Coping Avg. & .039 & .033 & .038 & .377 & .006 & .004 & .026 & .888 & .032 & .019 & .027 & .469 \\
\hline Total Eng. Fall & $.800 * *$ & 859 & .060 & .000 & $.797 * *$ & .856 & .060 & .000 & $.797 * *$ & .856 & .060 & .000 \\
\hline Peer Count & $-.111^{* *}$ & -.015 & .006 & .009 & $-.116^{* *}$ & -.016 & .006 & .006 & $-.117 * *$ & -.016 & .006 & .005 \\
\hline \multirow[t]{2}{*}{ Sex } & $.117 * *$ & .151 & .054 & .005 & $.116^{* *}$ & .150 & .056 & .007 & $.121^{* *}$ & .156 & .055 & .004 \\
\hline & \multicolumn{4}{|c|}{ Self-Pity } & \multicolumn{4}{|c|}{ Rumination } & \multicolumn{4}{|c|}{ Projection } \\
\hline Predictor & $\beta$ & $B$ & S.E. & $p$ & $\beta$ & $b$ & S.E. & $p$ & $\beta$ & $b$ & S.E. & $p$ \\
\hline Peers' Coping Avg. & .054 & .030 & .024 & .216 & $.133 * *$ & .088 & .028 & .000 & -.013 & -.006 & .024 & .790 \\
\hline Total Eng. Fall & $.803 * *$ & .863 & .060 & .000 & $.785 * *$ & .841 & .059 & .000 & $.794 * *$ & .853 & .061 & .000 \\
\hline Peer Count & $-.116^{* *}$ & -.016 & .006 & .006 & $-.131 * *$ & -.018 & .006 & .002 & $-.116^{* *}$ & -.016 & .006 & 006 \\
\hline \multirow[t]{2}{*}{ Sex } & $.118 * *$ & .152 & .054 & .005 & $.123 * *$ & .159 & .053 & .003 & $.111^{*}$ & .143 & .058 & .014 \\
\hline & \multicolumn{4}{|c|}{ Total Maladaptive } & & & & & & & & \\
\hline Predictor & $\beta$ & $B$ & S.E. & $p$ & & & & & & & & \\
\hline Peers' Coping Avg. & .066 & .059 & .040 & .140 & & & & & & & & \\
\hline Total Eng. Fall & $.805 * *$ & .866 & .060 & .000 & & & & & & & & \\
\hline Peer Count & $-.117^{* *}$ & -.016 & .006 & .005 & & & & & & & & \\
\hline Sex & $.131 * *$ & .170 & .056 & .002 & & & & & & & & \\
\hline
\end{tabular}


Table 5.10. Predictors of Spring Engagement when Controlling for Fall Engagement - Maladaptive Coping - Peers and Individual

\begin{tabular}{|c|c|c|c|c|c|c|c|c|c|c|c|c|}
\hline \multirow[b]{2}{*}{ Predictor } & \multicolumn{4}{|c|}{ Confusion } & \multicolumn{4}{|c|}{ Escape } & \multicolumn{4}{|c|}{ Concealment } \\
\hline & $B$ & $b$ & S.E. & $p$ & $\beta$ & $b$ & S.E. & $p$ & $\beta$ & $b$ & S.E. & $p$ \\
\hline Peers' Coping Avg. & .038 & .032 & .037 & .389 & .009 & .005 & .026 & .841 & .030 & .018 & .027 & .491 \\
\hline Individual Coping & -.056 & -.025 & .019 & .191 & -.042 & -.013 & .013 & .319 & .009 & .003 & .013 & .826 \\
\hline Total Eng. Fall & $.786^{* *}$ & .840 & .061 & .000 & $.792 * *$ & .850 & .060 & .000 & $.798 * *$ & .856 & .060 & .000 \\
\hline Peer Count & $-.111 * *$ & -.015 & .006 & .009 & $-.113^{* *}$ & -.015 & .006 & .007 & $-.117 * *$ & -.016 & .006 & .005 \\
\hline \multirow[t]{2}{*}{ Sex } & $.116^{* *}$ & .150 & .054 & .005 & $.110^{*}$ & .143 & .056 & .011 & $.121 * *$ & .157 & .055 & .004 \\
\hline & \multicolumn{4}{|c|}{ Self-Pity } & \multicolumn{4}{|c|}{ Rumination } & \multicolumn{4}{|c|}{ Projection } \\
\hline Predictor & $B$ & $b$ & S.E. & $p$ & $\beta$ & $b$ & S.E. & $p$ & $\beta$ & $b$ & S.E. & $p$ \\
\hline Peers' Coping Avg. & .056 & .031 & .024 & .196 & $.124 *$ & .083 & .029 & .004 & -011 & -.005 & .024 & .821 \\
\hline Individual Coping & -.041 & -.012 & .013 & .354 & .068 & .025 & .015 & .093 & $-.087 *$ & -.026 & .013 & .049 \\
\hline Total Eng. Fall & $.789 * *$ & .843 & .062 & .000 & $.783 * *$ & .839 & .059 & .000 & $.768 * *$ & .823 & .062 & .000 \\
\hline Peer Count & $-.112 * *$ & -.015 & .006 & .007 & $-.131 * *$ & -.018 & .006 & .002 & $-.109 * *$ & -.015 & .006 & .009 \\
\hline \multirow[t]{2}{*}{ Sex } & $.117^{* *}$ & .151 & .054 & .005 & $.120 * *$ & .155 & .053 & .003 & $.093 *$ & .121 & .059 & .039 \\
\hline & \multicolumn{4}{|c|}{ Total MALADAPTIVE } & & & & & & & & \\
\hline Predictor & $\beta$ & $b$ & S.E. & $p$ & & & & & & & & \\
\hline Peers' Coping Avg. & .066 & .059 & .040 & .140 & & & & & & & & \\
\hline Individual Coping & -.028 & -.014 & .022 & .512 & & & & & & & & \\
\hline Total Eng. Fall & $.796^{* *}$ & .852 & .062 & .000 & & & & & & & & \\
\hline Peer Count & $-.115 * *$ & -.015 & .006 & .006 & & & & & & & & \\
\hline Sex & $.128 * *$ & .166 & .056 & .003 & & & & & & & & \\
\hline
\end{tabular}




\section{PEERS’ ACADEMIC COPING AND MOTIVATIONAL RESILIENCE}

\section{Chapter 6. Discussion}

Peers are a key element of the school context. Research has shown their potential to exert positive effects on students' academic achievement, motivation, and engagement (Wentzel \& Muenks, 2016). Their role is particularly important during the transition to middle school, a time of tremendous opportunity and many potential threats. An understanding of the ways peers can shape the trajectories of students' academic engagement is useful to researchers and practitioners interested in adolescent education and development. The results of this study offer a glimpse into the complex relationship between one salient aspect of peers in school, their ways of coping with everyday academic adversity, and one salient aspect of motivational resilience, the changes in students' academic engagement across the first year of middle school.

On average, early adolescence marks the beginning of a long-term decline in engagement, that is particularly steep at the beginning of middle school and that will continue across adolescence (Anderman \& Mueller, 2010). Students who buck this trend can be considered resilient. Other students with high levels of adaptive coping and low levels of maladaptive coping offer a potential resource for individual students facing the challenges of middle school. When these peers with positive coping skills and repertoires are found within a student's group of significantly affiliated peers, frequent interaction provides opportunities for the student's motivation and engagement to benefit from the potential influence of positive coping.

The analyses in this study did not provide statistically significant support for the hypothesized relationships between peers' overall coping profile, or total adaptive, or 


\section{PEERS' ACADEMIC COPING AND MOTIVATIONAL RESILIENCE}

total maladaptive coping, and changes in students' academic engagement over the first year of middle school. These results fall short of providing evidence that peers' coping is a resource for motivational resilience. There are several possible reasons for the findings, which will be explored in the strengths and limitations. A number of avenues are open for further exploration, which will be described under future research directions.

Peer group levels for two specific ways of coping, self-encouragement and rumination, were found to be significantly related to engagement change. The average level of self-encouragement in the peer group negatively predicted spring engagement controlling for fall engagement. Contrary to expectations, self-encouragement in the peer group was thus not seen to be a resource for student engagement. Self-encouragement includes self-soothing and is a response to adversity directed at regulating a student's emotional reaction, such as disappointment or discouragement. The presence of this specific way of coping at high levels in the peer group is seen here to have a negative effect on student engagement over time. This is a complicated finding, because the zeroorder correlation between peer group self-encouragement and student engagement was not significant. A suppression effect is involved, in that peers' self-encouragement is collinear with both of the control variables, peer group size and biological sex, and the negative effect of peers' self-encouragement is only revealed in the multiple regression with the controls included. The negative effect of peers' self-encouragement may indicate some ambiguity or multiplicity in the construct being measured by the items included in the subscale for self-encouragement. It's possible self-encouragement is sometimes adaptive and sometimes maladaptive, depending on the individual or the circumstances. 


\section{PEERS’ ACADEMIC COPING AND MOTIVATIONAL RESILIENCE}

There could be overlap with something other than self-encouragement coping. The measure might, for example, partially capture the extent to which students' peer group members, on average, have low levels of caring about school. Discriminant and predictive validity could be further investigated in future research.

The average level of rumination in the peer group positively predicted spring engagement controlling for fall engagement, as well as when also controlling for student's own level of rumination. This result was not consistent with the expectation that peers' levels of maladaptive ways of academic coping are a liability for individual students. Rumination includes worry, but could be considered an active cognitive response to adversity. The presence of this specific way of coping at high levels in the peer group is seen here to have a positive effect on student engagement over time. This result may indicate some ambiguity or multiplicity in the construct being measured by the items included in the subscale for rumination. Rumination coping showed a complex patterns of correlations with other ways of coping, and could be sometimes adaptive and sometimes maladaptive, depending on the individual or the circumstances. Also, there could be overlap with something other than rumination coping. Since worry may indicate a high level of concern or mattering, the measure might partially capture the extent to which students' peer group members, on average, have high levels of caring about school. In this case, it might be that caring contributes to engagement change, instead of, or in addition to, rumination. Discriminant and predictive validity could be further investigated in future research. 


\section{PEERS’ ACADEMIC COPING AND MOTIVATIONAL RESILIENCE}

This study took advantage of longitudinal data to address relationships between engagement and both overall coping (adaptive, maladaptive, and overall coping profile) and eleven specific ways of coping. The results, both in the descriptive statistics and in the structural models, provide some interesting insights into relationship between students' motivational resilience and their peers' academic coping. Although the research hypotheses were not supported, the findings stimulate thinking about the processes involved and further questions that need to be asked. In the following sections, the strengths and limitations of the study are described, and then directions for future inquiry and the implications of the research are discussed.

\section{Strengths and Limitations}

Theoretical perspective. The study applies theoretical and methodological approaches that have proven effective in studying educational development. StageEnvironment Fit Theory (Eccles \& Midgley, 1989), provides an emphasis on the stagespecific developmental processes and on the paramount role of the school context, including the classroom environment and social relationships. The study also relies on a contextual approach based on Bronfenbrenner's bioecological systems theory (Bronfenbrenner \& Morris, 2006), which underscores the role of proximal processes in development. Building on that approach, the social contextual perspective on academic motivation (Wentzel, 2004; Wentzel et al., 2010; Patrick, Anderman \& Ryan, 2002), has encouraged researchers to explore the roles of specific social partners in the vicissitudes of engagement, motivation, and achievement. The social contextual perspective is fundamental to the current study. Students are embedded in an interactive multi-level 


\section{PEERS’ ACADEMIC COPING AND MOTIVATIONAL RESILIENCE}

system in which their affects, cognitions, and behaviors are both influenced by and, in turn, exert influence on their social context. For students in the middle school context, the contextual ecological system manifests in an age-specific way, which is explored in the measures and analyses conducted here. This study contributes to the body of literature supporting the contextual theoretical perspective by showing how it can be applied to the specific research concern of peers' coping and student academic engagement. The findings extend the scope of processes and situations that have been mapped empirically using this theoretical perspective.

Bioecological systems theory and the social contextual perspective underscore the importance of considering proximal processes, such as day to day interpersonal interactions, in developing an understanding of why and how the relationships between variables come about. The current study is limited in that it does not address the specific processes responsible for the effects, or examine variables that would assist scholars in distinguishing the roles of different processes. There is a lack of available theory that explains how peer coping could shape engagement, so this study might be the beginning of work in that direction

Constructs. This study contributes to the understanding of motivational resilience by investigating its link to peer group coping at a developmental stage that is characterized by normative declines in engagement. It falls short in not exploring more deeply other possible components of motivational resilience. Academic coping is itself a personal resource that may affect students' ability to bounce back from everyday challenges and setbacks. And because students select the members of their peer groups, 


\section{PEERS’ ACADEMIC COPING AND MOTIVATIONAL RESILIENCE}

this resource is also self-selected. Although the effect of rumination coping was not in the direction hypothesized, the correlations found in this study of rumination with other strategies suggest it is a complex behavior that may not be exclusively maladaptive but could sometimes be adaptive. By demonstrating in some small way that coping strategies used by peers, in this case peers use of rumination, is also a resource for students, the study expands the understanding of social resources to include not only social and instrumental support from others, but also the indirect influence of peers. Establishing the connection between peers coping and engagement provides evidence that these indirect influences can be a part of the ability of peers to serve as a resource that contributes to motivational resilience.

Another conceptual cornerstone of the study is the categorization of adaptive and maladaptive ways of coping and a student's coping profile (Skinner et al, 2013). By using the three aggregate scores, the analyses were able to evaluate the effect of coping style and repertoires, in addition to the effects of the 11 specific ways of coping. The usefulness of the data was amplified by taking advantaging of the computation of allocation scores for each way of coping, in addition to total adaptive, total maladaptive, and coping profiles. The use of allocation scores, as a transformation of the raw questionnaire scores based on relative responses on all coping items, provides a variable that reflects the importance of particular strategies in students' overall coping repertoires. Although the regression coefficients for total adaptive, total maladaptive, and coping profile were not significant predictors in these analyses, the $p$ values were relative low ( $p$ $=.140, .350$, and .139 , respectively), which encourages further investigation. In both the 


\section{PEERS’ ACADEMIC COPING AND MOTIVATIONAL RESILIENCE}

correlations and the structural models, the results demonstrate the usefulness of allocation scores and the importance of the repertoire of strategies, rather than just levels of individual ways of coping, to the understanding of academic coping. The encouraging results with respect to students' repertoires of coping strategies are consistent with other research showing the importance of repertoires and flexibility in strategy choice in the area of coping and emotion regulation (Bonnano \& Burton, 2013). The study is limited, however, in that the ways of coping covered may not constitute an exhaustive list. There might be additional ways of coping used in the face of academic adversity that could also be studied. Similarly, the components used to construct adaptive and maladaptive component averages may need further study.

Methods and measures. A particularly strong component of the proposed study is the use of Social Cognitive Mapping (SCM) to determine student's actual peer affiliations. While many studies rely on student's own perception of the attributes of their peers and their influence, or teacher reports, both of which contain limited information, the proposed study used more extensive observational data on peer affiliations, and actual measures of peer attributes and influences, rather than surveys of students' perceptions. A limitation of the study is that it focuses on peer groups and does not consider effects that might be related to other kinds of peer relationships, such as dyadic friendships, or crowd affiliations.

Measures of student engagement are taken from teacher surveys, which avoids the common method bias that would be inherent if both coping and engagement were measured by student report. However, teacher report is limited, particularly for emotional 


\section{PEERS’ ACADEMIC COPING AND MOTIVATIONAL RESILIENCE}

engagement, in that teachers may not be as good at detecting students' emotional engagement as the students who experience it. Also, both teacher report and student report measures are imperfect in that they may be subject to cognitive bias or limited information. Observations of student engagement made by a researcher could supplement both student report and teacher report and improve the measurement of student engagement. However, it is a significant strength of the study that the three important measures, student engagement, student coping, and peer group structure, were obtained from three different sources, teacher, self, and other students, respectively.

Structural equation modeling (SEM), like any other method, has some requirements for optimal performance. SEM requires large sample size. Many of the effects for peers coping were represented by small (standardized $\beta<.10$ ) and usually nonsignificant standardized regression coefficients predicting spring engagement controlling for fall engagement. There is a possibility that analyses may have failed to detect some small but potentially significant effects due to lack of power. This is a limitation of the study. Underlying assumptions for the use of structural equation modeling were generally met. The distributions of scores for all variables showed reasonable normality, with minimal levels of skewness and kurtosis, with the exception of a few of the peer group averages for coping, which showed some kurtosis, or flattening in the distributions. SEM does have some tolerance for nonnormality, more so than multiple regression (Kline, 2011). The possibility that the kurtosis statistics for some predictors may be associated with a bias in the significance levels of the results should be noted as a limitation of the study. 


\section{PEERS’ ACADEMIC COPING AND MOTIVATIONAL RESILIENCE}

Sample and generalizability. The data used in the study include an entire sixth grade cohort of the only public middle school in a small town. Participation rates were good for survey data and more than adequate for the mapping of peer affiliations. These strong characteristics of the sample contribute to good generalizability of study results, but only to populations with similar demographic characteristics. The sample is limited in not being ethnically or socio-economically diverse, and the results may not be applicable to more urban or more diverse settings. The sample was also collected about twenty years ago, and it is possible that the characteristics of the cohort may not be consistent with the characteristics of a more recent sample. It is not possible to know whether the results would be the same with a contemporary sample. The study would need to be replicated with current data and more diverse groups.

Research design. The study used two time points (spring and fall) and will thus have the benefits of a short-term longitudinal design. By examining change over time, results, where significant, support the possibility of a causal role of peers' coping in its ability to predict changes in student engagement. This would not be possible with a correlational study focused on a single time point. At the same time, the study is limited in that it includes only two time points. Because changes in engagement may occur within a relatively short period in responses to changes in circumstances and student experiences, it would be advantageous to have data for more time points over the course of the year. Three or even five measurement points would better serve the objective of examining trajectories of academic engagement and the effect of peers' coping on them. It would also be useful, but more costly and difficult, to obtain data from the last year of 


\section{PEERS’ ACADEMIC COPING AND MOTIVATIONAL RESILIENCE}

elementary school for the same students. This would permit better analysis of the effect of the transition itself.

The ability of the proposed longitudinal study to provide evidence for a causal relationship depends on the extent to which it rules out alternative explanations. This requires the inclusion of appropriate control variables and distinct predictors that might change the analytical results and clarify the understanding of the relationship or provide a different interpretation. Without this methodological due diligence, studies can appear to show peer effects that are actually spurious (Veronneau \& Vitaro, 2007). The study includes control variables expected to be relevant, biological sex and group size. Other variables might also be considered in future studies, including individual characteristics such as emotional reactivity or sociability, and characteristics of the group such as group group such as group average engagement of group membership, such as the strength of ties. These may be relevant for future studies.

\section{Future Research Directions}

Academic engagement is a reflection of motivational processes and a visible form of activity that takes place within social contexts, in participation with other students, teachers, and parents. Students are participating and interacting with their social partners in ways that reflect both their educational focus and their social nature. Future research can continue the tradition of the social contextual perspective on academic motivation and engagement (Wentzel, 2004) and continue to expand its application in the domain of peer relationships. Academic activity is bound up with social relationships. Starting from what we know about the positive potential of peers and schools, additional research on 


\section{PEERS’ ACADEMIC COPING AND MOTIVATIONAL RESILIENCE}

academic coping and motivational resilience can investigate further how peer processes and individual students interact, and how their effects combine to determine outcomes.

Further analysis could be undertaken to continue the investigation of the role of peers' academic coping in student engagement over time. Although the path coefficients between peer levels of total adaptive, total maladaptive, overall profile and many specific ways of coping, and student engagement were nonsignificant in the models tested, correlations indicate some important associations do exist. Five possible avenues are available for further exploration of the role of peers' coping as a resource for motivational resilience. These involve more differentiated ways to think about: 1) the sample; 2) the influence of the peer group; 3) academic engagement; 4) academic coping; and 5) the system of motivational resilience.

First, regarding the sample, descriptive statistics and supplemental analyses (Appendix B) reveal that significant differences between boys and girls exist in the association of ways of coping and engagement, both at the individual and at the peer group level. Further research could use multiple group structural equation models to investigate the separate relationships over time for each sex.

Second, regarding the influence of the peer group, the peer group coping variables used as predictors in this study were group averages. Supplemental analyses (see Appendix C) reveal that, in spite of the overall pattern of similarity between individuals and members of their peer group, there is also diversity within groups. Some peer group members may be above the student while others are below. These different subgroups of peers within the group could separately and differently influence the student. For 


\section{PEERS’ ACADEMIC COPING AND MOTIVATIONAL RESILIENCE}

example, it could be that it is the peers who are coping best who have the biggest impact. Further research could use separate variables for peers within the group with coping scores above and below the student or variables for peers with high versus low levels in comparison to the grand mean on each of the ways of coping and coping aggregates, as predictors of engagement change.

Third, regarding academic engagement, correlational analysis of the components of engagement with measures of individual and group coping reveal variety in the relationships between peers' and student's coping and specific behavioral and emotional engagement components. Supplemental analysis (Appendix D) reveals that the different ways of coping and coping composites are not consistently correlated with the components of academic engagement comprising the measure used in the study. Further research could investigate the item structure of the engagement measures. This possibility is highlighted by previous research (Skinner, et al, 2009) demonstrating a distinction between academic engagement and disaffection. It is also possible that peers affect behavioral and emotional engagement through different processes. Emotional engagement, which includes enthusiasm and interest, may be uniquely important in the investigation of both individual coping and peer effects. It was found to differently correlate with behavioral engagement in separate groups of students with contrasting characteristics in a late childhood sample (Blumenfeld et al., 2005). Helping and informational support from peers, available from good strategizers in the peer group, may link to modeling and identification, and may have direct effects on behavioral engagement. Enthusiasm and emotional support from peers, potentially available from 


\section{PEERS' ACADEMIC COPING AND MOTIVATIONAL RESILIENCE}

peers strong in self-encouragement and commitment, may have stronger effects on emotional engagement than other adaptive ways of coping. Factor analysis would be a potential method to begin pursuing this line of inquiry.

Fourth, regarding academic coping, the unique behavior of rumination coping in the correlations, at both the individual and group level, suggest that it may not behave as a clearly maladaptive strategy. Although not positively correlated with any adaptive way of coping, it is significantly negatively correlated only with self-encouragement, and the correlation is modest compared to other maladaptive ways $(r=-.25)$. Rumination at the individual level is not significantly positively correlated with any of the five other ways of maladaptive coping, and is significantly negatively correlated with escape and projection ( $r=-.25$ and -.19). Rumination, as dwelling or worry, may sometimes be adaptive, as when it leads to more productive future efforts, and sometimes maladaptive, as when it leads to staying stuck and delayed re-engagement. This mixed pattern suggests that rumination might be removed from the total maladaptive average, to obtain a better measure of the maladaptive component in peers' and student's repertoires.

Fifth, regarding the system of motivational resilience, additional covariates can be considered. These include the engagement of the student's peer group members, and the development of individual student academic coping over time. Individual coping at the fall time point was tested as a control in the current study, but possible effects of peers' coping on changes in individual coping over time were not investigated. Another potential variable of interest that was not included is average level of engagement of the student's peer group members. Previous research has shown that peer group levels of 


\section{PEERS’ ACADEMIC COPING AND MOTIVATIONAL RESILIENCE}

academic engagement do have an influence on student's own engagement over time (Kindermann, 2007). Future research could include peers' engagement as an additional predictor, to separate its effect from the effect of peer coping, and clarify its possible role in the relationship between peers' coping and individual engagement. It may be possible, for example, that the effect of peers' coping is mediated to some extent by peers' academic engagement. This would be the case if adaptive ways of coping by peer group members were associated with higher levels of engagement and their effect on individual peer group members were a result of the high engagement, rather than the coping itself. Future research on the effect of peers' coping could be designed to evaluate this possibility.

Within the social context, the influence of relationship quality or support from parents and teachers would be potential covariates to investigate. Also, because a contextual perspective is not only about social partners, but about the responses of the person in the social context, individual level variables and person-centered analyses may be important in addition to characteristics of the group. From the standpoint of the individual student in the school context, for example, more research could be conducted on the ways students experience and react to academic adversity, the factors that might explain these differences, and their amenability to change, whether through agedependent developmental processes, social influence, or interventions. Possible covariates include emotional reactivity, differences in ambient stress or academic adversity, coping flexibility, and social goals or social disposition. A question also arises about the relationship between academic adversity and other sources of stress in a 


\section{PEERS’ ACADEMIC COPING AND MOTIVATIONAL RESILIENCE}

student's life, as well as the differences in individual appraisals of challenge or threat and individual reactions to stressors. A heightened state of vigilance or a bias in interpretation, as well as dispositional reactivity may contribute to differences in use of coping strategies. These factors could also contribute to differences in the strength of peer effects. Future research could investigate these possibilities.

Other potentially significant predictor variables might be perceived control, ability beliefs, causal attributions, academic goal orientations, or self-system process status. Also, the proposed study looks at peers' help-seeking and comfort-seeking, but there could be measures of help providing and providing of emotional support in future studies. This would be useful to better understand the role of peers. More observational studies of day to day interactions in formal and informal settings involving school are also needed to build on existing research and clarify how peers influence each other.

Beyond these five specific approaches to continue the investigation begun in this study, additional considerations point to avenues available for reviewing and expanding the conceptual foundations. The results of this study add to the evidence of a nexus between peers and engagement, but the precise mechanisms that account for the relationship are not known. Future research can be targeted to explore the proximal processes involved in coping with adversity and maintaining motivational resilience in the social context of school. Peer effects are more than a matter of good or bad characteristics rubbing off or the result of social conformity (Kindermann \& Skinner, in press). Fredericks has listed aspects of peers which positively influence engagement as including academic orientation, encouragement \& modeling, sharing information, asking 


\section{PEERS’ ACADEMIC COPING AND MOTIVATIONAL RESILIENCE}

questions and providing explanations, working in cooperative groups, opportunities for belonging, and positive social norms (Fredricks, 2011). Previous research on mechanisms of peer influence (see Laurson, 2018, for a review) has described both direct (modeling and imitation, assistance and encouragement, peer pressure to conform) and indirect pathways. Many indirect pathways are integral components of the social nexus between academic endeavor and affiliative bonds that exists in the school context. These include relatedness (Furrer \& Skinner, 2003, Martin \& Dowson, 2009), belonging (Gray, Hope, \& Matthews, 2018), positive emotion (King, McInerney, Ganotice, \& Villarosa, 2015), cooperation (Johnson \& Johnson, 2009), social support (Song, Bong, Lee, \& Kim, 2015), social facilitation (Uziel, 2007), shared motivation (Carr \& Walton, 2014), and social goals (Ben-Eliyahu, Linnenbrink-Garcia, \& Putallaz, 2017). Based on existing studies described in the literature review, it appears that the most fruitful area of investigation for understanding the relationship between academic engagement and peers' coping may be the indirect processes involving relatedness, belonging, and positive emotion. The benefit to engagement of having peers who make school fun (Symonds \& Hargreaves, 2016), warrants further exploration. Distinguishable from, but correlated with, relatedness and belonging, fun and enjoyment are key academic emotions (Harley, Pekrun, Taxer, and Gross, 2019).

Researchers have the opportunity to take what we know about peers and what we know about engagement and fill in the gap in our understanding of how the two are connected and how influence works. This will require research that investigates the 


\section{PEERS’ ACADEMIC COPING AND MOTIVATIONAL RESILIENCE}

proximal processes involving academic tasks in classroom contexts, processes that have social dimensions and are often primarily social in nature.

\section{Implications}

The results of this study have relevant implications for teachers, parents, and education researchers. Teachers will be able to use the findings about rumination and self-encouragement to better understand the important role of academic coping in school outcomes, and the way peers may be involved. Realizing that peers' ways of coping with everyday adversity at school can affect their peer group members might encourage teachers to pay more attention to the dynamics of peer relationships in the classroom, and the subtle ways their behavior affects these processes. Parents may potentially benefit by considering the insight into the positive role peers may play in their children's lives and its implications for their monitoring of peer relationships and their own involvement in children's education. For education researchers and teacher educators, the study results underscore the fact that peer relationships are important in multiple and sometimes unexpected ways, and that teachers can leverage their understanding of these processes (Farmer, McAuliffe Lines, \& Hamm, 2011; Kindermann, 2011). This should encourage consideration of the role of peers' coping and into the various mechanisms and processes that may be involved in this effect. Insight into complex peer effects may also be useful to those studying and teaching about cooperative and collaborative learning.

The results of the current study may also contribute to future research involving the design of interventions for teacher education and classroom practices. As we accumulate knowledge about peer effects and the underlying processes, understanding 


\section{PEERS’ ACADEMIC COPING AND MOTIVATIONAL RESILIENCE}

and insight can be transmitted to teachers-in-training. Also, both teachers and students would benefit from becoming more aware of the different types of support occurring between classmates: instrumental, informational, and emotional. Interventions can encourage the frequency of positive forms of interaction and facilitate awareness as a safeguard against negative forms of interaction.

\section{Conclusion}

The potential impact on students' education and development of the many changes inherent in early adolescence and the transition to middle school is substantial. The everyday adversity and challenges presented during this transition, and the way students deal with them through their academic coping, influence their engagement on a daily basis. Peers are a critical element in the unfolding of this process. This connection

will contribute to how well students do in school, what level of education they attain, and the trajectories of their lives after school. It is important for research to explore the relationships between peers and student motivational resilience, and for educators to implement interventions that can leverage our knowledge to produce better outcomes. This study makes a small contribution to that effort and paves the way for further investigation. 


\section{PEERS’ ACADEMIC COPING AND MOTIVATIONAL RESILIENCE}

\section{References}

Altermatt, E. R. \& Pomerantz, E. M. (2003). The development of competence-related and motivational beliefs: An investigation of similarity and influence among friends. Journal of Educational Psychology, 95, 111-123.

Altermatt, E. R., \& Pomerantz, E. M. (2005). The implications of having high-achieving versus low-achieving friends: A longitudinal analysis. Social Development, 14(1), $61-81$

Anderman, E. M., \& Mueller, C. E. (2010). Middle school transitions and adolescent development. Handbook of research on schools, schooling, and human development (pp. 198-215).

Appleton, J. J., Christenson, S. L., Kim, D., \& Reschly, A. (2006). Measuring cognitive and psychological engagement: Validation of the Student Engagement Instrument. Journal of School Psychology, 44, 427-445.

Arbuckle, J. L. (2017). Amos (Version 25.0) [Computer Program]. Chicago, IL: SPSS.

Azmitia, M., \& Cooper, C. R. (2001). Good or bad? Peer influences on Latino and European American adolescents' pathways through school. Journal of Education for Students Placed at Risk, 6, 45-71.

Barber, B. K., \& Olsen, J. A. (2004). Assessing the transition to middle and high school. Journal of adolescent research, 19, 3-30.

Baumeister, R. F., \& Leary, M. R. (1995). The need to belong: Desire for interpersonal attachments as a fundamental human motivation. Psychological Bulletin, 117, 497529. 


\section{PEERS’ ACADEMIC COPING AND MOTIVATIONAL RESILIENCE}

Ben-Eliyahu, A., Linnenbrink-Garcia, L., \& Putallaz, M. (2017). The intertwined nature of adolescents' social and academic lives: Social and academic goal orientations. Journal of Advanced Academics, 28(1), 66-93.

Belmont, M. J., Skinner, E. A., Wellborn, J. G., \& Connell, J. P. (1992). Student report measure of Teacher as Social Context. In Teacher as Social Context (TASC). Two Measures of Teacher Provision of Involvement, Structure, and Autonomy Support. Technical Report: University of Rochester, Rochester, NY.

Berndt, T. J. (1996). Transitions in friendship and friends' influence. In J. A. Graber, J. Brooks-Gunn, \& A. C. Petersen (Eds.), Transitions through adolescence: Interpersonal domains and context (pp. 57-84). Hillsdale, NJ: Lawrence Erlbaum Associates, Inc.

Blumenfeld, P., Modell, J., Bartko, W. T., Secada, W., Fredricks, J., Friedel, J., et al. (2005). School engagement of inner city students during middle childhood. In C. R. Cooper, C. Garcia Coll, W. T. Bartko, H. M. Davis, \& C. Chatman (Eds.), Developmental pathways through middle childhood: Rethinking diversity and contexts as resources (pp. 145-170). Mahwah, NJ: Lawrence Erlbaum Associates.

Bonanno, G. A., \& Burton, C. L. (2013). Regulatory flexibility: an individual differences perspective on coping and emotion regulation. Perspectives on Psychological Science, 8(6), 591-612.

Boulton, M. J., Don, J., \& Boulton, L. (2011). Predicting children's liking of school from their peer relationships. Social Psychology of Education, 14, 489-501. 


\section{PEERS’ ACADEMIC COPING AND MOTIVATIONAL RESILIENCE}

Briggs, S. R., \& Cheek, J. M. (1986). The role of factor analysis in the development and evaluation of personality scales. Journal of Personality, 54, 106-148.

Bronfenbrenner, U., \& Morris, P. A. (2006). The bioecological model of human development. In W. Damon \& R. M. Lerner (Eds.), Handbook of child psychology, Vol. 1: Theoretical models of human development (6 ${ }^{\text {th }}$ ed., pp. 793-828). New York: Wiley.

Brown, B. B., \& Larson, J. (2009). Peer relationships in adolescence. In R. M. Lerner \& L. Steinberg (Eds.), Handbook of Adolescent Psychology (Vol. 1, pp. 74-103). New York: John Wiley \& Sons, Inc.

Burke, M. A., \& Sass, T. R. (2013). Classroom peer effects and student achievement. Journal of Labor Economics, 31(1), 51-82.

Burnett, P. C., \& Fanshawe, J. P. (1997). Measuring school-related stressors in adolescents. Journal of Youth and Adolescence, 26, 415-428.

Cairns, R. B., \& Cairns, B. D. (1994). Lifelines and risks: Pathways of youth in our time. New York: Cambridge University Press.

Cairns, R. B., Perrin, J. E., \& Cairns, B. D. (1985). Social structure and social cognition in early adolescence: Affiliative patterns. The Journal of Early Adolescence, 5(3), $339-355$.

Cantin, S., \& Boivin, M. (2004). Change and stability in children's social network and self-perceptions during transition from elementary to junior high school. International Journal of Behavioral Development, 28(6), 561-570. 


\section{PEERS' ACADEMIC COPING AND MOTIVATIONAL RESILIENCE}

Carr, P. B., \& Walton, G. M. (2014). Cues of working together fuel intrinsic motivation. Journal of Experimental Social Psychology, 53, 169-184.

Chen, J. J.-L. (2005). Relation of academic support from parents, teachers, and peers to Hong Kong adolescents' academic achievement: The mediating role of academic engagement. Genetic, Social \& General Psychology Monographs, 131(2), 77-127.

Connor-Smith, J. K., Compas, B. E., Wadsworth, M. E., Thomsen, A. H., \& Saltzman, H. (2000). Responses to stress in adolescence: Measurement of coping and involuntary stress responses. Journal of Counseling and Clinical Psychology, 68, 976-992.

Cook, T. D., Deng, Y., \& Morgano, E. (2007). Friendship influences during early adolescence: The special role of friends' grade point average. Journal of Research on Adolescence, 17(2), 325-356.

Davidson, R. J. (1998). Affective style and affective disorders: Perspectives from affective neuroscience. Cognition and Emotion, 12(3), 307-330.

Dishion, T. J. \& Tipsord, J. M. (2011) Peer contagion in child and adolescent social and emotional development. Annual Review of Psychology, 62, 189-214.

Eccles, J. S., \& Midgley, C. (1989). Stage/environment fit: Developmentally appropriate classrooms for early adolescents. In R. E. Ames \& C. Ames (Eds.), Research on motivation in education (Vol. 3, pp. 139-186). New York: Academic Press.

Eccles, J. S., Midgley, C., Wigfield, A., Buchanan, C. M., Reuman, D., Flanagan, C., \& MacIver, D. (1993). Development during adolescence: The impact of stageenvironment fit on young adolescents' experiences in schools and in families. American Psychologist, 48(2), 90-101. 


\section{PEERS' ACADEMIC COPING AND MOTIVATIONAL RESILIENCE}

Ellis, B. J., Boyce, W. T., Belsky, J., Bakermans-Kranenburg, M. J., \& Van Ijzendoorn, M. H. (2011). Differential susceptibility to the environment: An evolutionaryneurodevelopmental theory. Development and Psychopathology, 23, 7-28.

Enders, C. K., \& Bandalos, D. L. (2001). The relative performance of full information maximum likelihood estimation for missing data in structural equation models. Structural Equation Modeling: A Multidisciplinary Journal, 8(3), 430-457.

Farmer, T. W., Chen, C.-C., Hamm, J. V., Moates, M. M., Mehtaji, M., Lee, D., \& Huneke, M. R. (2016). Supporting teachers' management of middle school social dynamics: The scouting report process. Intervention in School and Clinic, 52(2), 6776.

Farmer, T. W., McAuliffe Lines, M., \& Hamm, J. V. (2011). Revealing the invisible hand: The role of teachers in children's peer experiences. Journal of Applied Developmental Psychology, 32, 247-256.

Fredricks, J. A. (2011). Engagement in school and out-of-school contexts: A multidimensional view of engagement. Theory into Practice, 50, 327-355.

Fredricks, J.A., Blumenfeld, P.C., Paris, A.H. (2004). School engagement: Potential of the concept, state of the evidence. Review of Educational Research, 74(1), 59-109.

Furrer, C., \& Skinner, E. (2003). Sense of relatedness as a factor in children's academic engagement and performance. Journal of Educational Psychology, 95(1), 148-162.

Goldstein, S. E., Boxer, P., \& Rudolph, E. (2015). Middle school transition stress: Links with academic performance, motivation, and school experiences. Contemporary School Psychology, 19, 21-29. 


\section{PEERS' ACADEMIC COPING AND MOTIVATIONAL RESILIENCE}

Gottfired, A. E., Fleming, J. S., \& Gottfried, A. W. (2001). Continuity of academic intrinsic motivation from childhood through late adolescence: A longitudinal study. Journal of Education Psychology, 93, 3-13.

Gray, D. L., Hope, E. C., \& Matthews, J. S. (2018). Black and belonging at school: A case for interpersonal, instructional, and institutional opportunity structures. Educational Psychologist, 53, 97-113.

Hamm, J. V. (2000). "Do birds of a feather flock together? The variable bases for African American, Asian American, and European American adolescents' selection of similar friends." Developmental Psychology, 36, 209-219.

Hamm, J. V., \& Faircloth, B. S. (2005). The role of friendship in adolescents's sense of school belonging. New Directions for Child and Adolescent Development, 2005(107), 61-78.

Harley, J. M., Pekrun, R., Taxer, J. L., \& Gross, J. J. (2019). Emotion regulation in achievement situations: An integrated model. Educational Psychologist, 54(2), 106126.

Johnson, D. W., \& Johnson, R. T. (2009). An educational psychology success story: Social Interdependence Theory and Cooperative Learning. Educational Researcher, $38,365-379$.

Juvonen, J., Espinoza, G., \& Knifsend, C. (2012). The role of peer relationships in student academic and extracurricular engagement. In S. Christenson, A. Reschly, \& C. Wylie (Eds.), Handbook of research on student engagement (pp. 387-401). New York: Springer Science. 


\section{PEERS' ACADEMIC COPING AND MOTIVATIONAL RESILIENCE}

Kandel, D.B. (1978). Homophily, selection, and socialization in adolescent friendships.

The American Journal of Sociology, 84, 2, 427-436.

Kindermann, T. A. (1993). Natural peer groups as contexts for individual development: The case of children's motivation in school. Developmental Psychology, 29, 970 977.

Kindermann, T. A. (1996). Strategies for the study of individual development within naturally-existing peer groups. Social Development, 5, 158-173.

Kindermann, T. A. (2007). Effects of naturally existing peer groups on changes in academic engagement in a cohort of sixth graders. Child Development, 78, 11861203.

Kindermann, T. A. (2011). Commentary: The invisible hand of the teacher. Journal of Applied Developmental Psychology, 32, 304-308.

Kindermann, T. A., \& Skinner, E. A. (In press). Is psychology suffering from an epidemic of "contagion"? Moving from metaphors to theoretically derived concepts and methods in the study of social influences. Theory and Psychology.

Kindermann, T., \& Gest, S. D. (2018). The peer group: Linking conceptualizations, theories, and methods. In W. Bukowski, B. Laursen \& K. Rubin (Eds.), Handbook of peer interactions, relationships and groups ( $2^{\text {nd }}$ ed., pp. 84-105). New York: Guilford.

Kindermann, T. A., McCollam, T. L., \& Gibson, E. (1996). Peer networks and students' classroom engagement during childhood and adolescence. In J. Juvonen \& K. R. 


\section{PEERS’ ACADEMIC COPING AND MOTIVATIONAL RESILIENCE}

Wentzel (Eds.), Social motivation: Understanding children's school adjustment (pp. 279-312). Cambridge, UK: Cambridge University Press.

King, R. B., McInerney, D. M., Ganotice, F. A. Jr., \& Villarosa, J. B. (2015). Positive affect catalyzes academic engagement: Cross-sectional, longitudinal, and experimental evidence. Learning and Individual Differences, 39, 64-72.

Kiuru, N., Aunola, K., Vuori, J., \& Nurmi, J.-E. (2007). The role of peer groups in adolescents' educational expectations and adjustment. Journal of Youth and Adolescence, 36, 995-1009.

Ladd, G. W., Herald-Brown, S. L., \& Kochel, K. P. (2009). Peers and motivation. In Handbook of motivation at school (pp. 323-348). New York: Routledge/Taylor \& Francis Group.

Larson, R., \& Richards, M. H. (1991). Daily companionship in late childhood and early adolescence: Changing developmental contexts. Child Development, 62(2), 284-300.

Larson, R., Richards, M. H., Moneta, G., Holmbeck, G., \& Duckett, E. (1996). Changes in adolescents' daily interactions with their families from ages 10 to 18 :

Disengagement and transformation. Developmental Psychology, 32, 744-754.

Laursen, B. (2017). Making and keeping friends: The importance of being similar. Child Development Perspectives, 11(4), 282-289.

Laursen, B. (2018). Peer influence. In W. Bukowski, B. Laursen \& K. Rubin (Eds.), Handbook of peer interactions, relationships and groups ( $2^{\text {nd }}$ ed., pp. 447-469). New York: Guilford. 


\section{PEERS' ACADEMIC COPING AND MOTIVATIONAL RESILIENCE}

Laursen, B., \& Collins, W. A. (2009). Parent-child relationships during adolescence. In R. M. Lerner \& L. D. Steinberg (Eds.), Handbook of adolescent psychology (vol. 2, pp. 3-42). Hoboken, NJ: John Wiley \& Sons.

Leung, M.-C. (1996). Social networks and self enhancement in Chinese children: A comparison of self-reports and peer reports of group memberships. Social Development, 5, $146-157$.

Li, Y., Lynch, A. D., Kalvin, C., Liu, J., \& Lerner, R. M. (2011). Peer relationships as a context for the development of school engagement during early adolescence. International Journal of Behavioral Development, 35(4), 329-342.

Liem, G. A. D., \& Martin, A. J. (2011). Peer relationships and adolescents' academic and non-academic outcomes: Same-sex and opposite-sex peer effects and the mediating role of school engagement. British Journal of Educational Psychology, 81(2), 183206.

Lynch, A. D., Lerner, R. M., \& Leventhal, T. (2013). Adolescent academic achievement and school engagement: An examination of the role of school-wide peer culture. Journal of Youth and Adolescence, 42(1), 6-19.

Martin., A. J. (2013). Academic buoyancy and academic resilience: Exploring 'everyday' and 'classic' resilience in the face of academic adversity. School Psychology International, 34, 488-500.

Martin, A. J., \& Dowson, M. (2009). Interpersonal relationships, motivation, engagement, and achievement: Yields for theory, current issues, and educational practice. Review of Educational Research, 79, 327-365. 


\section{PEERS' ACADEMIC COPING AND MOTIVATIONAL RESILIENCE}

Martin, A. J., \& Marsh, H. W. (2008). Academic buoyancy: Towards an understanding of students' everyday academic resilience. Journal of School Psychology, 46(1), 53-83.

Martin, A. J., \& Marsh, H. W. (2009). Academic resilience and academic buoyancy: Multidimensional and hierarchical conceptual framing of causes, correlates, and cognate constructs. Oxford Review of Education, 35, 353-370.

Midgley, C., Middleton, M. J., Gheen, M. H., \& Kumar, R. (2002). Stage-environment fit revisited: A goal theory approach to examining school transitions. In C. Midgley (Ed.), Goals, goal structures, and patterns of adaptive learning (pp. 109-142). Mahwah, NJ: Lawrence Erlbaum Associates Publishers.

Nelson, R. M., \& DeBacker, T. K. (2008). Achievement motivation in adolescents: The role of peer climate and best friends. Journal of Experimental Education, 76, 170189.

Nock, M. K., Wedig, M. M., Holmberg, E. B., \& Hooley, J. M. (2008). The Emotion Reactivity Scale: Development, evaluation, and relation to self-injurious thoughts and behaviors. Behavior Therapy, 39(2), 107-116.

Patrick, H., Anderman, L. H., \& Ryan, A. M. (2002). Social motivation and the classroom social environment. In C. Midgley (Ed.), Goals, goal structures, and patterns of adaptive learning (pp. 85-108). Mahwah, NJ, US: Lawrence Erlbaum Associates Publishers.

Patrick, H., Ryan. A. M., \& Kaplan. (2007). Early adolescents' perceptions of the classroom social environment, motivational beliefs, and engagement. Journal of Educational Psychology, 99, 83-98. 


\section{PEERS' ACADEMIC COPING AND MOTIVATIONAL RESILIENCE}

Pitzer, J., \& Skinner, E. (2017). Predictors of changes in students' motivational resilience over the school year: The roles of teacher support, self-appraisals, and emotional reactivity. International Journal of Behavioral Development, 41, 15-29.

Reschly, A. L., Huebner, E. S., Appleton, J. J., \& Antaramian, S. (2008). Engagement as flourishing: the contribution of positive emotions and coping to adolescents' engagement at school and with learning. Psychology in the Schools, 45, 419-431.

Roeser, R. W., Midgley, C., \& Urdan, T. C. (1996). Perceptions of the school psychological environment and early adolescents' psychological and behavioral functioning in school: The mediating role of goals and belonging. Journal of Educational Psychology, 88, 408-422.

Ryan, A. M. (2001). The peer group as a context for the development of young adolescent motivation and achievement. Child Development, 72, 1135-1150.

Ryan, A. M. \& Shin, H. (2018). Peers, academics, and teachers. In W. Bukowski, B. Laursen \& K. Rubin (Eds.), Handbook of peer interactions, relationships and groups ( $2^{\text {nd }}$ ed., pp. 637-656). New York: Guilford.

Shih, S.-S. (2015). The relationships among Taiwanese adolescents' perceived classroom environment, academic coping, and burnout. School Psychology Quarterly, 30(2), $307-320$.

Shin, H., \& Ryan, A. M. (2014). Early adolescent friendships and academic adjustment: Examining selection and influence processes with longitudinal social network analysis. Developmental Psychology, 50, 2462-2472. 


\section{PEERS’ ACADEMIC COPING AND MOTIVATIONAL RESILIENCE}

Skinner, E. A. (2016). Engagement and disaffection as central to processes of motivation resilience and development. In K. R. Wentzel \& G. B. Ramani (Eds.), Handbook of social influences in school contexts: Social-emotional, motivation, and cognitive outcomes (pp. 13-30). New York: Routledge.

Skinner, E. A., Kindermann, T. A., Connell, J. P., \& Wellborn, J. G. (2009). Engagement and disaffection as organizational constructs in the dynamics of motivational development. In K. Wentzel \& A. Wigfield (Eds.), Handbook of motivation at school (pp. 223-245). Mahwah, NJ: Erlbaum.

Skinner, E. A., Kindermann, T. A., \& Furrer, C. J. (2009). A motivational perspective on engagement and disaffection conceptualization and assessment of children's behavioral and emotional participation in academic activities in the classroom. Educational and Psychological Measurement, 69(3), 493-525.

Skinner, E. A., \& Pitzer, J. R. (2012). Developmental dynamics of student engagement, coping, and everyday resilience. In S. L. Christenson, A. L. Reschly, \& C. Wylie (Eds.), Handbook of research on student engagement (pp. 21-44). New York: Springer US.

Skinner, E. A., Pitzer, J. R., \& Steele, J. (2013). Coping as a part of motivational resilience in school: A multidimensional measure of families, allocations, and profiles of academic coping. Educational and Psychological Measurement, 73, 803835. 


\section{PEERS' ACADEMIC COPING AND MOTIVATIONAL RESILIENCE}

Skinner, E. A., Pitzer, J. R., \& Steele, J. (2016). Can student engagement serve as a motivational resource for academic coping, persistence, and learning during late elementary and early middle school? Developmental Psychology, 52, 2099-2117.

Skinner, E. A., \& Saxton, E. (In press). The development of academic coping in children and youth: A comprehensive review and critique. Developmental Review.

Song, J., Bong, M., Lee, K., \& Kim, S. (2015). Longitudinal investigation into the role of perceived social support in adolescents' academic motivation and achievement. Journal of Educational Psychology, 107(3), 821-841.

Steglich, C., Snijders, T. A. B., \& Pearson, M. (2010). Dynamic networks and behavior: Separating selection from influence, Sociological Methodology, 40, 329-393.

Steinberg, L., \& Monahan, K. C. (2007). Age differences in resistance to peer influence. Developmental Psychology, 43, 1531-1543.

Symonds, J., \& Hargreaves, L. (2016). Emotional and motivational engagement at school transition: A qualitative Stage-Environment Fit study. Journal of Early Adolescence, $36,54-85$.

Upadyaya, K., \& Salmela-Aro, K. (2013). Development of school engagement in association with academic success and well-being in varying social contexts: A review of empirical research. European Psychologist, 18(2), 136-147.

Uziel, L. (2007). Individual differences in the social facilitation effect: A review and meta-analysis. Journal of Research in Personality, 41(3), 579-601.

Veronneau, M.-H., Vitaro, F., Brendgen, M., Dishion, T. J., \& Tremblay, R. E. (2010). Transactional analysis of the reciprocal links between peer experiences and academic 


\section{PEERS' ACADEMIC COPING AND MOTIVATIONAL RESILIENCE}

achievement from middle childhood to early adolescence. Developmental Psychology, 46, 773-790.

Vitaliano, P. P., Maiuro, R. D., Russo, J., \& Becker, J. (1987). Raw versus relative scores in the assessment of coping strategies, Journal of Behavioral Medicine, 10(1), 1-18.

Von Eye, A. (1990). Introduction to configural frequency analysis: The search for types and antitypes in cross-classifications. New York: Cambridge University Press.

Wang, M.-T., \& Eccles, J. S. (2012). Social support matters: Longitudinal effects of social support on three dimensions of school engagement from middle to high school. Child Development, 83(3), 877-895.

Wellborn, J. (1992). Engaged and disaffected action: The conceptualization and measurement of motivation in the academic domain. Unpublished Dissertation, Department of Psychology, University of Rochester, Rochester, NY.

Wentzel, K. R. (1998). Social relationships and motivation in middle school: The role of parents, teachers, and peers. Journal of Educational Psychology, 90(2), 202-209.

Wentzel, K. R. (2004). Understanding classroom competence: The role of socialmotivational and self-processes. In R. Kail (ed.), Advances in child development and behavior (Vol. 32, pp. 213-241). New York: Elsevier.

Wentzel, K. R. (2017). Peers, motivation, and academic performance at school. In A. J. Elliot, C. S. Dweck, \& D. S. Yeager (Eds.), Handbook of competence and motivation: Theory and application (2nd ed., pp. 586-603). New York: Guilford. 


\section{PEERS' ACADEMIC COPING AND MOTIVATIONAL RESILIENCE}

Wentzel, K. R., Battle, A., Russell, S. I., \& Looney, L. B. (2010). Social supports from teachers and peers as predictors of academic and social motivation. Contemporary Educational Psychology, 35, 193-202.

Wentzel, K. R., \& Caldwell, K. (1997). Friendships, peer acceptance, and group membership: Relations to academic achievement in Middle School. Child Development, 68, 1198-1209.

Wentzel, K. R., Donlan, A., \& Morrison, D. (2012). Peer relationships and social motivational processes. In A. M. Ryan \& G. W. Ladd (Eds.), Peer relationships and adjustment at school (pp. 79-105). Charlotte, NC: IAP Information Age Publishing.

Wentzel, K. R., McNamara Barry, C., \& Caldwell, K. A. (2004). Friendships in middle school: Influences on motivation and school adjustment. Journal of Educational Psychology, 96, 195-203.

Wentzel, K. R., \& Muenks, K. (2016). Peer influence on students' motivation, academic achievement, and social behavior. In K. R. Wentzel \& G. B. Ramani (Eds.), Handbook of social influences in school contexts: Social-emotional, motivation, and cognitive outcomes (pp. 13-30). New York: Routledge.

Wentzel, K. R., Muenks, K., McNeish, D., \& Russell, S. (2017). Peer and teacher supports in relation to motivation and effort: A multi-level study. Contemporary Educational Psychology, 49, 32-45.

Wentzel, K. R., \& Ramani, G. B. (Eds.) (2016). Handbook of social influences in school contexts: Social-emotional, motivation, and cognitive outcomes. New York: Routledge. 


\section{PEERS' ACADEMIC COPING AND MOTIVATIONAL RESILIENCE}

Wentzel, K. R., Russell, S., \& Baker, S. (2016). Emotional support and expectations from parents, teachers, and peers predict adolescent competence at school. Journal of Educational Psychology, 108(2), 242-255.

Wigfield, A., Eccles, J. S., Fredricks, J. A., Simpkins, S., Roeser, R., \& Schiefele, U. (2015). Development of achievement motivation and engagement. In R. M. Lerner (Series Ed.) \& M. Lamb (Volume Ed.), Handbook of child psychology and developmental science, 7th Ed. Vol.3. Socioemotional processes (pp. 657-700). New York: John Wiley.

Wigfield, A., Lutz, S. L., \& Wagner, A. L. (2005). Early adolescents' development across the middle school years: Implications for school counselors. Professional School Counseling, 9(2), 112-119.

You, S., \& Sharkey, J. (2009). Testing a developmental-ecological model of student engagement: a multilevel latent growth curve analysis. Educational Psychology, 29(6), 659-684.

Zimmer-Gembeck, M. J., Chipuer, H. M., Hanisch, M., Creed, P. A., McGregor, L. (2006). Relationships at school and stage-environment fit as resources for adolescent engagement and achievement. Journal of Adolescence, 29, 911-933. 


\section{PEERS’ ACADEMIC COPING AND MOTIVATIONAL RESILIENCE}

\section{Appendix A. Raw Coping Score Results}

To provide a point of comparison to illustrate the advantage of allocation scores, for individual and peers' coping and their effects on engagement change in the first year of middle school, supplemental analyses were conducting using the raw coping scores. Tables A.1 and A.2 provide the means, range and skewness of distributions of the variables. These data are followed by a presentation of the results of analyses of structural models of peers' coping and engagement using raw scores. Table A.5 contains the results for adaptive coping and Table A.6 contains the results for maladaptive coping. Neither the peer group averages for coping profile, total adaptive coping, or any of the five specific ways of adaptive coping significantly predicted spring engagement controlling for fall engagement, and controlling for peer group size and for sex. Both the peer group averages for total maladaptive coping $(b=.202, \mathrm{SE}=.098, \beta=.090$ (standardized), $p<05)$ and rumination coping $(b=.261, \mathrm{SE}=.078, \beta=.142$ (standardized), $p<001)$ positively predicted spring engagement controlling for fall engagement, and controlling for peer group size and sex. These relationships were in the opposite direction of what was expected. None of the peer group averages of the five other specific ways of maladaptive coping significantly predicted spring engagement controlling for fall engagement and controlling for peer group size and for sex.

To control for differences in the level of academic adversity faced by students, a measure was developed from questionnaire data obtained from the same students during the original data collection that forms the basis for the current study. Exploratory factor analysis (EFA) was used to investigate a pool of 12 items formulated to capture negative 


\section{PEERS' ACADEMIC COPING AND MOTIVATIONAL RESILIENCE}

life events at school. Three principal factors were found. The items in the first factor were characterized as general academic adversity, in the second factor as teacher relationship quality, and items in the third factor were characterized as low academic performance.

Five items were selected with high loadings on the first factor and relatively low loadings on the other two factors, to create a scale from the available items to best measure academic adversity, with minimal overlap with the other two constructs indicated in the EFA. The Cronbach's alpha for the five item scale in the current study is .69, slightly less than a common guideline level of .70 for good reliability. The mean inter-item correlation, however, was .31 , which is within the desirable range of .20 to .40 suggested for scales representing a single construct and having less than 10 items (Briggs \& Cheek, 1986). The items in the scale, rated on a four point Likert scale from never to all the time, are: "I can't understand what the teacher explains," "I answer the teacher's question wrong," "I get a bad grade on my report card," "I have a problem with the teacher," and "I have trouble with problems on a test." 


\section{PEERS' ACADEMIC COPING AND MOTIVATIONAL RESILIENCE}

Table A.1. Summary of Descriptive Statistics - Raw Scores - Individual Coping

\begin{tabular}{lcllrrrr}
\hline & $n$ & $M$ (S.D.) & Min & Max & Alpha & Skew & Kurtosis \\
\hline Student Eng. Fall & 304 & $3.08(.62)$ & 1.46 & 4.00 & .87 & -.23 & -.82 \\
Student Eng. Spg. & 288 & $3.07(.68)$ & 1.35 & 4.00 & .89 & -.31 & -.85 \\
Sex & 366 & $1.47(.50)$ & 1.00 & 2.00 & & .11 & -2.00 \\
Peer Group Size & 366 & $5.59(4.81)$ & 0.00 & 20.00 & & .73 & -.30 \\
Acad. Adversity & 308 & $2.05(.49)$ & 1.00 & 4.00 & .69 & .75 & .63 \\
Adaptive Coping: & & & & & & & \\
\hline Strategizing & 313 & $3.09(.54)$ & 1.00 & 4.00 & .67 & -.51 & .75 \\
Help-seeking & 315 & $3.09(.61)$ & 1.20 & 4.00 & .77 & -.50 & .11 \\
Comfort-seeking & 310 & $2.97(.59)$ & 1.00 & 4.00 & .67 & -.42 & .08 \\
Self- Encourgmnt. & 326 & $2.98(.53)$ & 1.00 & 4.00 & .58 & -.52 & .78 \\
Commitment & 321 & $2.96(.56)$ & 1.40 & 4.00 & .65 & -.26 & -.18 \\
\hline All Adaptive & 329 & $3.01(.44)$ & 1.28 & 3.92 & & -.43 & .56 \\
Maladaptive & & & & & & & \\
Coping: & & & & & & & \\
\hline Confusion & 315 & $2.16(.53)$ & 1.00 & 3.70 & .77 & .06 & -.45 \\
Escape & 315 & $1.95(.61)$ & 1.00 & 3.80 & .75 & .34 & -.39 \\
Concealment & 323 & $2.09(.66)$ & 1.00 & 3.80 & .75 & .17 & -.60 \\
Self-pity & 323 & $2.12(.76)$ & 1.00 & 4.00 & .82 & .19 & -.82 \\
Rumination & 316 & $2.62(.63)$ & 1.00 & 4.00 & .69 & .00 & -.45 \\
Projection & 325 & $1.86(.68)$ & 1.00 & 4.00 & .79 & .65 & -.13 \\
\hline All Maladaptive & 329 & $2.13(.50)$ & 1.00 & 3.42 & & .07 & -.46 \\
Coping Profile & 329 & $2.94(.37)$ & 1.73 & 3.85 & & .05 & -.43 \\
\hline Note: Missing values for descriptive statistics were handled with pair-wise deletion.
\end{tabular}




\section{PEERS’ ACADEMIC COPING AND MOTIVATIONAL RESILIENCE}

Table A.2. Summary of Descriptive Statistics - Raw Scores Peer Group Coping Averages

\begin{tabular}{lcccccc}
\hline & $n$ & $M($ S.D. $)$ & Min & Max & Skew & Kurtosis \\
\hline Adaptive Coping: & & & & & & \\
\hline Strategizing & 286 & $3.09(.28)$ & 1.80 & 4.00 & -.46 & 2.43 \\
Help-seeking & 285 & $3.09(.33)$ & 1.50 & 3.89 & -.87 & 2.78 \\
Comfort-seeking & 284 & $3.01(.30)$ & 2.00 & 3.80 & -.23 & 1.46 \\
Self-Encourgmnt. & 287 & $2.98(.25)$ & 2.00 & 3.67 & -73 & 1.72 \\
Commitment & 285 & $2.97(.30)$ & 1.80 & 3.80 & -.27 & 1.69 \\
\hline All Adaptive & 287 & $3.02(.23)$ & 2.02 & 3.60 & -.58 & 1.41 \\
Maladaptive & & & & & & \\
Coping: & & & & & & \\
\hline Confusion & 285 & $2.15(.30)$ & 1.15 & 3.23 & .47 & 1.98 \\
Escape & 285 & $1.94(.35)$ & 1.00 & 3.20 & .60 & 1.65 \\
Concealment & 285 & $2.06(.36)$ & 1.00 & 3.80 & .50 & 3.44 \\
Self-pity & 286 & $2.09(.42)$ & 1.00 & 3.60 & .19 & 1.11 \\
Rumination & 286 & $2.60(.35)$ & 1.00 & 3.70 & -.58 & 2.38 \\
Projection & 287 & $1.85(.40)$ & 1.00 & 3.50 & .86 & 1.99 \\
\hline All Maladaptive & 287 & $2.11(.29)$ & 1.24 & 3.37 & .37 & 2.30 \\
Coping Profile & 352 & $2,84(.24)$ & 2.25 & 3.61 & -.03 & .29 \\
\hline
\end{tabular}

Note: Missing values for descriptive statistics were handled with pair-wise deletion. 


\section{PEERS' ACADEMIC COPING AND MOTIVATIONAL RESILIENCE}

Table A.3. Individual Raw Coping Scores Selected Correlations

\begin{tabular}{|c|c|c|c|c|c|c|c|c|}
\hline & \multicolumn{3}{|c|}{ Group } & \multirow{2}{*}{$\begin{array}{l}\text { Fall } \\
\text { Eng. }\end{array}$} & \multirow{2}{*}{$\begin{array}{l}\text { Spring } \\
\text { Eng. }\end{array}$} & \multirow[b]{2}{*}{ ADAP } & \multirow[b]{2}{*}{ MAL } & \multirow[b]{2}{*}{ PRFL } \\
\hline & Sex & Size & Adv & & & & & \\
\hline \multicolumn{9}{|l|}{ Sex } \\
\hline Group Size & $.28^{* *}$ & & & & & & & \\
\hline Academic Adversity & $-.21 * *$ & -.08 & & & & & & \\
\hline Fall Engagement & $.15^{*}$ & $.19^{* *}$ & $-.48 * *$ & & & & & \\
\hline Spring Engagement & $.21 * *$ & .07 & $-.47 * *$ & $.74 * *$ & & & & \\
\hline Strategizing & $.22 * *$ & .02 & $-.30 * *$ & $.15^{*}$ & $.22 * *$ & $.79 * *$ & $-.18 * *$ & $.56^{* *}$ \\
\hline Help-Seeking & $.27 * *$ & .09 & $-.30 * *$ & $.20 * *$ & $.24 * *$ & $.78 * *$ & $-.31 * *$ & $.65^{* *}$ \\
\hline Comfort-Seeking & $.23 * *$ & .08 & $-.15^{* *}$ & $.12 *$ & .11 & $.73 * *$ & -.07 & $.44 * *$ \\
\hline Self-Encouragement & $.13^{*}$ & -.01 & $-.22 * *$ & .11 & $.16^{* *}$ & $.76^{* *}$ & $-.11 *$ & $.48^{* *}$ \\
\hline Commitment & $.14^{*}$ & .10 & $-.17 * *$ & 02 & .04 & $.77 * *$ & $-.12 *$ & $.50 * *$ \\
\hline Total Adaptive & $.27 * *$ & .09 & $-.30 * *$ & $.15^{*}$ & $.19^{* *}$ & & $-.18 * *$ & $.66^{* *}$ \\
\hline Confusion & -.08 & -.04 & $.52 * *$ & $-.28 * *$ & $-.23 * *$ & $-.16^{* *}$ & $.90 * *$ & $-.75 * *$ \\
\hline Escape & $-.13 *$ & -.02 & $.41^{* *}$ & $-.19^{* *}$ & $-.17 * *$ & $-.37 * *$ & $.71^{* *}$ & $-.72 * *$ \\
\hline Concealment & -.06 & -.02 & $.48^{* *}$ & $-.21 * *$ & $-.14^{*}$ & $-.29 * *$ & $.83^{* *}$ & $-.78 * *$ \\
\hline Self-Pity & -.04 & -.03 & $.53 * *$ & $-.32 * *$ & $.27 * *$ & -.09 & $.86^{* *}$ & $-.71 * *$ \\
\hline Rumination & .08 & .05 & $.15^{* *}$ & -.06 & .04 & $.33 * *$ & $.53 * *$ & $-.22 * *$ \\
\hline Projection & $-.22 * *$ & -.07 & $.57 * *$ & $-.35^{* *}$ & $-.34 * *$ & $-.32 * *$ & $.77 * *$ & $-.75 * *$ \\
\hline Total Maladaptive & -.08 & -.03 & $.58 * *$ & $-.31 * *$ & $-.24 * *$ & $-.18 * *$ & & $-.85^{* *}$ \\
\hline Coping Profile & $.20 * *$ & .06 & $-.59 * *$ & $.32 * *$ & $.28 * *$ & $.66^{* *}$ & $-.85 * *$ & \\
\hline
\end{tabular}

Note: Missing values for descriptive statistics were handled with pair-wise deletion.

$* p<.05 . * * p<.01$. 


\section{PEERS' ACADEMIC COPING AND MOTIVATIONAL RESILIENCE}

Table A.4. Peer Group Average Raw Coping Scores Selected Correlations

\begin{tabular}{|c|c|c|c|c|c|c|c|c|}
\hline & \multicolumn{3}{|c|}{ Group } & \multirow{2}{*}{$\begin{array}{l}\text { Fall } \\
\text { Eng. }\end{array}$} & \multirow{2}{*}{$\begin{array}{l}\text { Spring } \\
\text { Eng. }\end{array}$} & \multirow[b]{2}{*}{ ADAP } & \multirow[b]{2}{*}{ MAL } & \multirow[b]{2}{*}{ PRFL } \\
\hline & Sex & Size & Adv & & & & & \\
\hline \multicolumn{9}{|l|}{ Sex } \\
\hline Group Size & $.28^{* *}$ & & & & & & & \\
\hline Academic Adversity & $-.21 * *$ & -.08 & & & & & & \\
\hline Fall Engagement & $.15^{*}$ & $.19^{* *}$ & $-.48 * *$ & & & & & \\
\hline Spring Engagement & $.21 * *$ & .08 & $-.47 * *$ & $.74 * *$ & & & & \\
\hline Strategizing & $.34 * *$ & .10 & $-.22 * *$ & $.13 *$ & $.18^{* *}$ & $.80^{* *}$ & $-.35 * *$ & $.66^{* *}$ \\
\hline Help-Seeking & $.38^{* *}$ & $.22 * *$ & $-.15 *$ & .11 & $.16^{*}$ & $.77 * *$ & $-.37 * *$ & $.66^{* *}$ \\
\hline Comfort-Seeking & $.30 * *$ & .05 & -.11 & .10 & $.13^{*}$ & $.73 * *$ & -.06 & $.40 * *$ \\
\hline Self-Encouragement & $.25 * *$ & -.03 & -.04 & -.03 & -.02 & $.71 * *$ & $-.14^{*}$ & $.46^{* *}$ \\
\hline Commitment & $.17 * *$ & $.15^{*}$ & -.00 & -.06 & .01 & $.74^{* *}$ & .05 & $.31 * *$ \\
\hline Total Adaptive & $.40 * *$ & $.15^{* *}$ & $-.14 *$ & .08 & $.14^{*}$ & & $-.22 * *$ & $.65^{* *}$ \\
\hline Confusion & -.04 & -.09 & $.20 * *$ & $-.14 *$ & -.06 & $-.12 *$ & $.88^{* *}$ & $-.72 * *$ \\
\hline Escape & $-.18^{*}$ & .01 & $.19^{* *}$ & $-.13^{*}$ & $-.13^{*}$ & $-.43 * *$ & $.72 * *$ & $-.76^{* *}$ \\
\hline Concealment & -.10 & .04 & $.20 * *$ & -.06 & -.03 & $-.28 * *$ & $.86^{* *}$ & $-.82 * *$ \\
\hline Self-Pity & -.01 & .02 & $.20 * *$ & -.11 & -.06 & -.10 & $.92 * *$ & $-.77 * *$ \\
\hline Rumination & .02 & .11 & .03 & .04 & $.15^{*}$ & $.34 * *$ & $.53 * *$ & $-.25 * *$ \\
\hline Projection & $-.32 * *$ & $-.12 *$ & $.25^{* *}$ & $-.21 * *$ & $-.22 * *$ & $-.41 * *$ & $.81^{* *}$ & $-.82 * *$ \\
\hline Total Maladaptive & $-.13 *$ & -.01 & $.23 * *$ & $-.14^{*}$ & -.08 & $-.22 * *$ & & \\
\hline Coping Profile & $.28 * *$ & $.12 *$ & $-.33 * *$ & $.15^{* *}$ & $.14^{*}$ & $.65^{* *}$ & $-.88^{*}$ & \\
\hline
\end{tabular}

Note: Missing values for descriptive statistics were handled with pair-wise deletion. 
Table A.5. Predictors of Spring Engagement when controlling for Fall Engagement Adaptive Coping Raw Scores - Peers

\begin{tabular}{|c|c|c|c|c|c|c|c|c|c|c|c|c|}
\hline \multirow[b]{2}{*}{ Predictor } & \multicolumn{4}{|c|}{ Strategizing } & \multicolumn{4}{|c|}{ Help-Seeking } & \multicolumn{4}{|c|}{ Comfort-Seeking } \\
\hline & $\beta$ & $b$ & S.E. & $p$ & $\beta$ & $b$ & S.E. & $p$ & $\beta$ & $b$ & S.E. & $p$ \\
\hline Peers' Coping Avg. & .014 & .032 & .107 & .765 & .013 & .026 & .093 & .777 & .041 & .087 & .095 & .364 \\
\hline Acad. Adversity & -.094 & -.123 & .066 & .061 & -.097 & -.126 & .065 & .053 & -.097 & -.127 & .065 & .052 \\
\hline Total Eng. Fall & $.743 * *$ & .796 & .066 & .000 & $.743 * *$ & .795 & .066 & .000 & $.741 * *$ & .794 & .066 & .000 \\
\hline Peer Count & $-.096^{*}$ & -.014 & .006 & .022 & $-.098 *$ & -.014 & .006 & .021 & $-.095^{*}$ & -.014 & .006 & .023 \\
\hline \multirow[t]{2}{*}{ Sex } & $.095^{*}$ & .122 & .057 & .032 & $.094 *$ & .121 & .058 & .036 & $.087 *$ & .112 & .056 & .047 \\
\hline & \multicolumn{4}{|c|}{ Self-Encouragement } & \multicolumn{4}{|c|}{ Commitment } & \multicolumn{4}{|c|}{ Total Adaptive } \\
\hline Predictor & $\beta$ & $b$ & S.E. & $p$ & $\beta$ & $b$ & S.E. & $p$ & $\beta$ & $b$ & S.E. & $p$ \\
\hline Peers' Coping Avg. & -.057 & -.148 & .114 & .193 & .041 & .088 & .094 & .349 & .025 & .071 & .133 & .594 \\
\hline Acad. Adversity & -.096 & -.125 & .014 & .235 & $-.101 *$ & -.132 & .065 & .043 & -.097 & -.126 & .065 & .054 \\
\hline Total Eng. Fall & $.742 * *$ & .795 & .065 & .000 & $.744 * *$ & .797 & 066 & .000 & $.743 * *$ & .795 & .066 & .000 \\
\hline Peer Count & $-.102 *$ & -.015 & .006 & .015 & $-.101 *$ & -.015 & .006 & .018 & $-.098 *$ & -.014 & .006 & .021 \\
\hline \multirow[t]{2}{*}{ Sex } & $.116^{* *}$ & .149 & .056 & 008 & $.091 *$ & .118 & .055 & .031 & $.089 *$ & .115 & .058 & .049 \\
\hline & \multicolumn{4}{|c|}{ Coping Profile } & & & & & & & & \\
\hline Predictor & $\beta$ & $b$ & S.E. & $p$ & & & & & & & & \\
\hline Peers' Coping Avg. & -.069 & -.215 & .140 & $\begin{array}{c}\Gamma \\
.124\end{array}$ & & & & & & & & \\
\hline Acad. Adversity & $-.107^{*}$ & -.140 & .066 & 033 & & & & & & & & \\
\hline Total Eng. Fall & $.746^{* *}$ & .800 & .066 & .000 & & & & & & & & \\
\hline Peer Count & $-.097 *$ & -.014 & .006 & .021 & & & & & & & & \\
\hline Sex & $.117 * *$ & .151 & .056 & .007 & & & & & & & & \\
\hline
\end{tabular}


Table A.6. Predictors of Spring Engagement when Controlling for Fall Engagement Maladaptive Coping Raw Scores - Peers

\begin{tabular}{|c|c|c|c|c|c|c|c|c|c|c|c|c|}
\hline \multirow[b]{2}{*}{ Predictor } & \multicolumn{4}{|c|}{ Confusion } & \multicolumn{4}{|c|}{ Escape } & \multicolumn{4}{|c|}{ Concealment } \\
\hline & $\beta$ & $b$ & S.E. & $p$ & $\beta$ & $b$ & S.E. & $p$ & $\beta$ & $b$ & S.E. & $p$ \\
\hline Peers' Coping Avg. & .070 & .152 & .095 & .109 & .028 & .052 & .082 & .528 & .063 & .113 & .078 & .149 \\
\hline Total Eng. Fall & $.743 * *$ & .796 & .065 & .000 & $.744 * *$ & .797 & .066 & .000 & $.740 * *$ & .792 & .065 & .000 \\
\hline Peer Count & $-.091 *$ & -.013 & .006 & .029 & $-.097 *$ & -.014 & .006 & 021 & $-.098 *$ & -.014 & .006 & .019 \\
\hline \multirow[t]{2}{*}{ Sex } & $.097^{*}$ & .125 & .054 & .020 & $.103 *$ & .132 & .055 & .015 & $.104 *$ & .134 & .054 & .013 \\
\hline & \multicolumn{4}{|c|}{ Self-Pity } & \multicolumn{4}{|c|}{ Rumination } & \multicolumn{4}{|c|}{ Projection } \\
\hline Predictor & $\beta$ & $B$ & S.E. & $p$ & $\beta$ & $b$ & S.E. & $p$ & $\beta$ & $b$ & S.E. & $p$ \\
\hline Peers' Coping Avg. & .078 & .120 & .066 & .072 & $.142 * *$ & .261 & .078 & .000 & .033 & .053 & .075 & .479 \\
\hline Acad. Adversity & $-.115^{*}$ & -.150 & .066 & .022 & $-.111 *$ & -.145 & .064 & .024 & $-.102 *$ & -.133 & .065 & .042 \\
\hline Total Eng. Fall & $.744 * *$ & .798 & .065 & .000 & $.732 * *$ & .785 & .065 & .000 & $.747 * *$ & .801 & .066 & .000 \\
\hline Sex & \multicolumn{4}{|c|}{ Total Maladaptive } & & & & & & & & \\
\hline Predictor & $\beta$ & $B$ & S.E. & $p$ & & & & & & & & \\
\hline Peers' Coping Avg. & $.090 *$ & .202 & .098 & .038 & & & & & & & & \\
\hline Acad. Adversity & $-.116^{*}$ & -.151 & .066 & .021 & & & & & & & & \\
\hline Total Eng. Fall & $.746^{* *}$ & .801 & .065 & .000 & & & & & & & & \\
\hline Peer Count & $-.100^{*}$ & .138 & .054 & .010 & & & & & & & & \\
\hline Sex & $.107 *$ & .138 & .054 & .010 & & & & & & & & \\
\hline
\end{tabular}




\section{PEERS' ACADEMIC COPING AND MOTIVATIONAL RESILIENCE}

\section{Appendix B. Biological Sex and Academic Coping}

Several ways of coping showed variation by biological sex. The correlations of each way of coping, as well as total adaptive, total maladaptive, and coping profile, for both allocation scores and raw coping scores, are shown in Table B.1. All of the adaptive ways of coping were positively and significantly correlated with sex in the raw scores, including the combined adaptive coping. The positive correlations indicate that the mean levels were higher for girls than for boys. The correlations were dampened, but still positive and significant, in the allocation scores, except for commitment, which became nonsignificantly correlated with biological sex in the allocation scores. The story was different for the relationships between average levels of adaptive coping in the peer group and biological sex. In the raw scores, all of the peer group averages for adaptive ways were positively and highly significantly correlated with biological sex, indicating higher mean levels for girls' groups. In the allocation scores, however, the significant correlations for comfort-seeking and self-encouragement were negative, indicating higher mean peer group average levels for boys' peer groups. The correlation with biological sex became negative but nonsignificant in the allocation scores for average peer group level of help-seeking.

Among the maladaptive ways of coping, two of these, escape and projection, were negatively and significantly correlated with biological sex, indicating higher mean levels for boys' groups. The combined measure of all maladaptive ways was also negatively and significantly correlated with sex in both the raw and allocation scores. The correlations for escape and projection were also negatively and significantly correlated with sex in the 


\section{PEERS’ ACADEMIC COPING AND MOTIVATIONAL RESILIENCE}

allocation scores, but the correlations were amplified, in comparison to the statistics for the raw scores. Concealment became negatively and significantly correlated with sex in the allocation scores. For peer group averages of maladaptive coping, escape, projection, and the combined maladaptive score were negatively and significantly correlated with sex, indicating higher average levels in boys' peer groups. In the allocation scores, escape continued to be negatively and significantly correlated, and at a higher level (-.386 versus -.175). Projection and combined maladaptive coping, however, are positively significantly correlated with biological sex in the allocation scores, indicating higher levels for girls' peer groups. In addition, rumination is also positively significantly correlated with sex in the allocation scores, but not in the raw scores. 


\section{PEERS' ACADEMIC COPING AND MOTIVATIONAL RESILIENCE}

Table B.1. Individual Coping Allocation Score Descriptive Statistics for Boys and Girls

\begin{tabular}{|c|c|c|c|c|c|c|c|}
\hline & $\begin{array}{c}\text { Correlation } \\
\text { w/Sex }\end{array}$ & Sex & $\mathrm{N}$ & Mean & S.D. & Skew & Kurtosis \\
\hline \multirow[t]{2}{*}{ Strategizing } & $.17 * *$ & B & 163 & 10.82 & 1.99 & -.12 & .47 \\
\hline & & G & 150 & 11.50 & 1.90 & .23 & -.33 \\
\hline \multirow{2}{*}{ Help-Seeking } & $.21 * *$ & B & 164 & 10.69 & 2.22 &.- .08 & .09 \\
\hline & & G & 151 & 11.67 & 2.35 & -.09 & .26 \\
\hline \multirow[t]{2}{*}{ Comfort-Seeking } & $.20 * *$ & B & 160 & 10.32 & 2.00 & -.16 & .33 \\
\hline & & G & 150 & 11.09 & 1.94 & -.02 & .29 \\
\hline \multirow[t]{2}{*}{ Self-Encouragement } & n.s. & B & 171 & 10.59 & 2.08 & -.24 & .60 \\
\hline & & G & 155 & 10.92 & 1.66 & .17 & -.01 \\
\hline \multirow[t]{2}{*}{ Commitment } & n.s. & $\mathrm{B}$ & 168 & 10.46 & 2.02 & .87 & .76 \\
\hline & & G & 153 & 10.82 & 1.86 & .19 & -.05 \\
\hline \multirow[t]{2}{*}{ Total Adaptive } & $.21 * *$ & B & 174 & 10.55 & 1.52 & .05 & .33 \\
\hline & & G & 155 & 11.20 & 1.48 & .13 & -.56 \\
\hline \multirow[t]{2}{*}{ Confusion } & n.s. & B & 164 & 7.83 & 1.49 & .29 & 1.48 \\
\hline & & G & 151 & 7.54 & 1.38 & -.42 & -.40 \\
\hline \multirow[t]{2}{*}{ Escape } & $-.18 * *$ & B & 164 & 7.32 & 2.09 & .54 & .81 \\
\hline & & G & 151 & 6.61 & 1.92 & .20 & -.74 \\
\hline \multirow[t]{2}{*}{ Concealment } & $-.11 *$ & B & 169 & 7.64 & 2.11 & .27 & .33 \\
\hline & & G & 154 & 7.18 & 1.95 & .01 & -.61 \\
\hline \multirow[t]{2}{*}{ Self-Pity } & n.s. & B & 169 & 7.65 & 2.13 & -.21 & -.82 \\
\hline & & G & 154 & 7.29 & 2.27 & .20 & -.94 \\
\hline \multirow[t]{2}{*}{ Rumination } & n.s. & B & 165 & 9.26 & 1.76 & -.06 & -.15 \\
\hline & & G & 151 & 9.40 & 1.71 & .14 & .10 \\
\hline \multirow[t]{2}{*}{ Projection } & $-.27 * *$ & B & 170 & 7.17 & 2.30 & .37 & -.29 \\
\hline & & G & 155 & 6.03 & 1.84 & .87 & .76 \\
\hline \multirow[t]{2}{*}{ Total Maldaptive } & $-.18 * *$ & B & 174 & 7.78 & 1.30 & -.27 & .28 \\
\hline & & G & 155 & 7.33 & 1.23 & -.11 & -.60 \\
\hline \multirow[t]{2}{*}{ Coping Profile } & n.s. & B & 174 & 9.69 & .95 & .02 & -.38 \\
\hline & & G & 155 & 9.87 & .93 & -.06 & -.58 \\
\hline
\end{tabular}




\section{PEERS’ ACADEMIC COPING AND MOTIVATIONAL RESILIENCE}

\section{Appendix C. Group Averages and Diversity in the Peer Group}

The investigation of effects of peers' ways of coping on student engagement in the present study was conducted using the peer group average to characterize coping strategy use by group members. There is, however, considerable diversity within groups. In a group average, the presence of coping levels of students above the mean may be obscured by the simultaneous presence of other group members with coping levels below the mean. To gain insight into the magnitude of the within group diversity, the difference of each student to the average of their group of significantly affiliated peers was calculated. Table C.1 shows the mean, standard deviation, and mean absolute value of individual difference to group, as well as the mean of all group averages and the correlation of individual levels to group averages for all ways of coping and coping combinations.

Correlations between the individual and the group averages were small or nonsignificant. Many group members had large differences between their own coping and the average coping in the group. The mean of the mean group average for all 11 specific ways of coping was 9.08, while the mean standard deviation of the difference between individual level and their group's average for all 11 ways of coping was 2.04 , and the mean absolute value of difference to group was 1.68 . In percentage terms, about one third of students were more than $22.5 \%$ above or below their group's average, while on average a student was $18.5 \%$ above or below their group's average. This indicates a considerable amount of diversity within groups, and remarkable divergence of many group members from the group average. The use of the group average to represent the 


\section{PEERS' ACADEMIC COPING AND MOTIVATIONAL RESILIENCE}

capability of the group to serve as a resource or act as a liability may not capture the full potential of peer groups to function in those ways, because it ignores the presence within the group of potentially influential group members who differ may differ significantly from the group average. One possibility for further research into the effects of peer group coping would be to asses both high and low components of the group, and their predictive potential, by creating separate variables for those components. This could be done in at least two ways. The high subgroup could be those group members who are above the target student, and the low subgroup those below the student. Alternatively, the high subgroup could be those group members who are above the grand mean for all students in the sample, with the low subgroup of each peer group consisting of students below the grand mean. The coping allocation scores for the students in each subgroup could then be averaged, and the separate averages for high and low components of each student's peer group tested as predictors of engagement change. 
PEERS’ ACADEMIC COPING AND MOTIVATIONAL RESILIENCE

Table C.1. Individual Coping to Group Average - Correlation and Difference Statistics

\begin{tabular}{|c|c|c|c|c|c|c|c|c|}
\hline & \multirow{2}{*}{$\begin{array}{l}\text { Indiv. } \\
\text { Corr } \\
\text { to Grp }\end{array}$} & \multirow{2}{*}{$\begin{array}{c}\text { Group } \\
\text { Averages } \\
\text { Mean }\end{array}$} & \multirow[b]{2}{*}{ SD } & \multicolumn{5}{|c|}{ Individual Difference to Group Average } \\
\hline & & & & $\begin{array}{l}M \text { Abs. } \\
\text { Value }\end{array}$ & $M$ & SD & Min & Max \\
\hline Strategizing & $.20 * *$ & 11.15 & 1.13 & 1.69 & .03 & 2.10 & -6.12 & 4.69 \\
\hline Help-Seeking & .07 & 11.20 & 1.32 & 2.04 & .00 & 2.57 & -8.77 & 8.68 \\
\hline Comfort-Seeking & .09 & 10.84 & 1.05 & 1.64 & -.03 & 2.11 & -6.00 & 6.00 \\
\hline Self-Encouragement & .08 & 10.78 & .99 & 1.58 & .04 & 2.02 & -6.57 & 5.25 \\
\hline Commitment & .04 & 10.71 & 1.00 & 1.67 & -.05 & 2.17 & -5.79 & 5.45 \\
\hline Total Adaptive & $.13 *$ & 10.92 & .85 & 1.32 & -.01 & 1.66 & -5.22 & 4.28 \\
\hline Confusion & .01 & 7.66 & .76 & 1.26 & .02 & 1.61 & -4.83 & 6.64 \\
\hline Escape & $.13 *$ & 6.95 & 1.12 & 1.73 & -.01 & 2.13 & -6.32 & 5.85 \\
\hline Concealment & .10 & 7.35 & 1.06 & 1.79 & .05 & 2.22 & -4.63 & 7.48 \\
\hline Self-Pity & $.17 * *$ & 7.38 & 1.17 & 1.85 & .01 & 2.30 & -5.64 & 5.96 \\
\hline Rumination & $.13^{*}$ & 9.29 & .97 & 1.45 & -.04 & 1.89 & -5.12 & 6.19 \\
\hline Projection & $.16^{*}$ & 6.60 & 1.26 & 1.78 & -.04 & 2.32 & -8.52 & 7.39 \\
\hline Total Maladaptive & $.14^{*}$ & 7.53 & .72 & 1.11 & -.01 & 1.39 & -4.18 & 4.35 \\
\hline Coping Profile & $.20 * *$ & 9.81 & .54 & .79 & -.00 & .99 & -2.53 & 2.44 \\
\hline \multirow[t]{2}{*}{ Average of 11 Ways } & & 9.08 & & 1.68 & & 2.04 & & \\
\hline & & $100 \%$ & & $18.5 \%$ & & $22.5 \%$ & & \\
\hline
\end{tabular}

$* p<.05 . * * p<.01$. 


\section{PEERS’ ACADEMIC COPING AND MOTIVATIONAL RESILIENCE}

\section{Appendix D. Engagement, its Components, and Academic Coping}

The present study made use of existing subscales composed of positive items for behavioral engagement, negative items for behavioral engagement (reversed), positive items for emotional engagement, and negative items for emotional engagement (reversed). The negative items for behavioral and emotional engagement, which were reversed and used in the present study to measure engagement, have been shown in other research, when not reversed, to function as measures of behavioral disengagement and emotional disaffection (Skinner et al., 2009). In the current study, the positive and negative items (reversed) for emotional engagement were combined into a single subscale. Items for each of the three groups were then averaged to create three manifest indicators in the measurement model. Fall and spring engagement were then modeled as latent variables with three indicators each. Although the latent variables loaded well on the three indicators at each time point, supplementary investigation reveals that there are some differences in the correlations of the components of engagement with the various peer group coping measures. These correlations are shown in Table D.1.

Peers' total adaptive coping in fall, as well as their strategizing, help-seeking, and comfort-seeking showed small but significant correlations with total engagement in spring, as did the negative items for behavior engagement (reversed), and the negative items (reversed) for emotional engagement. The pattern for maladaptive coping was somewhat more complicated, with again differences between the subscales. Only the negative (reversed) items for emotional engagement significantly correlated with peers total maladaptive coping. The variation in the relationships between the separate peer 


\section{PEERS’ ACADEMIC COPING AND MOTIVATIONAL RESILIENCE}

coping measures and the components of engagement, suggest that the investigation of the relationship between peer group coping and engagement might benefit from more specificity in modeling the components of the outcome. For example, the effect of peers coping on student emotional engagement might be tested separately.

Table D.1.

Correlations between Group Average Coping and Spring Engagement Components

\begin{tabular}{lccccc}
\hline \multirow{2}{*}{$\begin{array}{l}\text { Fall Coping Allocation } \\
\text { Score Group Averages }\end{array}$} & $\begin{array}{c}\text { Total } \\
\text { Engagement }\end{array}$ & $\begin{array}{c}\text { Beh. Eng. } \\
\text { Positive }\end{array}$ & $\begin{array}{c}\text { Beh. Eng. } \\
\text { Neg. Rev. }\end{array}$ & $\begin{array}{c}\text { Emo. Eng. } \\
\text { Positive }\end{array}$ & $\begin{array}{c}\text { Emo. Eng. } \\
\text { Neg. Rev. }\end{array}$ \\
\cline { 2 - 6 } Strategizing & $.18^{*}$ & .11 & $.16^{*}$ & $.14^{*}$ & $.16^{*}$ \\
Help-Seeking & $.16^{*}$ & .10 & $.14^{*}$ & $.15^{*}$ & $.18^{* *}$ \\
Comfort-Seeking & $.14^{*}$ & .08 & $.16^{*}$ & .11 & $.16^{*}$ \\
Self-Encouragement & -.01 & -.06 & .04 & -.07 & .02 \\
Commitment & .02 & -.05 & .05 & -.01 & .07 \\
Total Adaptive & $.14^{*}$ & .06 & $.15^{*}$ & .09 & $.16^{*}$ \\
Confusion & & & & & \\
Escape & -.09 & -.05 & -.10 & -.05 & -.10 \\
Concealment & $-.14^{*}$ & -.06 & $-.18^{* *}$ & -.06 & -.09 \\
Self-Pity & -.03 & -.01 & -.00 & -.05 & -.10 \\
Rumination & -.08 & -.05 & -.06 & -.08 & -.10 \\
Projection & $.19^{* *}$ & $.14^{*}$ & $.21^{* *}$ & $.13^{*}$ & .10 \\
Total Maladaptive & $-.25^{* *}$ & $-.15^{*}$ & $-.26^{* *}$ & $-.20^{* *}$ & $-.25^{* *}$ \\
Coping Profile & -.11 & -.06 & -.11 & -.09 & $-14^{*}$ \\
\hline
\end{tabular}

$* p<.05 . * * p<.01$. 
PEERS' ACADEMIC COPING AND MOTIVATIONAL RESILIENCE

Appendix E. Measures

Student Engagement vs. Disaffection - Teacher-report (14 items; 4-point scale)

\begin{tabular}{ll}
\hline Behavioral & When we start something new in class, this student participates \\
Engagement & in discussions. \\
In my class, this student works as hard as he/she can. & When we start something new in class, this student doesn't pay \\
& attention. \\
Behavioral & When we start something new in class, this student thinks \\
Disaffection & about other things. \\
& In my class, this student does just enough to get by. \\
In my class, this student comes unprepared. \\
Emotional & In my class, this student appears enthusiastic. \\
Engagement & When working on classwork in my class, this student appears \\
& involved. \\
\hline When I explain new material, this student seems bored. \\
In my class, this student appears depressed. \\
In my class, this student appears angry. \\
Disaffection & In my class, this student appears anxious. \\
& When working on classwork in my class, this student appears \\
& worried. \\
& When working on classwork in my class, this student appears \\
frustrated.
\end{tabular}


Academic Coping - Student self-report (53 items; 4-point scale)

\begin{tabular}{|c|c|}
\hline ADAPTIVE: & $\begin{array}{l}\text { When something bad happens to me in school (like not } \\
\text { doing well on a test or not being able to answer an } \\
\text { important question), }\end{array}$ \\
\hline \multirow[t]{7}{*}{ Strategizing } & $\begin{array}{l}\text { I try to figure out what I did wrong so that it won't happen } \\
\text { again. }\end{array}$ \\
\hline & I try to see what I did wrong. \\
\hline & I think about some way to keep this from happening again. \\
\hline & I try to figure out how to do better next time. \\
\hline & I think of some things that will help me next time. \\
\hline & When I have trouble with a subject in school, \\
\hline & I ask for some help with understanding the material. \\
\hline \multirow{6}{*}{ Help-Seeking } & I get some help to understand the material better. \\
\hline & I ask the teacher to go over it with me. \\
\hline & I ask the teacher to explain what I didn't understand. \\
\hline & I get some help on the parts I didn't understand. \\
\hline & $\begin{array}{l}\text { When something bad happens to me in school (like not } \\
\text { doing well on a test or not being able to answer an } \\
\text { important question), }\end{array}$ \\
\hline & I talk about it with someone who will make me feel better. \\
\hline \multirow{6}{*}{ Comfort-Seeking } & I spend time with someone who will cheer me up. \\
\hline & I talk about it with someone I'm close to. \\
\hline & I discuss it with someone who will help me feel better about it. \\
\hline & $\begin{array}{l}\text { I talk with someone who will keep me from feeling bad about } \\
\text { it. }\end{array}$ \\
\hline & When I run into a problem on an important test, \\
\hline & I think about the times I did it right. \\
\hline \multirow{7}{*}{ Self-Encouragement } & I tell myself it's not so bad to make a mistake, \\
\hline & I tell myself I'll do better next time. \\
\hline & I tell myself I'll have another chance. \\
\hline & I tell myself it'll be okay. \\
\hline & When I have difficulty learning something, \\
\hline & I think about all the reasons it's important to me. \\
\hline & I remind myself that it's worth it to me in the long run. \\
\hline \multirow[t]{3}{*}{ Commitment } & $\begin{array}{l}\text { I remind myself that this is important in reaching my own } \\
\text { goals. }\end{array}$ \\
\hline & I remind myself that it's something that I really want to do. \\
\hline & I think about how this is important for my own personal goals. \\
\hline
\end{tabular}




\begin{tabular}{|c|c|}
\hline MALADAPTIVE: & $\begin{array}{l}\text { When I run into a problem on an important test, } \\
\text { I'm not sure what to do next. } \\
\text { I can't remember what to do. } \\
\text { My mind goes blank. } \\
\text { I get all confused. } \\
\text { It's difficult for me to think. }\end{array}$ \\
\hline Escape & $\begin{array}{l}\text { When something bad happens to me in school (like not } \\
\text { doing well on a test or not being able to answer an } \\
\text { important question), } \\
\text { I quit thinking about it. } \\
\text { I tell myself it's not such a big deal. } \\
\text { I tell myself it didn't matter. } \\
\text { I say it wasn't important. } \\
\text { I say I didn't care about it. }\end{array}$ \\
\hline Concealment & $\begin{array}{l}\text { When something bad happens to me in school (like not } \\
\text { doing well on a test or not being able to answer an } \\
\text { important question), } \\
\text { I try to keep people from finding out. } \\
\text { I make sure nobody find out. } \\
\text { I try to hide it. } \\
\text { I don't tell anyone about it. } \\
\text { I don't let anybody know about it. }\end{array}$ \\
\hline Self-Pity & $\begin{array}{l}\text { When something bad happens to me in school (like not } \\
\text { doing well on a test or not being able to answer an } \\
\text { important question), } \\
\text { I think about all the times this happens to me. } \\
\text { I say "This always happens to me." } \\
\text { I ask myself "Why is this always happening to me?" } \\
\text { I say "Here we go again." } \\
\text { I can't believe this is always happening to me. }\end{array}$ \\
\hline Rumination & $\begin{array}{l}\text { When something bad happens to me in school (like not } \\
\text { doing well on a test or not being able to answer an } \\
\text { important question), } \\
\text { I think about it all the time. } \\
\text { I'm always thinking about it afterwards. } \\
\text { I can't get it out of my head. }\end{array}$ \\
\hline Projection & $\begin{array}{l}\text { When I run into a problem on an important test, } \\
\text { I say it was the teacher's fault. } \\
\text { I say the teacher didn't tell us the right thing to study. } \\
\text { I say the teacher isn't fair. } \\
\text { I say the test was too hard. } \\
\text { I say the test was not fair. }\end{array}$ \\
\hline
\end{tabular}

